\title{
Direct, Regioselective N-alkylation of 1,3-Azoles
}

Shuai Chen*, Russell F. Graceffa*, Alessandro A. Boezio

Medicinal Chemsitry Department

Amgen, Inc.

360 Binney Street, Cambridge, Massachusetts, 02142

\section{Supporting information}

Table of Contents

General Experimental Details

S-2

Preparation of 2,2,6,6-Tetramethylpiperidinylmagnesium Chloride

S-2

General Alkylation Methods a-c

S-2-S-3

Procedure of Large Scale Synthesis of 2a

S-3

Solvent Study of Regioselective Methylation of 6-Chloropurine

S-4

Base Study of 6-Chloropurine Methylation: Organolithium and Organozinc bases

S-4

${ }^{1} \mathbf{H},{ }^{13} \mathbf{C},{ }^{19} \mathbf{F}$ Data and Spectra for Synthesized Products

S-5-S-47

2D NMR analysis of Compound 4d

References

S-48-S55

S-56 


\section{General Experimental Details:}

Unless otherwise noted, all reagents were purchased from commercial vendors and used without any further purification. Anhydrous solvents were obtained from Aldrich and used directly. All reactions involving air- or moisture-sensitive reagents were performed under nitrogen. Silica gel columns were performed using prepacked silica gel cartridges (Biotage) with Biotage Isolera One flash column system. ${ }^{1} \mathrm{H},{ }^{13} \mathrm{C}$ and ${ }^{19} \mathrm{~F}$ NMR spectra were recorded on a Bruker AV-400 (400 $\mathrm{MHz}$ ) spectrometer at ambient temperature. 2D NMR was recorded on a Bruker AV-600 (600 $\mathrm{MHz}$ ). All unknown product structures were confirmed by ROESY, HSQC and HMBC data. NMR spectra were processed using ACD Labs Chemistry (version 12; ACD, Toronto, Canada). All observed protons are reported as parts per million (ppm) downfield from internal reference in the appropriate solvent indicated. Data are reported as follows: chemical shift, multiplicity ( $\mathrm{s}=$ singlet, $\mathrm{d}=$ doublet, $\mathrm{t}=$ triplet, $\mathrm{q}=$ quartet, $\mathrm{br}=$ broad, $\mathrm{m}=$ multiplet), coupling constants, and number of protons. Low-resolution mass spectral (MS) data were determined on an Agilent 1100 Series LCMS with UV detection at $254 \mathrm{~nm}$ and a low resonance electrospray mode (ESI). Microwave reaction was conducted in Biotage Initiator microwave reactor. HRMS data was recorded on Agilent LC-MS TOF (time of flight), Model G1969A instrument.

\section{Preparation of 2,2,6,6-Tetramethylpiperidinylmagnesium chloride (TMPMgCl/THF solution) ${ }^{1}$ :}

Minor modification of literature preparation regarding reaction time and concentration.

To a $100 \mathrm{~mL}$ round bottom flask, THF $(20 \mathrm{~mL})$ was added followed by butylmagnesium chloride, 2.0 M solution in tetrahydrofuran $(5.0 \mathrm{~mL}, 10.0 \mathrm{mmol})$. Then 2,2,6,6-tetramethylpiperidine $(1.688 \mathrm{~mL}, 10 \mathrm{mmol})$ was added slowly. The stirred reaction mixture was heated to reflux and maintained at the temperature for 2 hours. The resulting 2,2,6,6tetramethylpiperidinylmagnesium chloride solution is $0.4 \mathrm{M}$ in THF.

\section{Alkylation Method a:}

To a $10 \mathrm{~mL}$ microwave flask equipped with a stir bar, starting material $(1 \mathrm{mmol})$ was added and the flask was purged with $\mathrm{N}_{2}$. THF ( $4 \mathrm{~mL}$ ) was added, followed by 1.1 equivalent of $\mathrm{MeMgCl}$ ( $1.1 \mathrm{mmol}, 0.367 \mathrm{~mL}, 3 \mathrm{M}$ in THF). The reaction mixture was stirred at room temperature for 30 minutes. The alkylating reagent was added in one portion and the reaction was stirred at the temperature shown for the time given in the table. The reaction was monitored by HPLC-MS and stopped when starting material disappeared. The reaction was cooled to room temperature followed by addition of methanol $(2 \mathrm{~mL})$ to neutralize the unreacted base. The reaction mixture 
was evaporated to dryness and directly purified by flash column chromatography, using a Biotage Isolera.

\section{Alkylation Method b:}

To a $10 \mathrm{~mL}$ microwave flask equipped with stir bar, starting material ( $1 \mathrm{mmol})$ was added and the flask was purged with $\mathrm{N}_{2}$. THF $(2 \mathrm{~mL})$ was added, followed by 1.1 equivalent of TMPMgCl ( $2.75 \mathrm{~mL}, 0.4 \mathrm{M}$ in THF) and the reaction was stirred at room temperature for 30 minutes. The alkylating reagent was added in one portion and the reaction was stirred at the temperature shown for the time given in the table. The reaction was monitored by LC-MS and stopped when starting material disappeared. The reaction was cooled to room temperature followed by the addition of methanol $(2 \mathrm{~mL})$ to neutralize the unreacted base. The reaction mixture was evaporated to dryness and directly purified by flash column chromatography, using a Biotage Isolera.

\section{Alkylation Method c:}

To a $10 \mathrm{~mL}$ microwave flask equipped with stir bar, starting material $(1 \mathrm{mmol})$ was added and the flask was purged with $\mathrm{N}_{2}$. THF ( $4 \mathrm{~mL}$ ) was added, followed by 1.1 equivalent of $\mathrm{MeMgCl}$ $(0.367 \mathrm{~mL}, 3 \mathrm{M}$ in THF) and the reaction was stirred at room temperature for 30 minutes. The alkylating reagent was added in one portion and the reaction was subjected to microwave irradiation at the temperature shown and for the time given in the table. The reaction was cooled to room temperature followed by the addition of methanol $(2 \mathrm{~mL})$ to neutralize the unreacted base. The reaction mixture was evaporated to dryness and directly purified by flash column chromatography, using a Biotage Isolera.

\section{Procedure of Large Scale Synthesis of 2a:}

6-chloro-9H-purine (30.00 g, $194 \mathrm{mmol}$ ) was added to a screw cap pressure vessel followed by THF (388 mL). Reaction was cooled to $0{ }^{\circ} \mathrm{C}$ and isopropylmagnesium chloride lithium chloride complex, 1.3 M solution in tetrahydrofuran $(194 \mathrm{~mL}, 252 \mathrm{mmol})$ was added dropwise into the reaction mixture over a period of 30 minutes. Then the reaction was stirred for 20 minutes and then iodomethane $(15.78 \mathrm{~mL}, 252 \mathrm{mmol})$ was added in one portion. Reaction was capped and heated to $70^{\circ} \mathrm{C}$. After 3 hours, the reaction was complete and was cooled down to room temperature followed by methanol addition to neutralize to unreacted isopropylmagnesium chloride lithium chloride. The solvent was removed with reduced pressure and the crude material was divided up into small portions and ran $6 \times 330$ ISCO columns, eluting with $0-50 \%$ of $90: 10$ $\mathrm{DCM} / \mathrm{MeOH}$. $23 \mathrm{~g}$ of off white solid 2a was isolated, calculated as $70 \%$ yield. 


\section{Solvent Study of Regioselective Methylation of 6-Chloropurine}

Table 1. Solvent Study of 6-Chloropurine Methylation
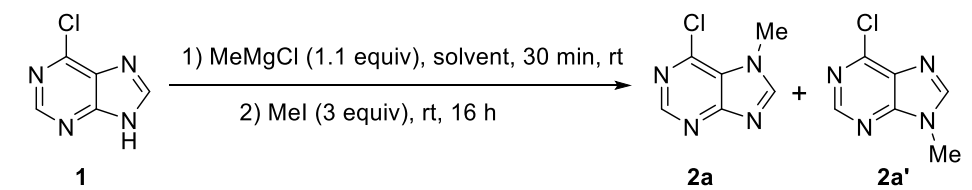

\begin{tabular}{cccc}
\hline Entry & Solvent & ${\text { Conversion }(\%)^{\mathrm{a}}}^{\mathbf{2 a}: 2 \mathbf{a}^{\mathrm{b}}}$ \\
\hline 1 & THF & 73 & $>100: 1$ \\
2 & 2-MeTHF & 5 & $>100: 1$ \\
3 & CPME & 0 & $\mathrm{n} / \mathrm{a}$ \\
4 & 1,4-dioxane & 13 & $22: 1$ \\
5 & Et $_{2} \mathrm{O}$ & 0 & $\mathrm{n} / \mathrm{a}$ \\
6 & DCM & 4 & $9: 1$ \\
\hline
\end{tabular}

${ }^{a}$ Determined by LCMS. ${ }^{b}$ Determined by crude NMR.

Solvent plays a role in the regioselectivity and progress of the reaction. At room temperature, THF gave best conversion along with excellent selectivity. Using 2-MeTHF, alkylation also occurred specifically on the N7 position. However, conversion was lower and the formation of dehalogenation and byproducts increased. Etheral solvents, CPME, diethyl ether and dioxane had poor solubility of starting material, and led to decreased product formation. Non-coordinating solvent DCM showed (9:1) selectivity with low conversion.

\section{Base Study of 6-Chloropurine Methylation: Organolithium and Organozinc bases}

Table 2. Base Study of 6-Chloropurine Methylation

\begin{tabular}{cccc}
\hline Entry & Base & Conversion $^{\mathrm{a}}$ & $\mathbf{2 a}^{\mathbf{2}} \mathbf{2} \mathbf{a}^{\mathrm{b}}$ \\
\hline 1 & $n-\mathrm{BuLi}$ & $>95$ & $3.3: 1$ \\
2 & $t$-BuLi & $>95$ & $2.5: 1$ \\
3 & $\mathrm{LDA}$ & $>95$ & $3.1: 1$ \\
4 & LHMDS & 85 & $3: 1$ \\
5 & $\mathrm{PhZnI}$ & 22 & $6.8: 1$ \\
6 & $\mathrm{NeopentylZnI}$ & 11 & $13: 1$ \\
7 & $\mathrm{~K}_{2} \mathrm{CO}_{3}$ & 90 & $1: 9$ \\
\hline
\end{tabular}

${ }^{\mathrm{a}}$ Determined by LCMS. ${ }^{\mathrm{b}}$ Determined by crude NMR. 


\section{NMR data of Products:}

6-chloro-7-methyl-7H-purine $(\mathbf{2 a})^{2}$

The titled compound was prepared using method a. White solid, $160 \mathrm{mg} .{ }^{1} \mathrm{H}$ NMR $(400 \mathrm{MHz}$, DMSO-d $\left._{6}\right) \delta=8.76(\mathrm{~s}, 1 \mathrm{H}), 8.73(\mathrm{~s}, 1 \mathrm{H}), 4.08(\mathrm{~s}, 3 \mathrm{H}) ;{ }^{13} \mathrm{C}$ NMR $\left(101 \mathrm{MHz}, \mathrm{DMSO}-\mathrm{d}_{6}\right) \delta=$ 161.4, 151.4, 151.3, 142.4, 122.7, 33.9. LCMS: $m / z=169.2(\mathrm{M}+\mathrm{H})$. The compound was purified with Biotage flash column system with 2 to $20 \%$ methanol in DCM.

6-chloro-7-ethyl-7H-purine $(\mathbf{2 b})^{3}$

The titled compound was prepared using method a. White solid, $147 \mathrm{mg} .{ }^{1} \mathrm{H}$ NMR (400MHz, DMSO-d $\left._{6}\right) \delta=8.85(\mathrm{~s}, 1 \mathrm{H}), 8.80(\mathrm{~s}, 1 \mathrm{H}), 4.52(\mathrm{q}, J=7.2 \mathrm{~Hz}, 2 \mathrm{H}), 1.48(\mathrm{t}, J=7.2 \mathrm{~Hz}, 3 \mathrm{H})$; ${ }^{13} \mathrm{C}$ NMR (101 MHz, DMSO-d6) $\delta=161.6,151.5,150.5$, 141.9, 121.8, 41.8, 16.7. LCMS: $\mathrm{m} / z$ $=183.0(\mathrm{M}+\mathrm{H})$. The compound was purified with Biotage flash column system with 2 to $20 \%$ methanol in DCM.

6-chloro-7-propyl-7H-purine (2c) ${ }^{4}$

The titled compound was prepared using method a. White solid, $166 \mathrm{mg} .{ }^{1} \mathrm{H}$ NMR (400MHz, DMSO-d $\left._{6}\right) \delta=8.84$ (s, $\left.1 \mathrm{H}\right), 8.80$ (s, $\left.1 \mathrm{H}\right), 4.47$ - 4.41 (m, $\left.2 \mathrm{H}\right), 1.87$ (sxt, J = 7.3 Hz, $\left.2 \mathrm{H}\right), 0.89$ (t, $J=7.4 \mathrm{~Hz}, 3 \mathrm{H}) ;{ }^{13} \mathrm{C}$ NMR (101 MHz, DMSO-d6) $\delta=161.6,151.5,150.9,142.0,121.97,47.9$, 24.2, 10.5. LCMS: $m / z=198.0(\mathrm{M}+\mathrm{H})$. The compound was purified with Biotage flash column system with 2 to $20 \%$ methanol in DCM.

7-butyl-6-chloro-7H-purine (2d) ${ }^{4}$

The titled compound was prepared using method a. Colorless oil, $52 \mathrm{mg} .{ }^{1} \mathrm{H}$ NMR (400MHz, DMSO-d $\left._{6}\right) \delta=8.83(\mathrm{~s}, 1 \mathrm{H}), 8.78(\mathrm{~s}, 1 \mathrm{H}), 4.46(\mathrm{t}, J=7.3 \mathrm{~Hz}, 2 \mathrm{H}), 1.86-1.74(\mathrm{~m}, 2 \mathrm{H}), 1.29$ $(\mathrm{dd}, J=7.5,15.1 \mathrm{~Hz}, 2 \mathrm{H}), 0.89(\mathrm{t}, J=7.3 \mathrm{~Hz}, 3 \mathrm{H}) ;{ }^{13} \mathrm{C}$ NMR $(101 \mathrm{MHz}$, DMSO-d6) $\delta=161.6$, 151.4, 150.9, 142.0, 142.0, 46.2, 32.9, 19.0, 13.3. LCMS: $m / z=211.2(\mathrm{M}+\mathrm{H})$. The compound was purified with Biotage flash column system with 2 to $20 \%$ methanol in DCM.

7-benzyl-6-chloro-7H-purine $(\mathbf{2 e})^{2}$

The titled compound was prepared using method a. White solid, $214 \mathrm{mg} .{ }^{1} \mathrm{H}$ NMR (400MHz, DMSO-d $\left._{6}\right) \delta=9.01(\mathrm{~s}, 1 \mathrm{H}), 8.82(\mathrm{~s}, 1 \mathrm{H}), 7.51-7.04(\mathrm{~m}, 5 \mathrm{H}), 5.76(\mathrm{~s}, 2 \mathrm{H}) ;{ }^{13} \mathrm{C}$ NMR (101 MHz, DMSO-d $\left.{ }_{6}\right) \delta=161.7,151.8,151.3,142.2$, 136.7, 128.8, 127.8, 126.5, 122.0, 49.4. LCMS: $m / z=245.1(\mathrm{M}+\mathrm{H})$. The compound was purified with Biotage flash column system with 2 to $20 \%$ methanol in DCM.

7-allyl-6-chloro-7H-purine $(\mathbf{2 f})^{2}$ 
The titled compound was prepared using method a. White solid, $174 \mathrm{mg} .{ }^{1} \mathrm{H}$ NMR (400MHz, CHLOROFORM-d) $\delta=8.92(\mathrm{~s}, 1 \mathrm{H}), 8.31(\mathrm{~s}, 1 \mathrm{H}), 6.18$ - $6.03(\mathrm{~m}, 1 \mathrm{H}), 5.43$ - 5.36 (m, $1 \mathrm{H})$, 5.21 - 5.09 (m, $3 \mathrm{H}) ;{ }^{13} \mathrm{C}$ NMR (101 MHz, CHLOROFORM-d) $\delta=161.6,152.7,148.8,143.3$, 131.7, 122.4, 119.7, 49.40. LCMS: $m / z=195.0(\mathrm{M}+\mathrm{H})$. The compound was purified with Biotage flash column system with 2 to $20 \%$ methanol in DCM.

6-chloro-7-(prop-2-yn-1-yl)-7H-purine (2g) ${ }^{2}$

The titled compound was prepared using method a. White foam, $138 \mathrm{mg} .{ }^{1} \mathrm{H}$ NMR (400MHz, CHLOROFORM-d) $\delta=8.87$ (br. s., 1 H), 8.50 (br. s., $1 \mathrm{H}$ ), 5.31 (br. s., $2 \mathrm{H}$ ), 2.68 (br. s., $1 \mathrm{H}$ );

${ }^{13} \mathrm{C}$ NMR (101 MHz, CHLOROFORM-d) $\delta=162.0,152.8,148.3,148.3,122.2,75.1,53.5,37.3$. LCMS: $m / z=193.2(\mathrm{M}+\mathrm{H})$. The compound was purified with Biotage flash column system with 2 to $20 \%$ methanol in DCM.

6-chloro-7-(2,2,2-trifluoroethyl)-7H-purine $(\mathbf{2 h})^{5}$

The titled compound was prepared using method a. Yellow foam, $193 \mathrm{mg} .{ }^{1} \mathrm{H}$ NMR (400MHz, DMSO-d $\left._{6}\right) \delta=8.94(\mathrm{~s}, 1 \mathrm{H}), 8.90(\mathrm{~s}, 1 \mathrm{H}), 5.54(\mathrm{q}, J=8.8 \mathrm{~Hz}, 2 \mathrm{H}) ;{ }^{13} \mathrm{C}$ NMR $(101 \mathrm{MHz}$, DMSO-d6) $\delta=161.4,152.3,151.5,142.4,124.5,122.1,121.7,46.8,46.5,46.1,45.8 ;{ }^{19} \mathrm{~F} \mathrm{NMR}$ (376MHz, DMSO-d6) $\delta=-73.0(\mathrm{t}, J=8.6 \mathrm{~Hz}, 3 \mathrm{~F})$. LCMS: $m / z=237.0(\mathrm{M}+\mathrm{H})$. The compound was purified with Biotage flash column system with 2 to $20 \%$ methanol in DCM.

2-(6-chloro-7H-purin-7-yl)-1-phenylethanone $(\mathbf{2 i})^{6}$

The titled compound was prepared using method a, slow addition of phenacyl bromide within one hour was required. Pale yellow oil, $187 \mathrm{mg}$. ${ }^{1} \mathrm{H}$ NMR (400 MHz, DMSO-d 6 ) $\delta=8.96$ (s, 1 $\mathrm{H}), 8.40(\mathrm{~s}, 1 \mathrm{H}), 8.16(\mathrm{dd}, J=1.3,8.4 \mathrm{~Hz}, 2 \mathrm{H}), 7.68(\mathrm{~d}, J=8.0 \mathrm{~Hz}, 2 \mathrm{H}), 6.39(\mathrm{~s}, 2 \mathrm{H}) ;{ }^{13} \mathrm{C}$ NMR (101 MHz, DMSO-d6) $\delta=191.0,153.5,149.5,146.3,143.1,134.8,133.5,129.2,128.3$, 114.9, 55.5. LCMS: $\mathrm{m} / \mathrm{z}=273.0(\mathrm{M}+\mathrm{H})$. The compound was purified with Biotage flash column system with 2 to $20 \%$ methanol in DCM.

2, 6-dichloro-7-methyl-7H-purine $(\mathbf{2} \mathbf{j})^{7}$

The titled compound was prepared using method a. White foam, $181 \mathrm{mg} .{ }^{1} \mathrm{H}$ NMR (400MHz, DMSO-d $\left._{6}\right) \delta=8.82(\mathrm{~s}, 1 \mathrm{H}), 4.07(\mathrm{~d}, J=0.3 \mathrm{~Hz}, 3 \mathrm{H}) ;{ }^{13} \mathrm{C}$ NMR $(101 \mathrm{MHz}, \mathrm{DMSO}-\mathrm{d} 6) \delta=$ $163.01,152.83,150.66,143.43,122.53,34.01$. LCMS: $\mathrm{m} / \mathrm{z}=203.0(\mathrm{M}+\mathrm{H})$. The compound was purified with Biotage flash column system with 2 to $20 \%$ methanol in DCM.

2, 6-dichloro-7-ethyl-7H-purine $(\mathbf{2 k})^{8}$

The titled compound was prepared using method a. Colorless oil, $155 \mathrm{mg} .{ }^{1} \mathrm{H}$ NMR (400MHz, $\left.\mathrm{DMSO}_{-} \mathrm{d}_{6}\right) \delta=8.90(\mathrm{~s}, 1 \mathrm{H}), 4.49$ (q, $\left.J=7.3 \mathrm{~Hz}, 2 \mathrm{H}\right), 1.47(\mathrm{t}, J=7.2 \mathrm{~Hz}, 3 \mathrm{H}) ;{ }^{13} \mathrm{C}$ NMR $(101$ 
MHz, DMSO-d6) $\delta=163.3,152.0,150.8,143.0,121.7,42.0,16.6 . \mathrm{LCMS}: \mathrm{m} / \mathrm{z}=217.0(\mathrm{M}+\mathrm{H})$. The compound was purified with Biotage flash column system with 2 to $20 \%$ methanol in DCM.

7-benzyl-2, 6-dichloro-7H-purine (2l) ${ }^{9}$

The titled compound was prepared using method a. White foam, $214 \mathrm{mg} .{ }^{1} \mathrm{H}$ NMR (400MHz, DMSO-d $\left.{ }_{6}\right) \delta=9.00(\mathrm{~s}, 1 \mathrm{H}), 7.38$ - $7.21(\mathrm{~m}, 3 \mathrm{H}), 7.21-7.08(\mathrm{~m}, 2 \mathrm{H}), 5.69(\mathrm{~s}, 2 \mathrm{H}) ;{ }^{13} \mathrm{C} \mathrm{NMR}$ (101 MHz, DMSO-d6) $\delta=163.4,152.9,151.1,143.2,136.4,128.8,127.9,126.5,121.9,49.5$. LCMS: $\mathrm{m} / \mathrm{z}=279.0(\mathrm{M}+\mathrm{H})$. The compound was purified with Biotage flash column system with 2 to $20 \%$ methanol in DCM.

7-allyl-2, 6-dichloro-7H-purine $(\mathbf{2 m})^{10}$

The titled compound was prepared using method a. Pale yellow foam, $168 \mathrm{mg} .{ }^{1} \mathrm{H}$ NMR $\left(400 \mathrm{MHz}, \mathrm{DMSO}_{-}\right) \delta=8.90(\mathrm{~s}, 1 \mathrm{H}), 6.22$ - $6.06(\mathrm{~m}, 1 \mathrm{H}), 5.34-5.18(\mathrm{~m}, 1 \mathrm{H}), 5.12(\mathrm{td}, J=$ 1.7, 5.0 Hz, $2 \mathrm{H}), 5.05$ - 4.91 (m, $1 \mathrm{H}) ;{ }^{13} \mathrm{C}$ NMR (101 MHz, DMSO-d6) $\delta=163.2,152.5,150.9$, 143.2, 133.6, 121.9, 117.5, 48.5. LCMS: $\mathrm{m} / \mathrm{z}=228.9(\mathrm{M}+\mathrm{H})$. The compound was purified with Biotage flash column system with 2 to $20 \%$ methanol in DCM.

2, 6-dichloro-7-(prop-2-yn-1-yl)-7H-purine (2n) ${ }^{10}$

The titled compound was prepared using method a. While foam, $183 \mathrm{mg} .{ }^{1} \mathrm{H}$ NMR $(400 \mathrm{MHz}$, DMSO-d $\left._{6}\right) \delta=8.95$ (s, $\left.1 \mathrm{H}\right), 5.38(\mathrm{~d}, J=2.2 \mathrm{~Hz}, 3 \mathrm{H}), 3.70$ (br. S., $\left.1 \mathrm{H}\right) ;{ }^{13} \mathrm{C}$ NMR $(101 \mathrm{MHz}$, DMSO-d6) $\delta=163.2,151.8,151.3,143.4,121.6,78.1,77.6,36.6$. LCMS: $\mathrm{m} / \mathrm{z}=227.1(\mathrm{M}+\mathrm{H})$. The compound was purified with Biotage flash column system with 2 to $20 \%$ methanol in DCM. 2, 6-dichloro-7-(2, 2, 2-trifluoroethyl)-7H-purine (2o $)^{5}$

The titled compound was prepared using method a. Yellow oil, $199 \mathrm{mg} .{ }^{1} \mathrm{H}$ NMR $(400 \mathrm{MHz}$, DMSO-d $_{6}$ ) $\delta=9.00$ (br. s., $1 \mathrm{H}$ ), 5.53 (d, $\left.J=7.8 \mathrm{~Hz}, 3 \mathrm{H}\right) ;{ }^{13} \mathrm{C}$ NMR (101 MHz, DMSO-d6) $\delta$ $=163.2,153.0,151.6,143.4,121.9,46.5,46.2 ;{ }^{19} \mathrm{~F}$ NMR $(376 \mathrm{MHz}, \mathrm{DMSO}-\mathrm{d} 6) \delta=-73.0(\mathrm{t}, J=$ $8.6 \mathrm{~Hz}, 3 \mathrm{~F})$. LCMS: $\mathrm{m} / \mathrm{z}=271.0(\mathrm{M}+\mathrm{H})$. The compound was purified with Biotage flash column system with 2 to $20 \%$ methanol in DCM.

N, N, 7-trimethyl-7H-purin-6-amine (4a) ${ }^{11}$

The titled compound was prepared using method a. While foam, $44 \mathrm{mg} .{ }^{1} \mathrm{H}$ NMR $(400 \mathrm{MHz}$, DMSO-d $\left._{6}\right) \delta=8.36(\mathrm{~s}, 1 \mathrm{H}), 8.34(\mathrm{~d}, J=0.4 \mathrm{~Hz}, 1 \mathrm{H}), 3.98(\mathrm{~d}, J=0.4 \mathrm{~Hz}, 3 \mathrm{H}), 3.06$ (s, $\left.6 \mathrm{H}\right)$; ${ }^{13} \mathrm{C}$ NMR (101 MHz, DMSO-d6) $\delta=160.7,154.8,150.8,147.7,114.7,41.3,35.0$. LCMS: $\mathrm{m} / z$ $=178.2(\mathrm{M}+\mathrm{H})$. The compound was purified with Biotage flash column system with 2 to $20 \%$ methanol in DCM. 
6-methoxy-7-methyl-7H-purine $(\mathbf{4 b})^{12}$

The titled compound was prepared using method a. Yellow oil, $93 \mathrm{mg} .{ }^{1} \mathrm{H}$ NMR (400MHz, $\left.\mathrm{DMSO}_{-} \mathrm{d}_{6}\right) \delta=8.51(\mathrm{~s}, 1 \mathrm{H}), 8.41(\mathrm{~s}, 1 \mathrm{H}), 4.09(\mathrm{~s}, 3 \mathrm{H}), 3.97(\mathrm{~s}, 3 \mathrm{H}) ;{ }^{13} \mathrm{C}$ NMR $(101 \mathrm{MHz}$, DMSO-d6) $\delta=161.2,156.9,151.1,147.3,113.0,53.9,33.7$. LCMS: $m / z=165.3(\mathrm{M}+\mathrm{H})$. The compound was purified with Biotage flash column system with 2 to $20 \%$ methanol in DCM.

7-methyl-6-(methylthio)-7H-purine $(4 \mathbf{c})^{13}$

The titled compound was prepared using method a. Yellow foam, $144 \mathrm{mg} .{ }^{1} \mathrm{H} \mathrm{NMR} \mathrm{(400MHz,}$ $\left.\mathrm{DMSO}_{-} \mathrm{d}_{6}\right) \delta=8.75(\mathrm{~s}, 1 \mathrm{H}), 8.49(\mathrm{~s}, 1 \mathrm{H}), 4.09$ (s, $\left.3 \mathrm{H}\right), 2.70(\mathrm{~s}, 3 \mathrm{H}) ;{ }^{13} \mathrm{C} \mathrm{NMR}(101 \mathrm{MHz}$, DMSO-d $\left._{6}\right) \delta=159.9,155.4,153.7,150.9,125.5,36.4,13.8$. LCMS: $m / z=181.2(\mathrm{M}+\mathrm{H})$. The compound was purified with Biotage flash column system with 2 to $20 \%$ methanol in DCM.

6, 7-dimethyl-7H-purine $(\mathbf{4 d})^{14}$

The titled compound was prepared using method a. White foam, $114 \mathrm{mg} .{ }^{1} \mathrm{H}$ NMR $(400 \mathrm{MHz}$, $\left.\mathrm{DMSO}_{-} \mathrm{d}_{6}\right) \delta=8.75(\mathrm{~s}, 1 \mathrm{H}), 8.53(\mathrm{~s}, 1 \mathrm{H}), 4.08(\mathrm{~s}, 3 \mathrm{H}), 2.86(\mathrm{~s}, 3 \mathrm{H}) ;{ }^{13} \mathrm{C}$ NMR $(101 \mathrm{MHz}$, DMSO-d6) $\delta=159.6,151.7,151.6,149.4,124.5,34.0,20.8$. LCMS: $m / z=149.1(\mathrm{M}+\mathrm{H})$. The compound was purified with Biotage flash column system with 2 to $20 \%$ methanol in DCM.

6-bromo-7-methyl-7H-purine $(\mathbf{4 e})^{15}$

The titled compound was prepared using method b. Pale yellow foam, $169 \mathrm{mg} .{ }^{1} \mathrm{H}$ NMR $\left(400 \mathrm{MHz}, \mathrm{DMSO}_{\mathrm{d}}\right) \delta=8.76(\mathrm{~s}, 1 \mathrm{H}), 8.73(\mathrm{~s}, 1 \mathrm{H}), 4.09(\mathrm{~s}, 3 \mathrm{H}) ;{ }^{13} \mathrm{C} \mathrm{NMR}(101 \mathrm{MHz}$, DMSO-d6) $\delta=160.3,151.5,133.1,124.9,33.9$. LCMS: $m / z=213.4(\mathrm{M}+\mathrm{H})$. The compound was purified with Biotage flash column system with 2 to $20 \%$ methanol in DCM.

7-methyl-7H-purine-6-carbonitrile (4f) ${ }^{16}$

The titled compound was prepared using method b. White foam, $124 \mathrm{mg}$. ${ }^{1} \mathrm{H}$ NMR (400 MHz, CHLOROFORM-d) $\delta 9.25$ (s, 1H), 8.37 (s, 1H), 4.24 (s, 3H); ${ }^{13} \mathrm{C}$ NMR (101 MHz, DMSO-d6) $\delta$ $161.9,153.2,151.9,126.0,122.7,114.4,32.5$ The compound was purified with Biotage flash column system with 2 to $20 \%$ methanol in DCM.

7-chloro-1-methyl-1H-imidazo[4,5-b]pyridine $(\mathbf{6 c})^{17}$

The titled compound was prepared using method b. Yellow oil, $137 \mathrm{mg} .{ }^{1} \mathrm{H}$ NMR (400MHz, DMSO-d $\left._{6}\right) \delta=8.49(\mathrm{~s}, 1 \mathrm{H}), 8.33(\mathrm{~d}, J=5.3 \mathrm{~Hz}, 1 \mathrm{H}), 7.35(\mathrm{~d}, J=5.2 \mathrm{~Hz}, 1 \mathrm{H}), 4.09$ - 4.04 (m, $3 \mathrm{H}) ;{ }^{13} \mathrm{C}$ NMR (101 MHz, DMSO-d6) $\delta=157.4$, 148.6, 144.5, 125.8, 123.2, 118.7, 33.9. LCMS: $m / z=168.6(\mathrm{M}+\mathrm{H})$. The compound was purified with Biotage flash column system with 2 to $20 \%$ methanol in DCM.

7-chloro-1, 2-dimethyl-1H-benzo[d]imidazole (6d) $)^{18}$ 
The titled compound was prepared using method a. Colorless foam, $158 \mathrm{mg} .{ }^{1} \mathrm{H}$ NMR $\left(400 \mathrm{MHz}, \mathrm{DMSO}-\mathrm{d}_{6}\right) \delta=7.49(\mathrm{dd}, J=1.0,7.9 \mathrm{~Hz}, 1 \mathrm{H}), 7.19(\mathrm{dd}, J=1.0,7.8 \mathrm{~Hz}, 1 \mathrm{H}), 7.12(\mathrm{t}$, $J=7.8 \mathrm{~Hz}, 1 \mathrm{H}), 4.00$ (s, $3 \mathrm{H}), 2.53$ (s, $3 \mathrm{H}) ;{ }^{13} \mathrm{C}$ NMR (400 MHz, DMSO-d6) $\delta=153.9,144.5$, 131.1, 122.8, 122.0, 117.5, 114.7, 32.1, 13.7. LCMS: $\mathrm{m} / \mathrm{z}=181.4(\mathrm{M}+\mathrm{H})$. The compound was purified with Biotage flash column system with 2 to $20 \%$ methanol in DCM.

4-bromo-3-methyl-3H-imidazo [4, 5-c]pyridine $(\mathbf{6 e})^{11}$

The titled compound was prepared using method b. Brown oil, $166 \mathrm{mg} .{ }^{1} \mathrm{H}$ NMR (400MHz, DMSO-d $\left._{6}\right) \delta=8.51(\mathrm{~s}, 1 \mathrm{H}), 8.11(\mathrm{~d}, J=5.5 \mathrm{~Hz}, 1 \mathrm{H}), 7.72(\mathrm{~d}, J=5.5 \mathrm{~Hz}, 1 \mathrm{H}), 4.15$ - $4.07(\mathrm{~m}$, $3 \mathrm{H}) ;{ }^{13} \mathrm{C}$ NMR (101 MHz, DMSO-d6) $\delta=150.1,149.6,141.0,130 .$, 122.7, 114.8, 33.8. LCMS: $\mathrm{m} / \mathrm{z}=212.1(\mathrm{M}+\mathrm{H})$. The compound was purified with Biotage flash column system with 2 to $20 \%$ methanol in DCM.

4-chloro-3-methyl-3H-imidazo[4,5-c]pyridine $(\mathbf{6 f})^{19}$

The titled compound was prepared using method b. Yellow foam, $128 \mathrm{mg}{ }^{1} \mathrm{H}$ NMR (400MHz, DMSO-d $\left._{6}\right) \delta=8.48(\mathrm{~s}, 1 \mathrm{H}), 8.11(\mathrm{~d}, J=5.2 \mathrm{~Hz}, 1 \mathrm{H}), 7.68(\mathrm{~d}, J=5.4 \mathrm{~Hz}, 1 \mathrm{H}), 4.09$ (s, $\left.3 \mathrm{H}\right)$;

${ }^{13} \mathrm{C}$ NMR (400MHz, DMSO-d6) $\delta=150.7,149.4,140.4,133.2,128.4,114.7,33.6$. LCMS: $\mathrm{m} / z=$ $168.0(\mathrm{M}+\mathrm{H})$. The compound was purified with Biotage flash column system with 2 to $20 \%$ methanol in DCM.

7-bromo-1-methyl-1H-imidazo[4,5-b]pyridine (6g)

The titled compound was prepared using method b. Pale yellow foam, $156 \mathrm{mg} .{ }^{1} \mathrm{H}$ NMR $\left(400 \mathrm{MHz}, \mathrm{DMSO}-\mathrm{d}_{6}\right) \delta=8.52(\mathrm{~s}, 1 \mathrm{H}), 8.25(\mathrm{~d}, J=5.2 \mathrm{~Hz}, 1 \mathrm{H}), 7.54(\mathrm{~d}, J=5.1 \mathrm{~Hz}, 1 \mathrm{H}), 4.08$ (s, $3 \mathrm{H}) ;{ }^{13} \mathrm{C}$ NMR (101 MHz, DMSO-d6) $\delta=156.7,148.9,144.4$, 124.8, 122.0, 113.5, 34.0. LCMS: $m / z=212.1(\mathrm{M}+\mathrm{H})$.HRMS: C7H6BrN3. Theoretical $211.9818(\mathrm{M}+\mathrm{H})$, found 211.9816(M+H). The compound was purified with Biotage flash column system with 2 to $20 \%$ methanol in DCM.

1-methyl-5-phenyl-1H-imidazole $(\mathbf{8 a})^{20}$

The titled compound was prepared using method a. Colorless foam, $120 \mathrm{mg} .{ }^{1} \mathrm{H}$ NMR $(400 \mathrm{MHz}$, CHLOROFORM-d) $\delta=7.71(\mathrm{~s}, 1 \mathrm{H}), 7.50-7.35(\mathrm{~m}, 5 \mathrm{H}), 7.12(\mathrm{~d}, J=1.0 \mathrm{~Hz}, 1 \mathrm{H}), 3.70(\mathrm{~s}, 3$ $\mathrm{H}) ;{ }^{13} \mathrm{C}$ NMR (101 MHz, CHLOROFORM-d) $\delta=138.8$, 133.6, 129.4, 128.8, 128.6, 128.2, 127.1, 32.8. LCMS: $m / z=159.4(\mathrm{M}+\mathrm{H})$. The compound was purified with Biotage flash column system with 2 to $20 \%$ methanol in DCM.

5-(tert-butyl)-1-methyl-1H-imidazole ( $\mathbf{8 b})^{21}$ 
The titled compound was prepared using method a. Colorless foam, $120 \mathrm{mg} .{ }^{1} \mathrm{H}$ NMR (400MHz, CHLOROFORM-d) $\delta=7.35$ (s, $1 \mathrm{H}), 6.75$ (s, $1 \mathrm{H}), 3.73$ (s, $3 \mathrm{H}), 1.34$ (s, $9 \mathrm{H}) ;{ }^{13} \mathrm{C} \mathrm{NMR}$ (101MHz, CHLOROFORM-d) $\delta=140.2$, 139.5, 125.1, 34.01=, 30.8, 29.6. LCMS: $\mathrm{m} / \mathrm{z}=139.2$ $(\mathrm{M}+\mathrm{H})$. The compound was purified with Biotage flash column system with 2 to $20 \%$ methanol in DCM.

\section{1,5-dimethyl-1H-imidazole $(\mathbf{8 c})^{22}$}

The titled compound was prepared using method a. Yellow oil, $61 \mathrm{mg} .{ }^{1} \mathrm{H}$ NMR (400 MHz, CHLOROFORM-d) $\delta 7.40(\mathrm{~s}, 1 \mathrm{H}), 6.78(\mathrm{~s}, 1 \mathrm{H}), 3.55(\mathrm{~s}, 3 \mathrm{H}), 2.20(\mathrm{~d}, J=1.04 \mathrm{~Hz}, 3 \mathrm{H}) ;{ }^{13} \mathrm{C}$ NMR $\left(101 \mathrm{MHz}, \mathrm{DMSO}-\mathrm{d}_{6}\right) \delta 137.2,127.2,125.7,30.6,8.6$. LCMS: $m / z=97.1(\mathrm{M}+\mathrm{H})$. The compound was purified with Biotage flash column system with 2 to $20 \%$ methanol in DCM.

5-chloro-1-methyl-1H-imidazole $(\mathbf{8 d})^{23}$

The titled compound was prepared using method a. White foam, $80 \mathrm{mg} .{ }^{1} \mathrm{H}$ NMR (400 MHz, CHLOROFORM-d) $\delta 7.44(\mathrm{~s}, 1 \mathrm{H}), 6.92(\mathrm{~d}, J=0.93 \mathrm{~Hz}, 1 \mathrm{H}), 3.58(\mathrm{~s}, 3 \mathrm{H}) ;{ }^{13} \mathrm{C}$ NMR $(101 \mathrm{MHz}$, CHLOROFORM-d) $\delta 137.1,125.7,118.2,31.4$. LCMS: $m / z=117.2(\mathrm{M}+\mathrm{H})$. The compound was purified with Biotage flash column system with 2 to $20 \%$ methanol in DCM.

5-bromo-1-methyl-1H-imidazole $(\mathbf{8 e})^{24}$

The titled compound was prepared using method b. White foam, $110 \mathrm{mg} .{ }^{1} \mathrm{H}$ NMR (400 MHz, CHLOROFORM-d) $\delta 7.46(\mathrm{~s}, 1 \mathrm{H}), 6.94$ (d, $J=1.04 \mathrm{~Hz}, 1 \mathrm{H}), 3.55$ (s, 3H); ${ }^{13} \mathrm{C}$ NMR $(101 \mathrm{MHz}$, CHLOROFORM-d) $\delta 138.3,129.5,103.8,32.7$. LCMS: $m / z=161.0(\mathrm{M}+\mathrm{H})$. The compound was purified with Biotage flash column system with 2 to $20 \%$ methanol in DCM.

1-methyl-1H-imidazole-5-carbonitrile $(\mathbf{8 f})^{25}$

The titled compound was prepared using method b. Colorless foam, $79 \mathrm{mg} .{ }^{1} \mathrm{H} \mathrm{NMR}(400 \mathrm{MHz}$, CHLOROFORM-d) $\delta 7.67(\mathrm{~s}, 1 \mathrm{H}), 7.62(\mathrm{~s}, 1 \mathrm{H}), 3.83(\mathrm{~s}, 3 \mathrm{H}) ;{ }^{13} \mathrm{C}$ NMR $\left(101 \mathrm{MHz}, \mathrm{DMSO}-\mathrm{d}_{6}\right) \delta$ 142.4, 139.6, 111.5, 104.9, 32.5. LCMS: $m / z=108.3(\mathrm{M}+\mathrm{H})$. The compound was purified with Biotage flash column system with 2 to $20 \%$ methanol in DCM.

1-allyl-5-phenyl-1H-imidazole $(\mathbf{8 g})^{26}$

The titled compound was prepared using method c. Yellow foam, $77 \mathrm{mg} .{ }^{1} \mathrm{H}$ NMR $(400 \mathrm{MHz}$, DMSO-d $\left._{6}\right) \delta=7.88-7.70(\mathrm{~m}, 3 \mathrm{H}), 7.45-7.35(\mathrm{~m}, 2 \mathrm{H}), 7.34-7.21(\mathrm{~m}, 1 \mathrm{H}), 6.73$ (d, J=2.3 $\mathrm{Hz}, 1 \mathrm{H}), 6.06$ (tdd, $J=5.8,10.3,17.1 \mathrm{~Hz}, 1 \mathrm{H}), 5.27-5.12(\mathrm{~m}, 2 \mathrm{H}), 4.80(\mathrm{td}, J=1.5,5.8 \mathrm{~Hz}, 2$ $\mathrm{H}) ;{ }^{13} \mathrm{C}$ NMR (101 MHz, DMSO-d6) $\delta=150.1,134.1,133.4,131.5,128.6,127.3,125.0,117.7$, 102.7. LCMS: $m / z=185.1(\mathrm{M}+\mathrm{H})$. The compound was purified with Biotage flash column system with 2 to $20 \%$ methanol in DCM.

5-phenyl-1-(prop-2-yn-1-yl)-1H-imidazole (8h) 
The titled compound was prepared using method c. Colorless oil, $64 \mathrm{mg} .{ }^{1} \mathrm{H}$ NMR $(400 \mathrm{MHz}$, DMSO-d $\left._{6}\right) \delta=7.85(\mathrm{~d}, J=1.1 \mathrm{~Hz}, 1 \mathrm{H}), 7.63-7.31(\mathrm{~m}, 5 \mathrm{H}), 7.08(\mathrm{~d}, J=1.2 \mathrm{~Hz}, 1 \mathrm{H}), 4.95(\mathrm{~d}$, $J=2.5 \mathrm{~Hz}, 2 \mathrm{H}$ ), $3.52-3.43$ (m, $1 \mathrm{H}$ ); ${ }^{13} \mathrm{C}$ NMR (101MHz, DMSO-d6) $\delta=139.0,132.1,129.3$, 128.8, 127.8, 127.8, 127.8, 79.0, 76.3, 34.6. LCMS: $m / z=183.1(\mathrm{M}+\mathrm{H})$. HRMS: C12H10N2. Theoretical $183.0922(\mathrm{M}+\mathrm{H})$, found $183.0927(\mathrm{M}+\mathrm{H})$. The compound was purified with Biotage flash column system with 2 to $20 \%$ methanol in DCM. 

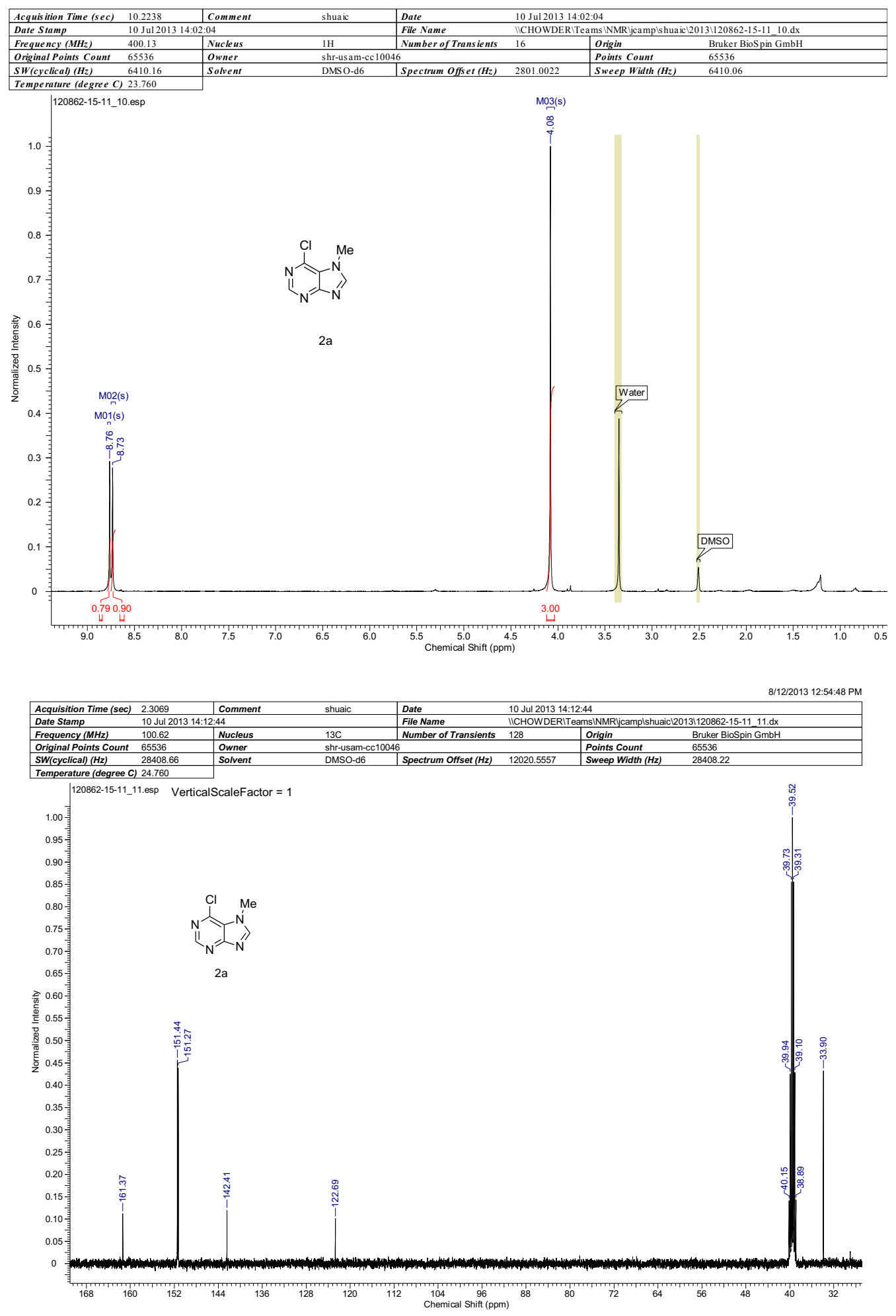

S-12 

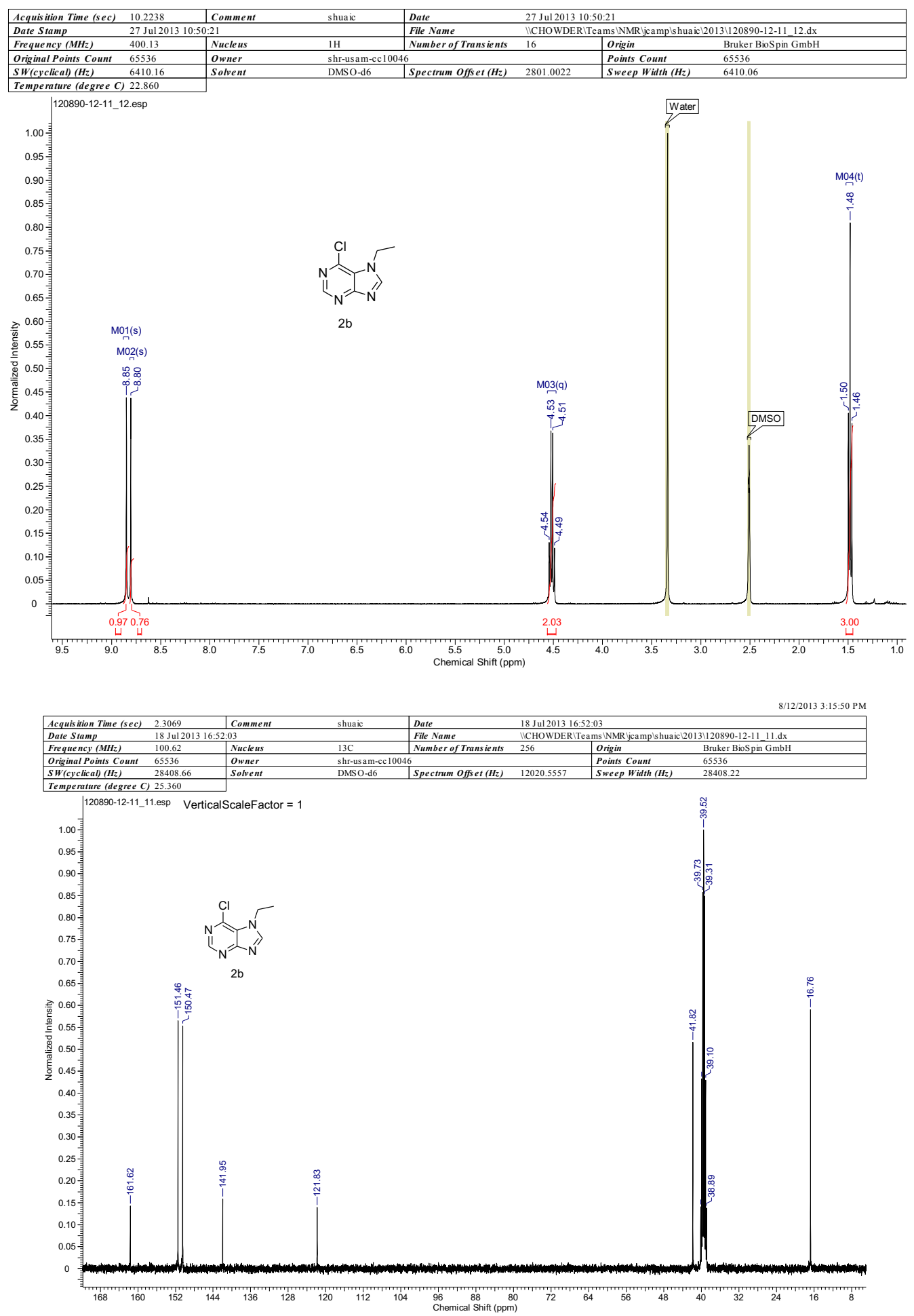

S-13 


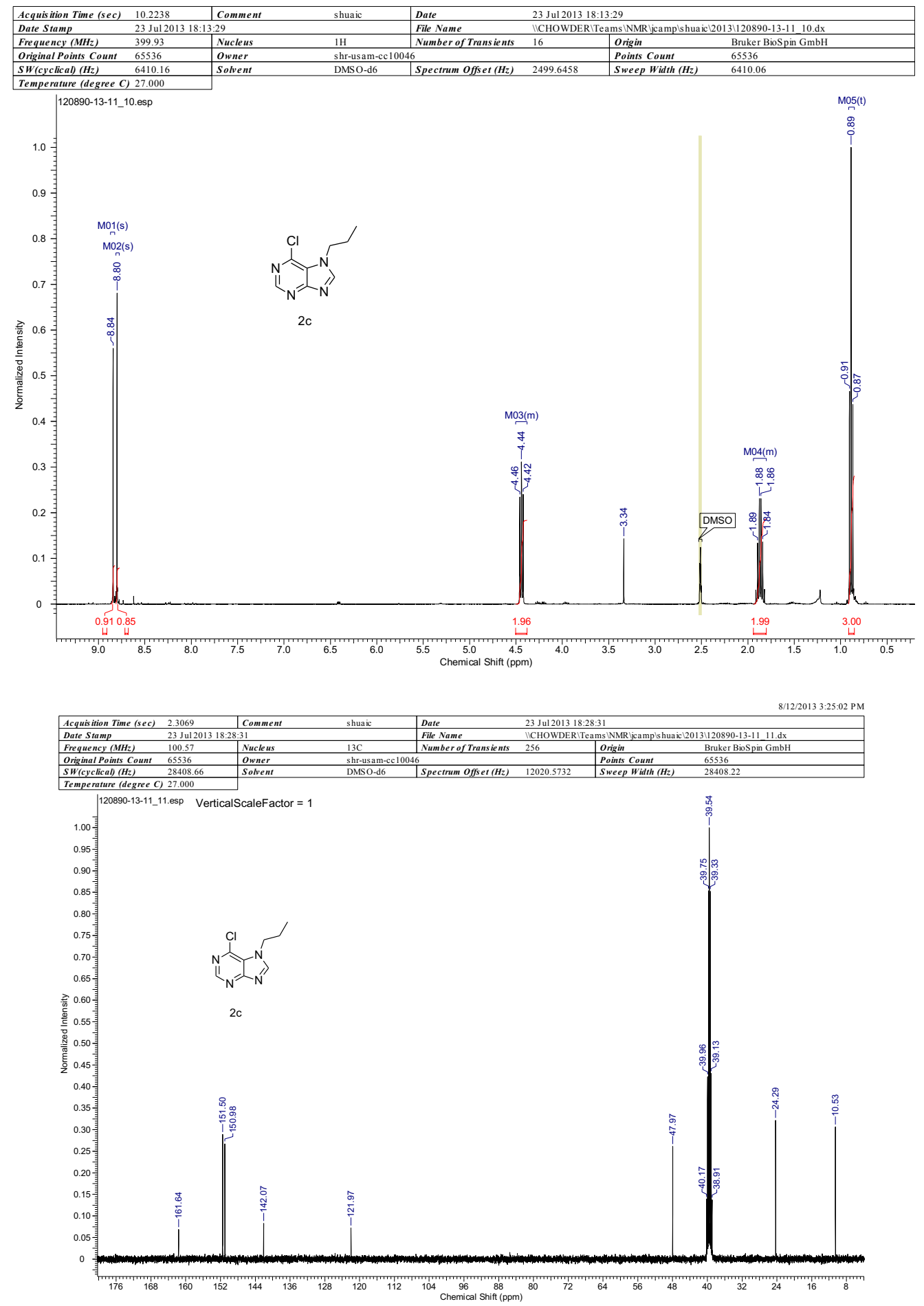

S-14 

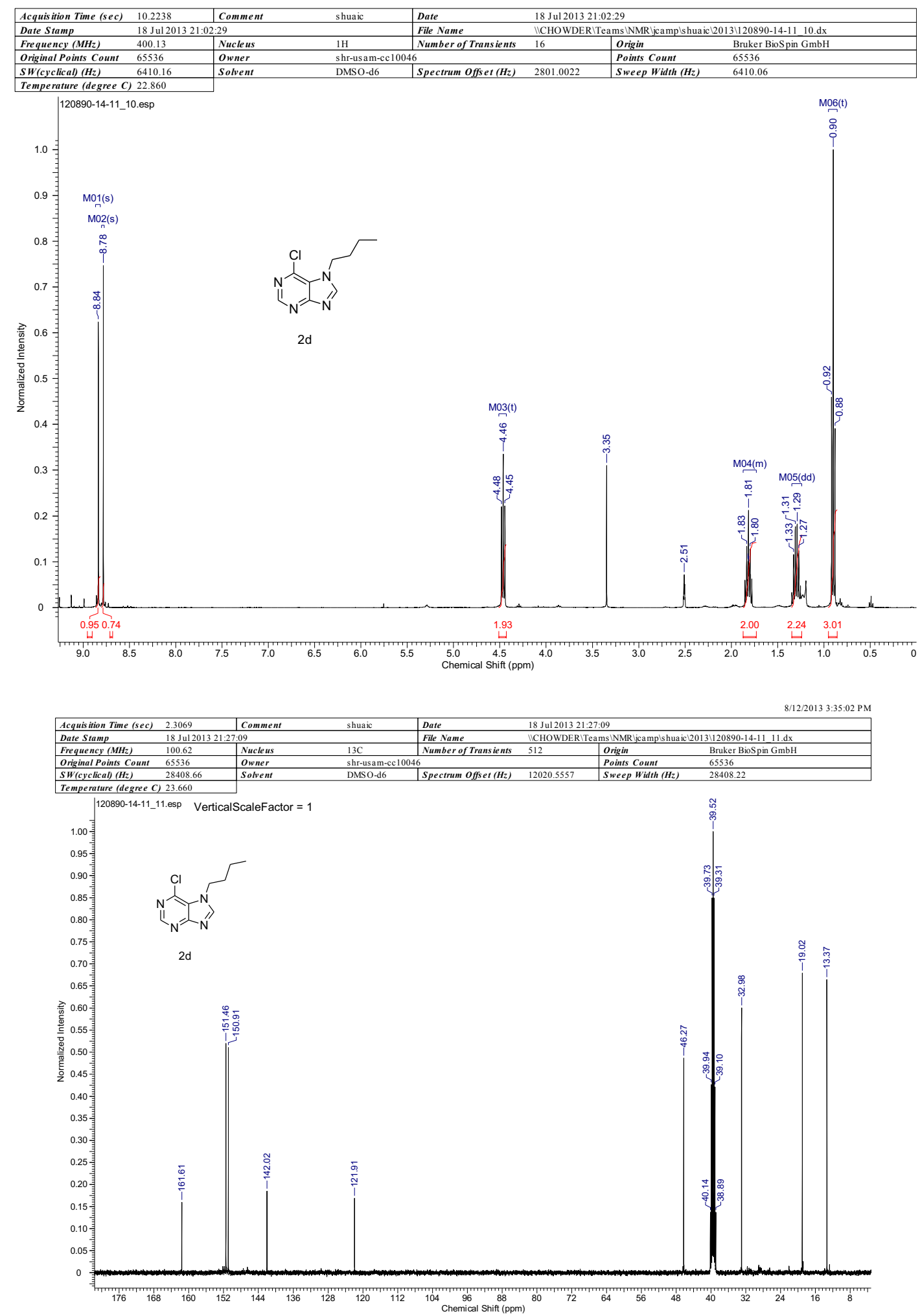

S-15 

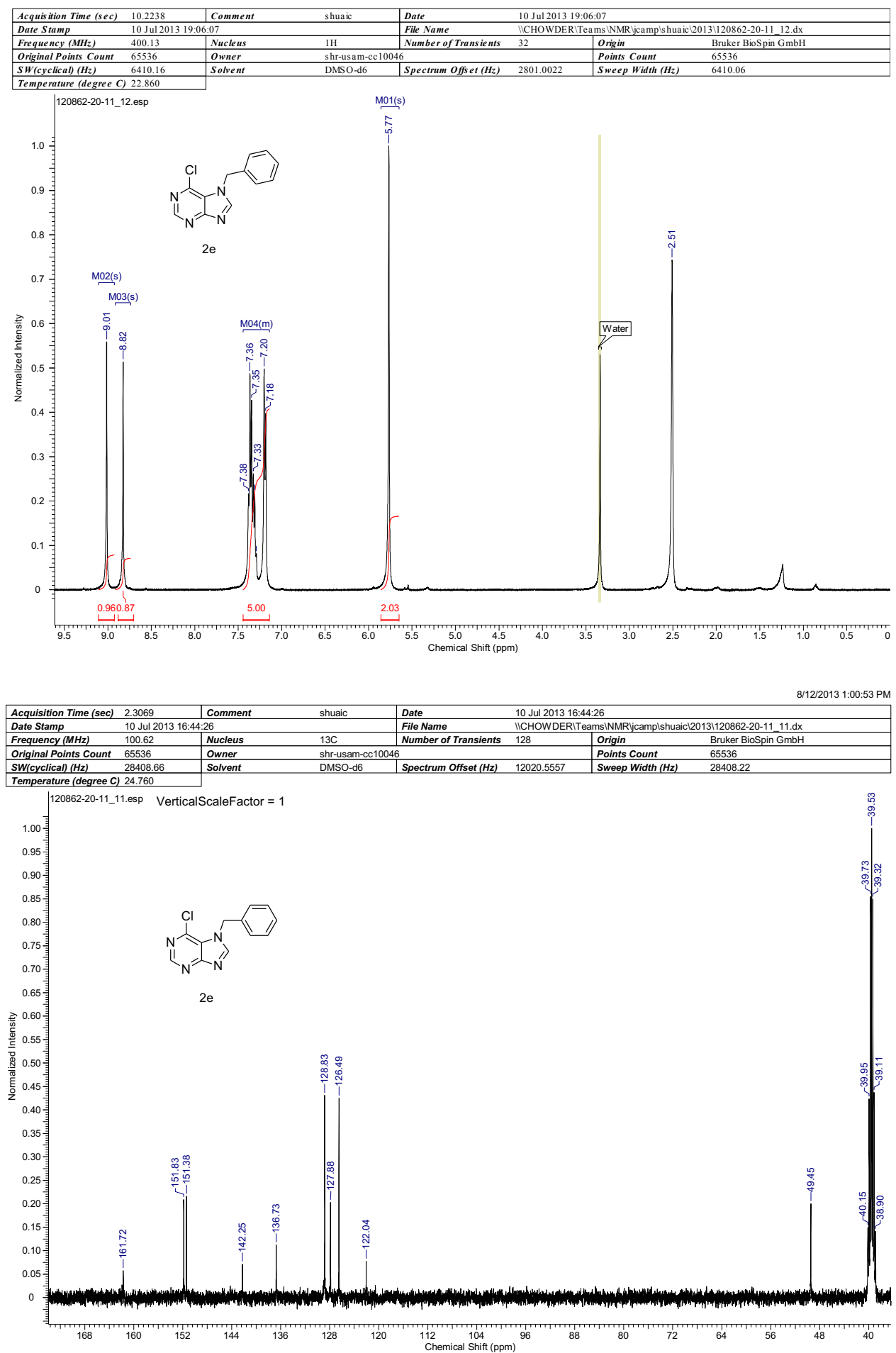

S-16 

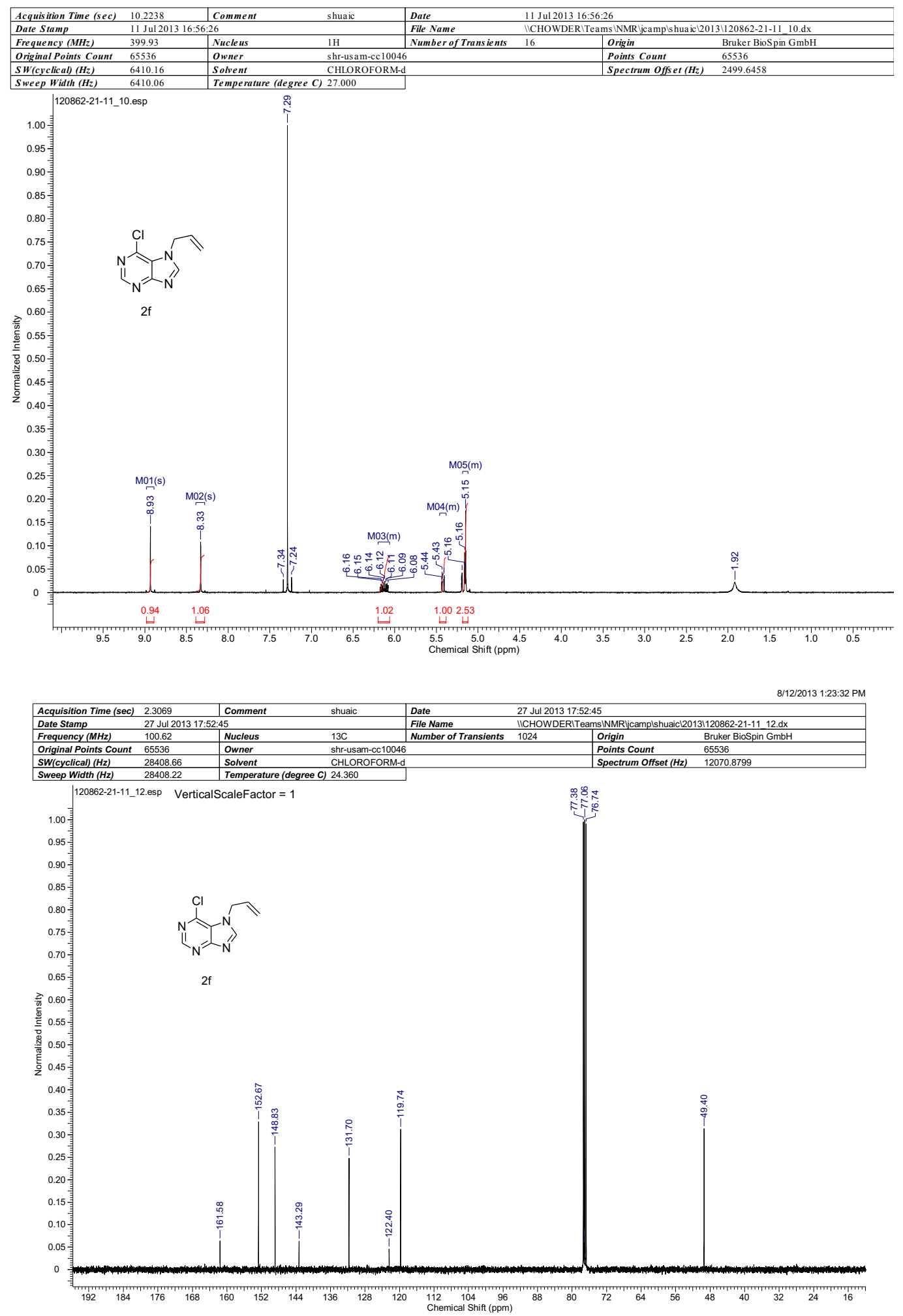

S-17 

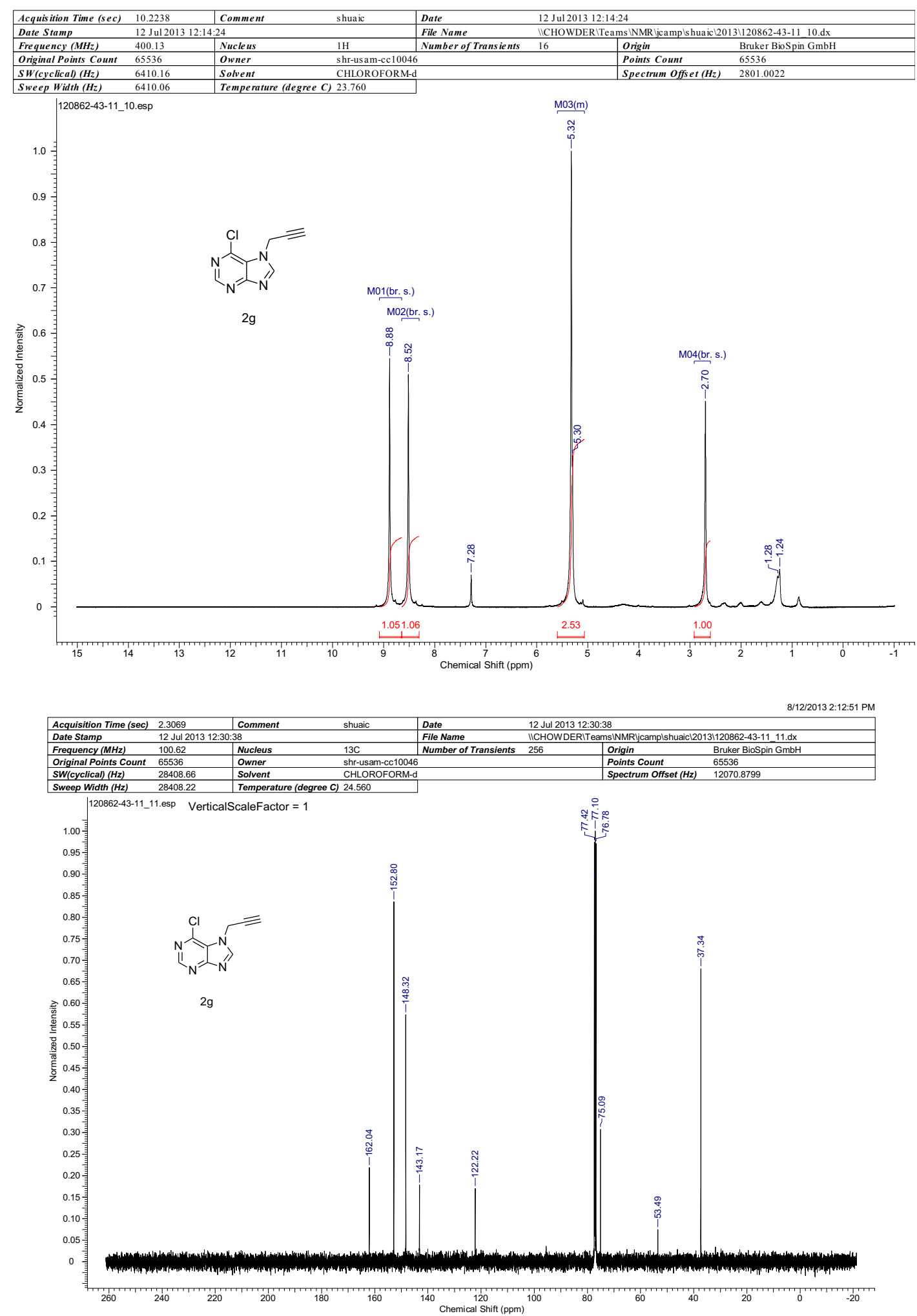

S-18 

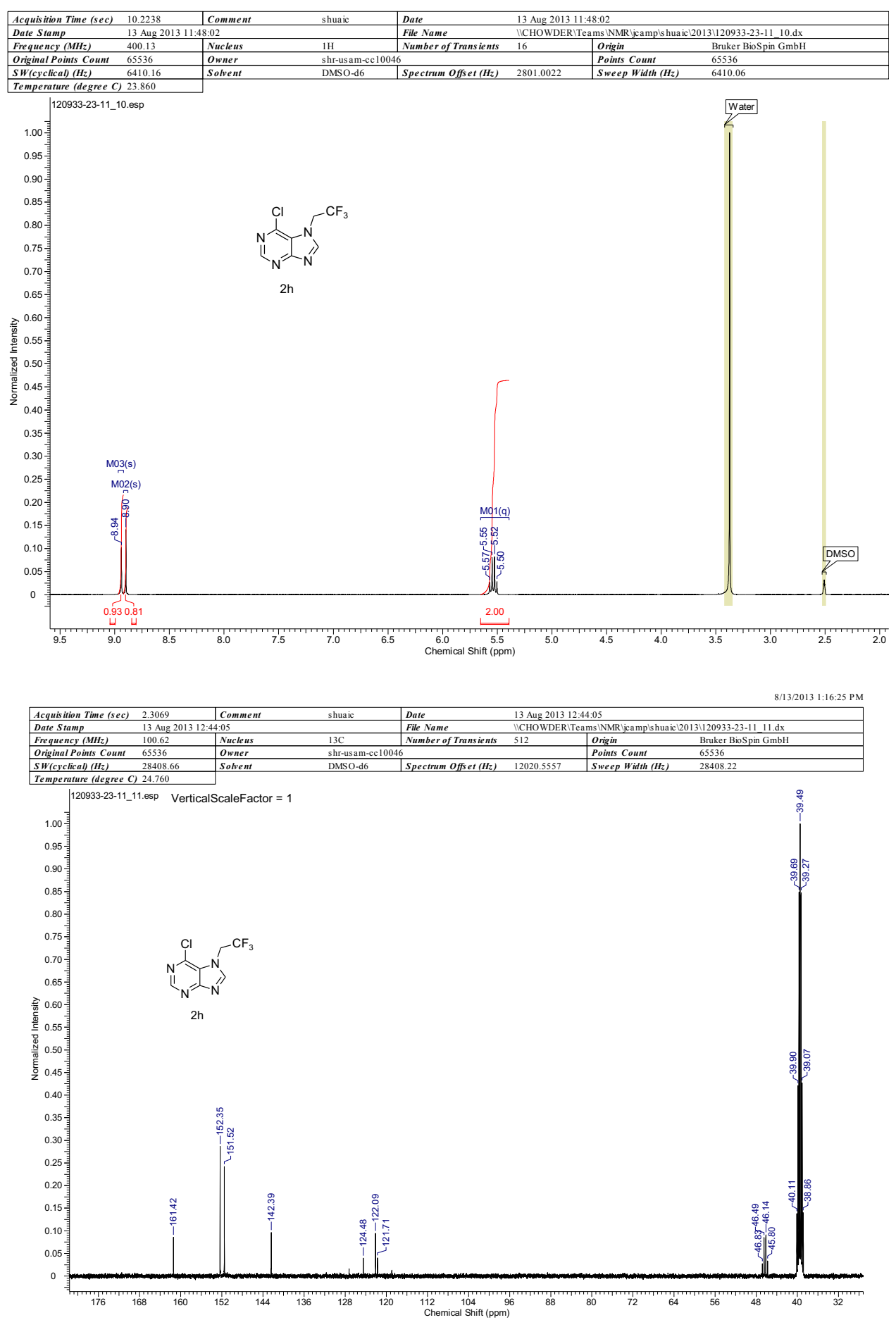

S-19 
8/13/2013 1:23:04 PM

\begin{tabular}{|c|c|c|c|c|c|c|c|}
\hline \multirow{3}{*}{\begin{tabular}{|l} 
Acquis ition Time (sec) \\
Date Stamp \\
\end{tabular}} & \multirow{2}{*}{$\begin{array}{l}0.8716 \\
13 \text { Aug } 201312\end{array}$} & \multirow{2}{*}{\begin{tabular}{|l|l|l|} 
Comment \\
0.26
\end{tabular}} & \multirow{3}{*}{ shuaic } & \multirow{3}{*}{\begin{tabular}{|l|} 
Date \\
File Name \\
Number of Transients \\
\end{tabular}} & \multicolumn{3}{|c|}{ 13 Aug 2013 12:50:26 } \\
\hline & & & & & MCHOWDER & ams $(N M R$ jocampishuaic & 3\120933-23-11_12.dx \\
\hline & 376.48 & Nucleus & & & 32 & Origin & Bruker BioSpin GmbH \\
\hline Original Points Count & 65536 & Owner & shr-usam-cc 10046 & & & Points Count & 65536 \\
\hline SW(cyclical) $\left(H_{z}\right)$ & 75186.82 & Solvent & DMSO-d6 & Spectrum Offset $\left(\mathrm{H}_{z}\right)$ & -23340.7500 & Sweep Width $\left(\mathrm{H}_{z}\right)$ & 75185.67 \\
\hline
\end{tabular}

Temperature (degree C) 24.060

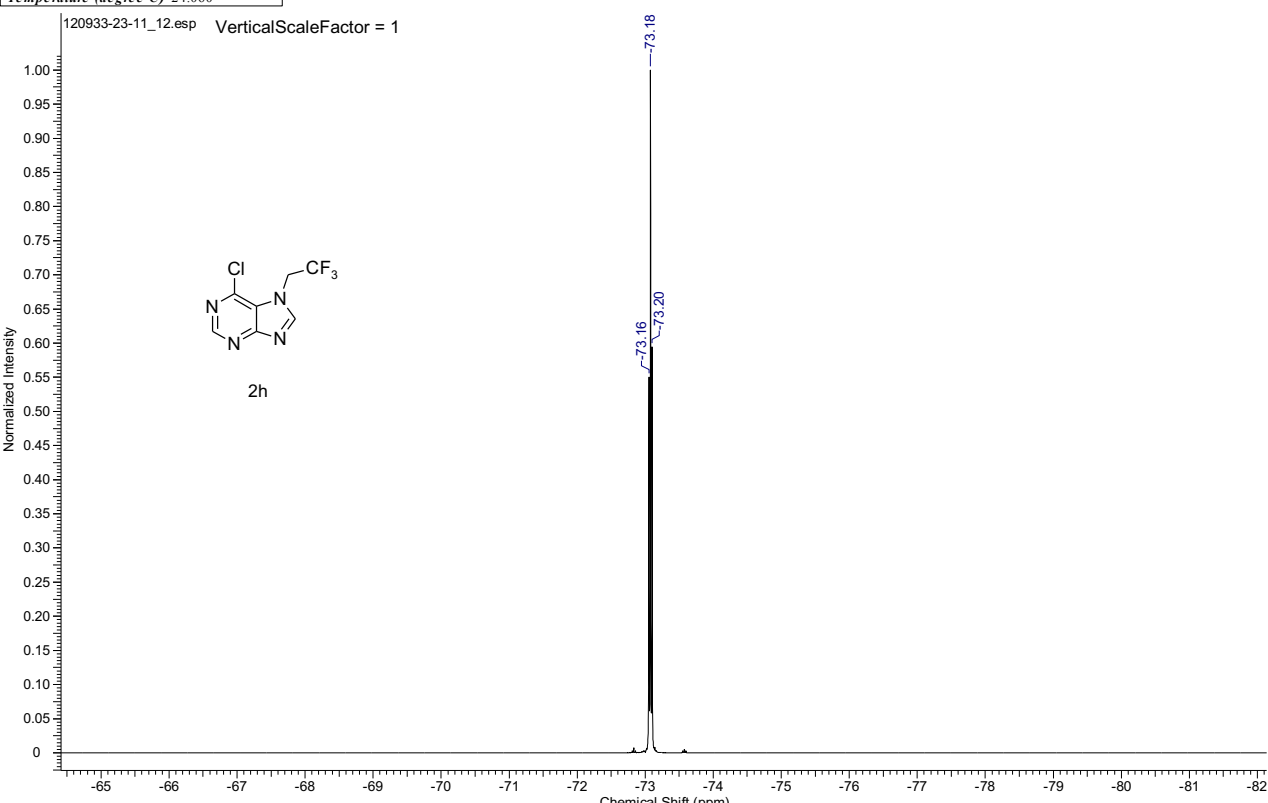

S-20 

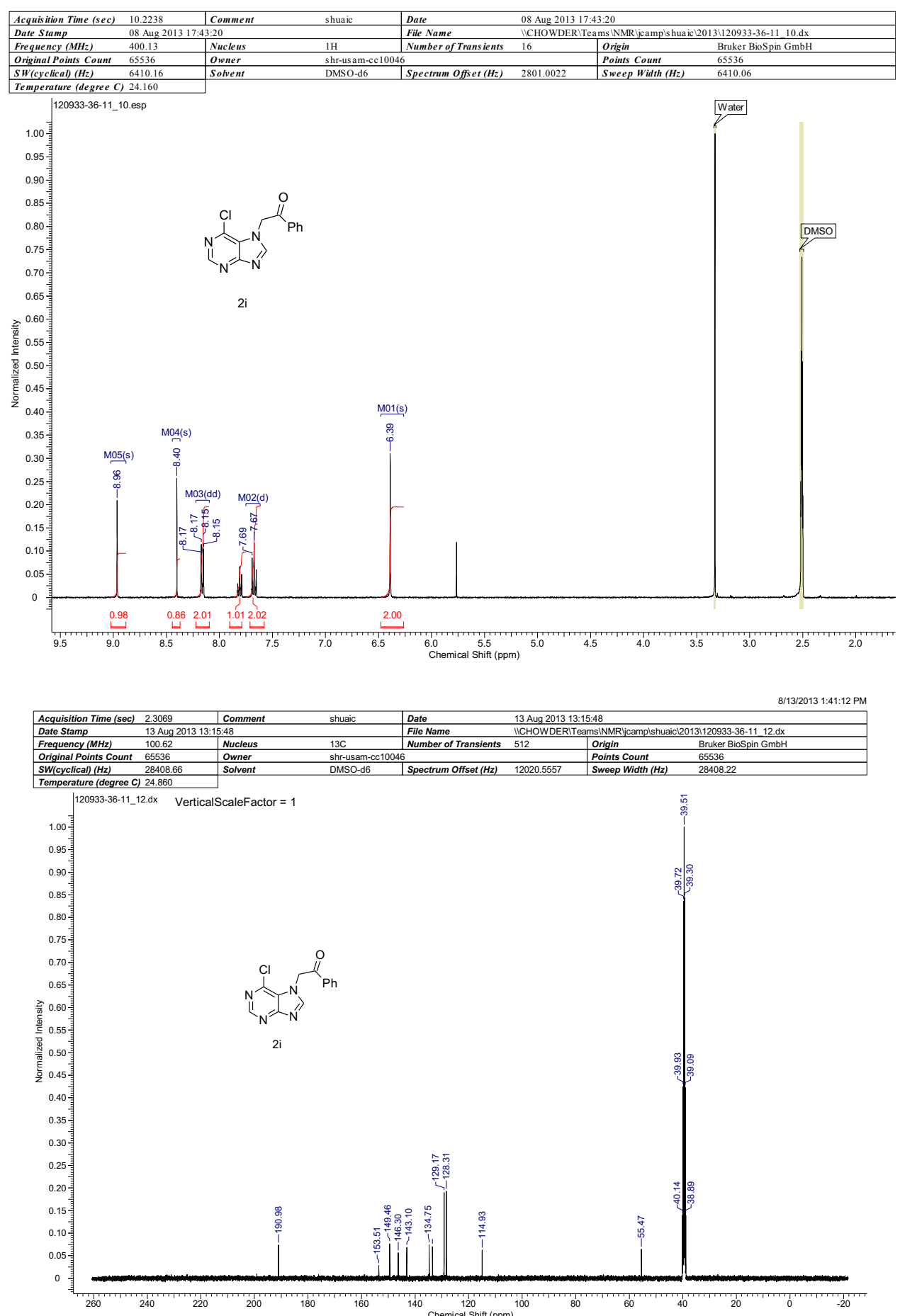

S-21 


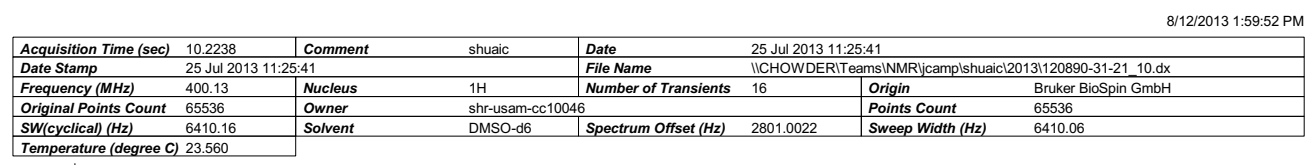

$\frac{\text { Temperature (degree C) 23.560 }}{\text { 120890-31-21_10.dx VerticalScaleFactor }=1}$

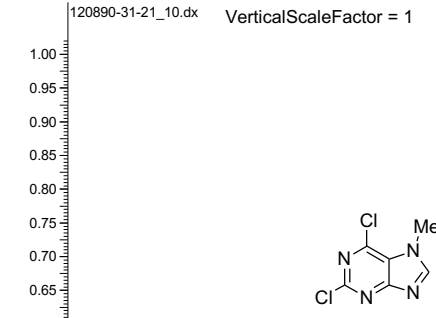

2j

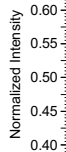

0.35 害
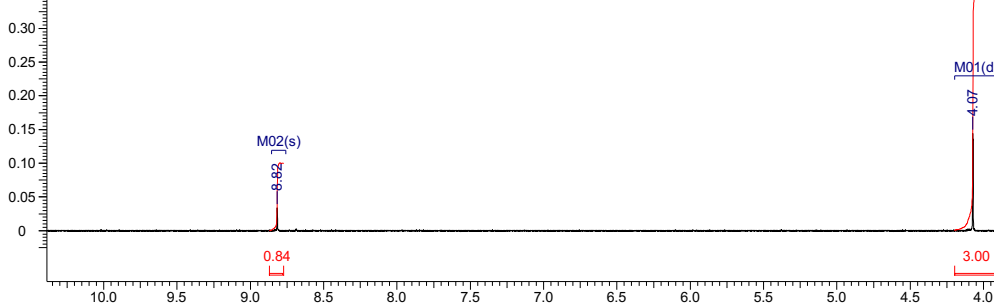

3.00
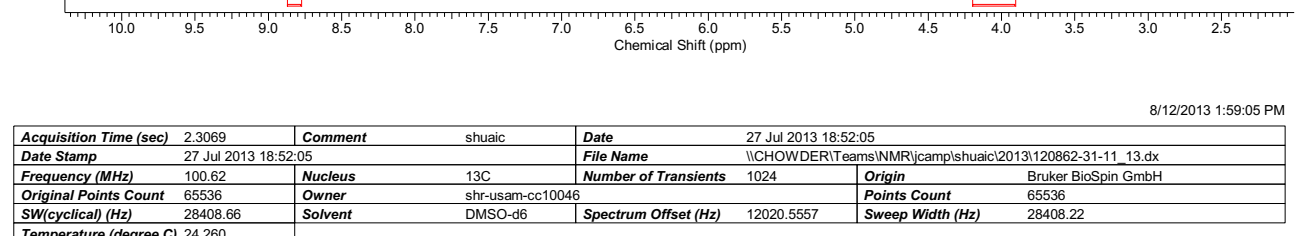

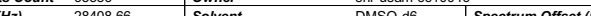
Temperature (degree C) 24260

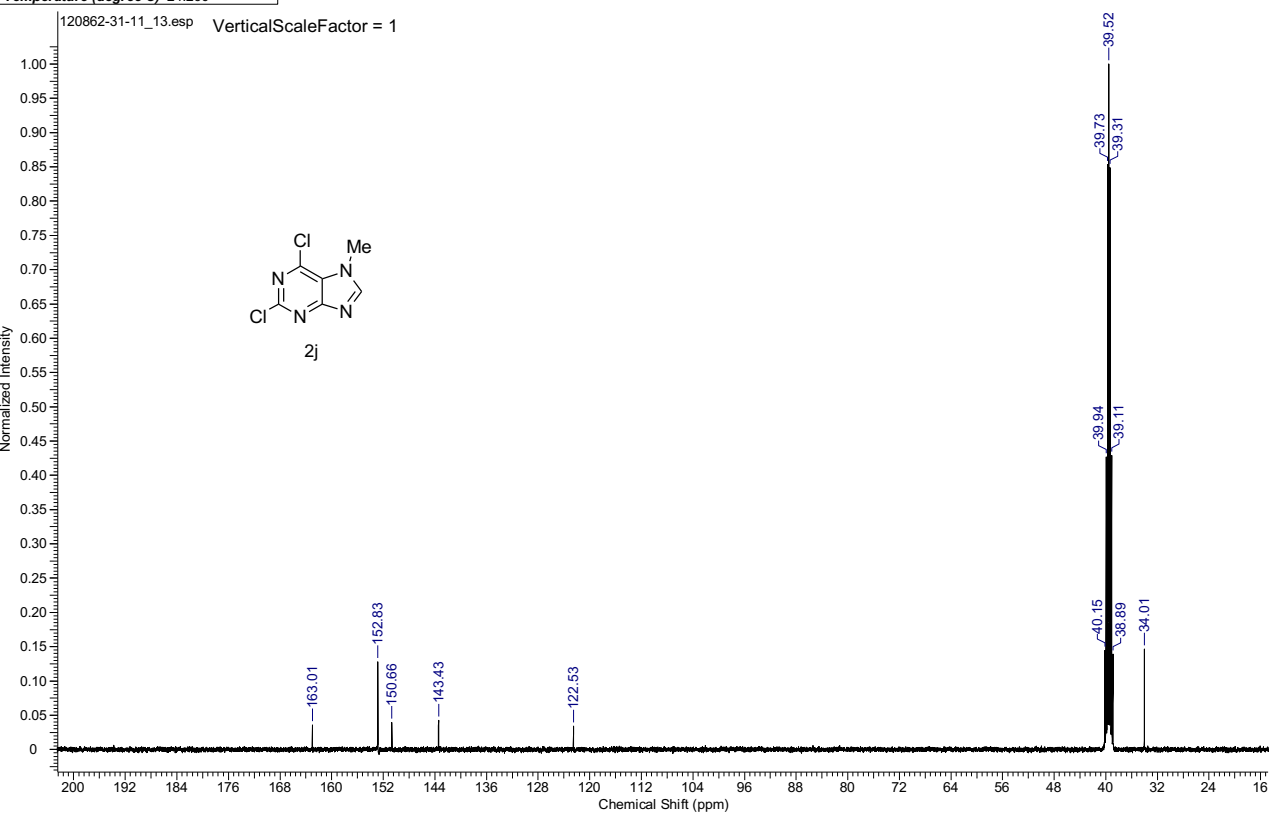



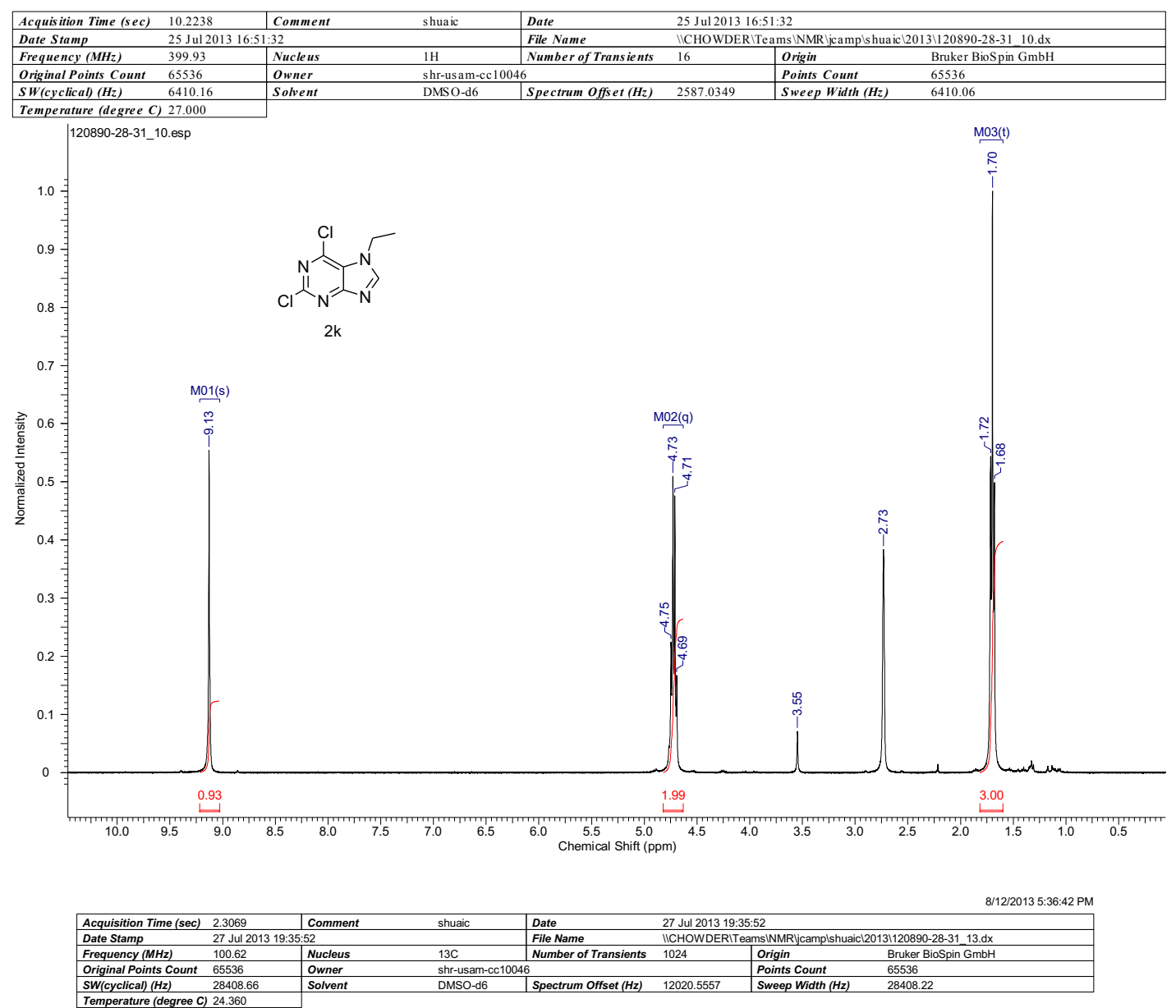

Tempera

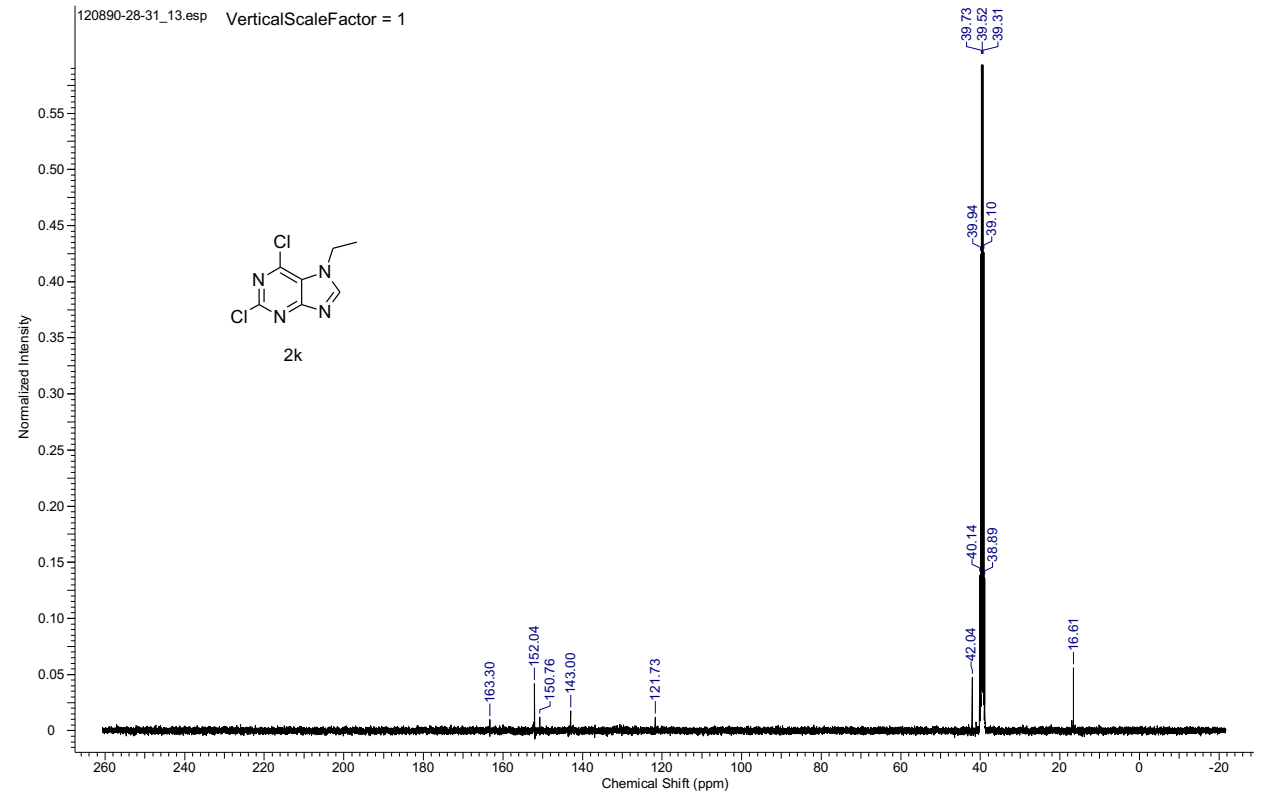

S-23 

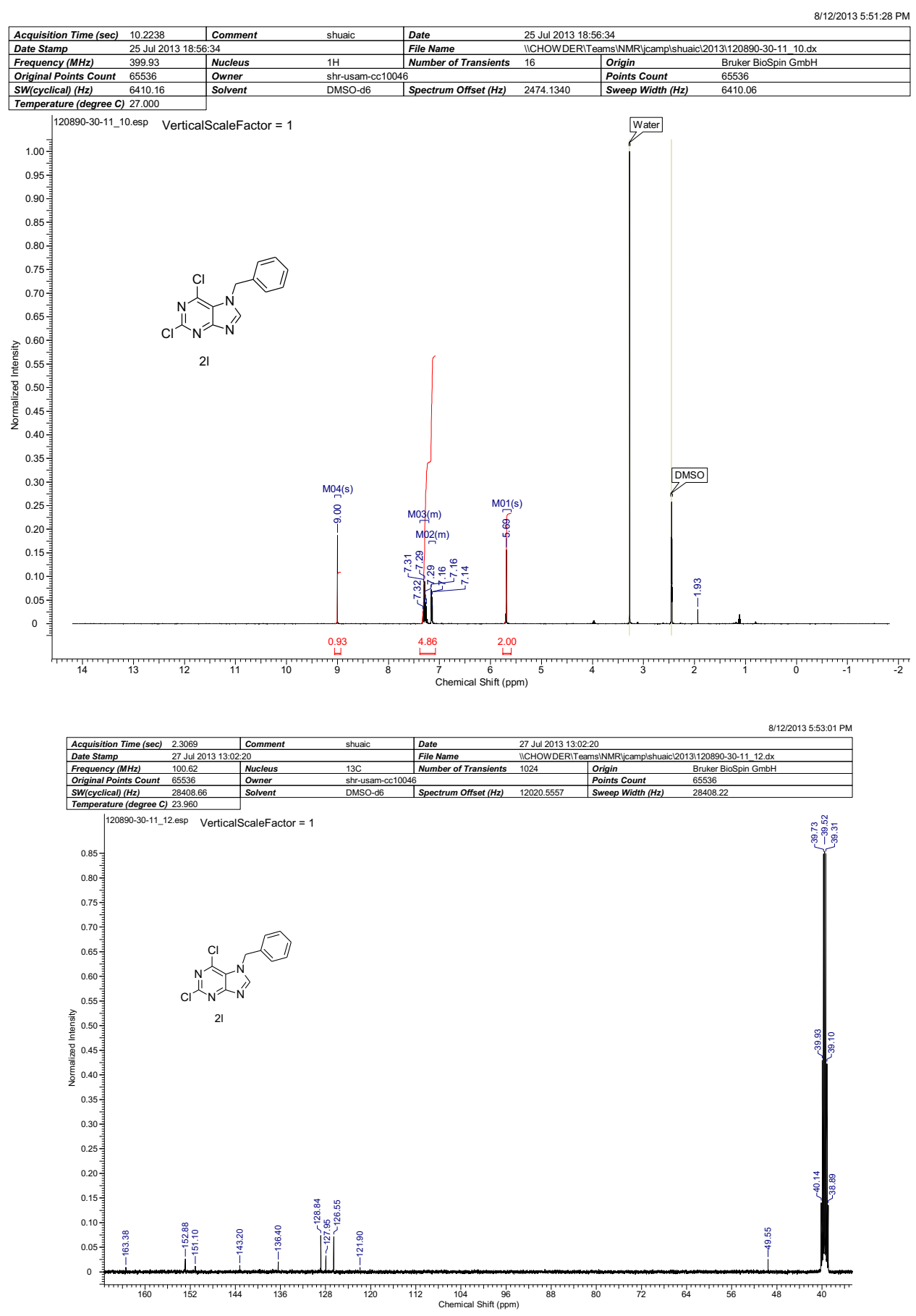

S-24 


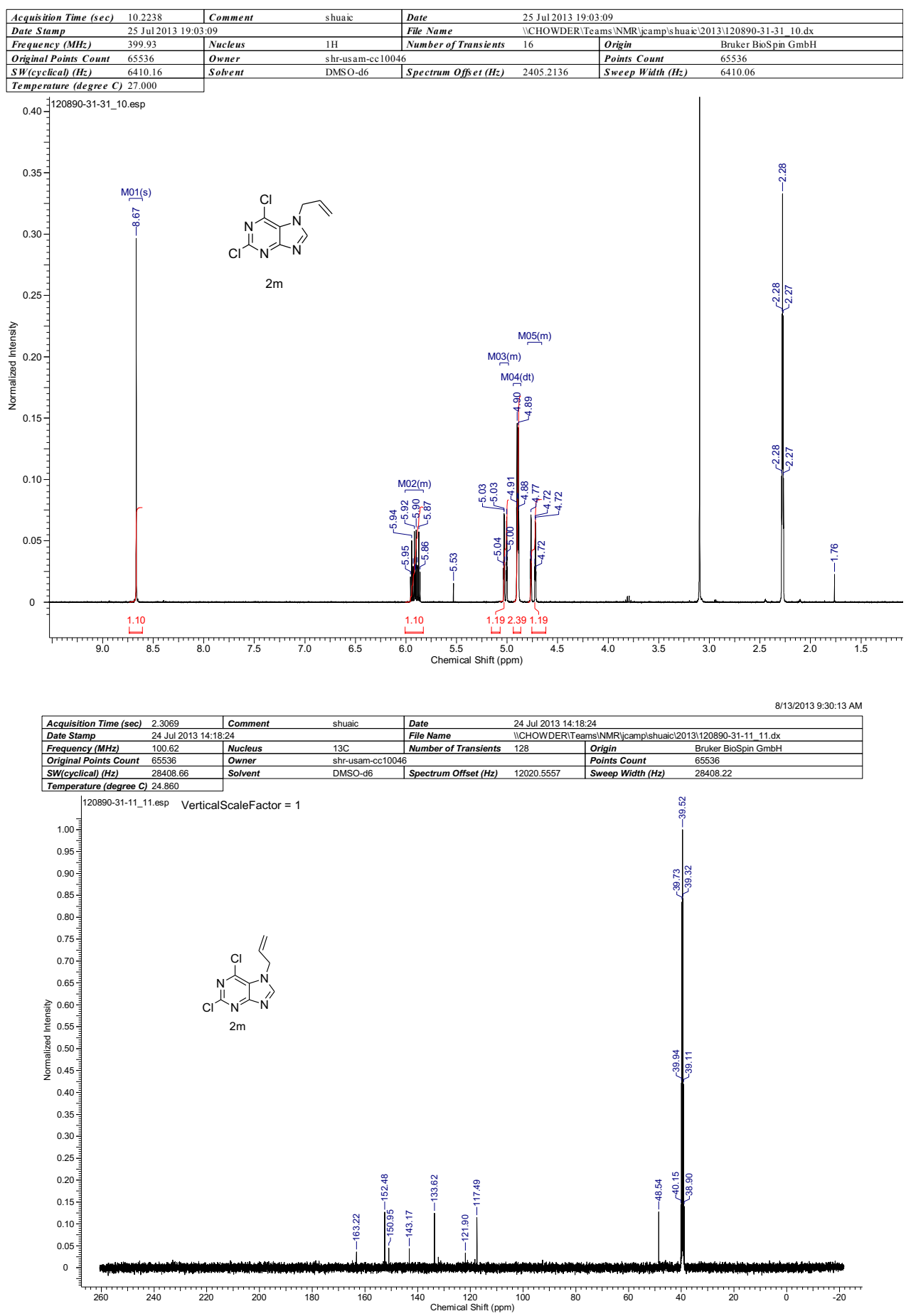

S-25 

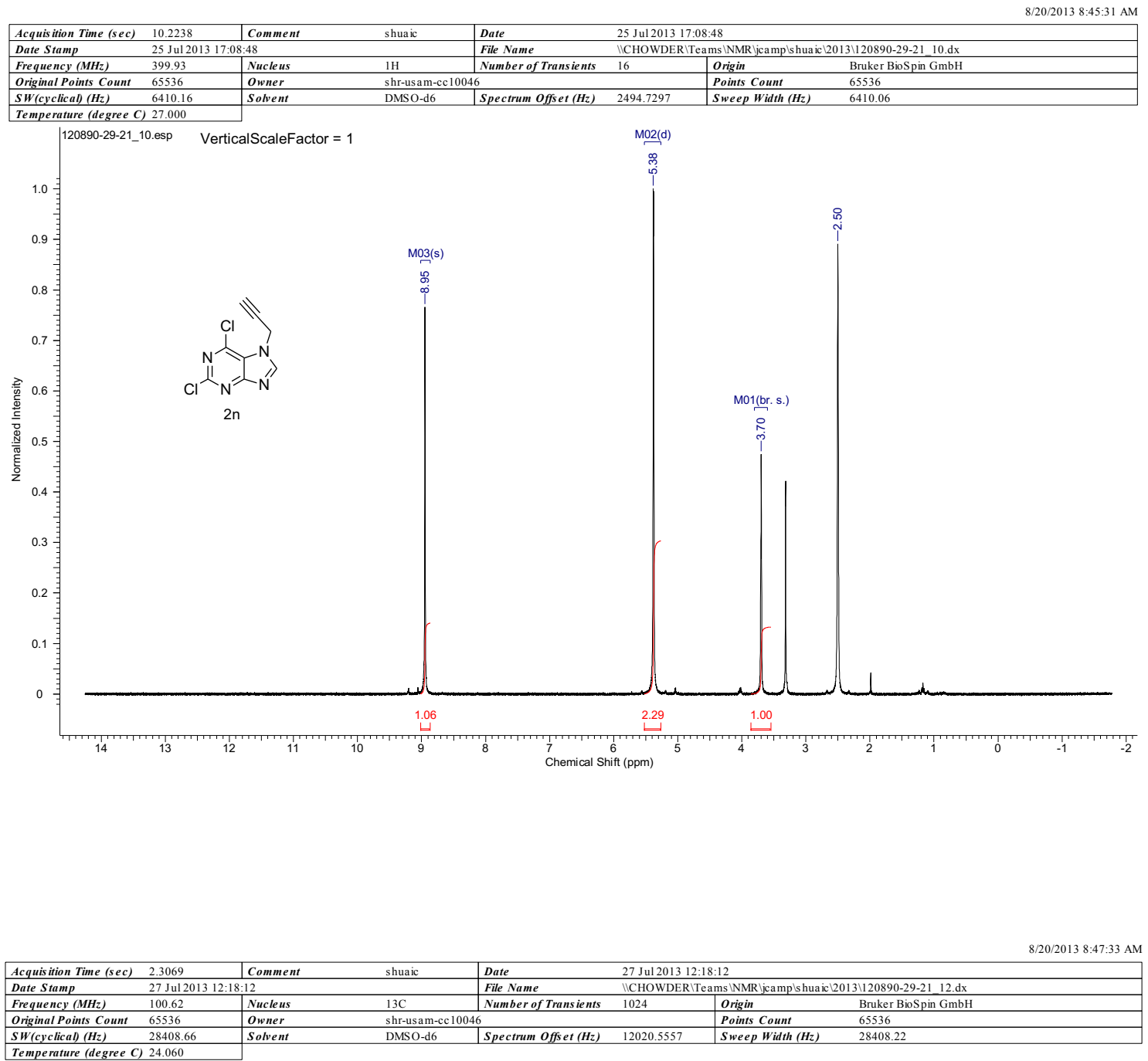

|120890-29-21_12.esp VerticalScaleFactor $=1$

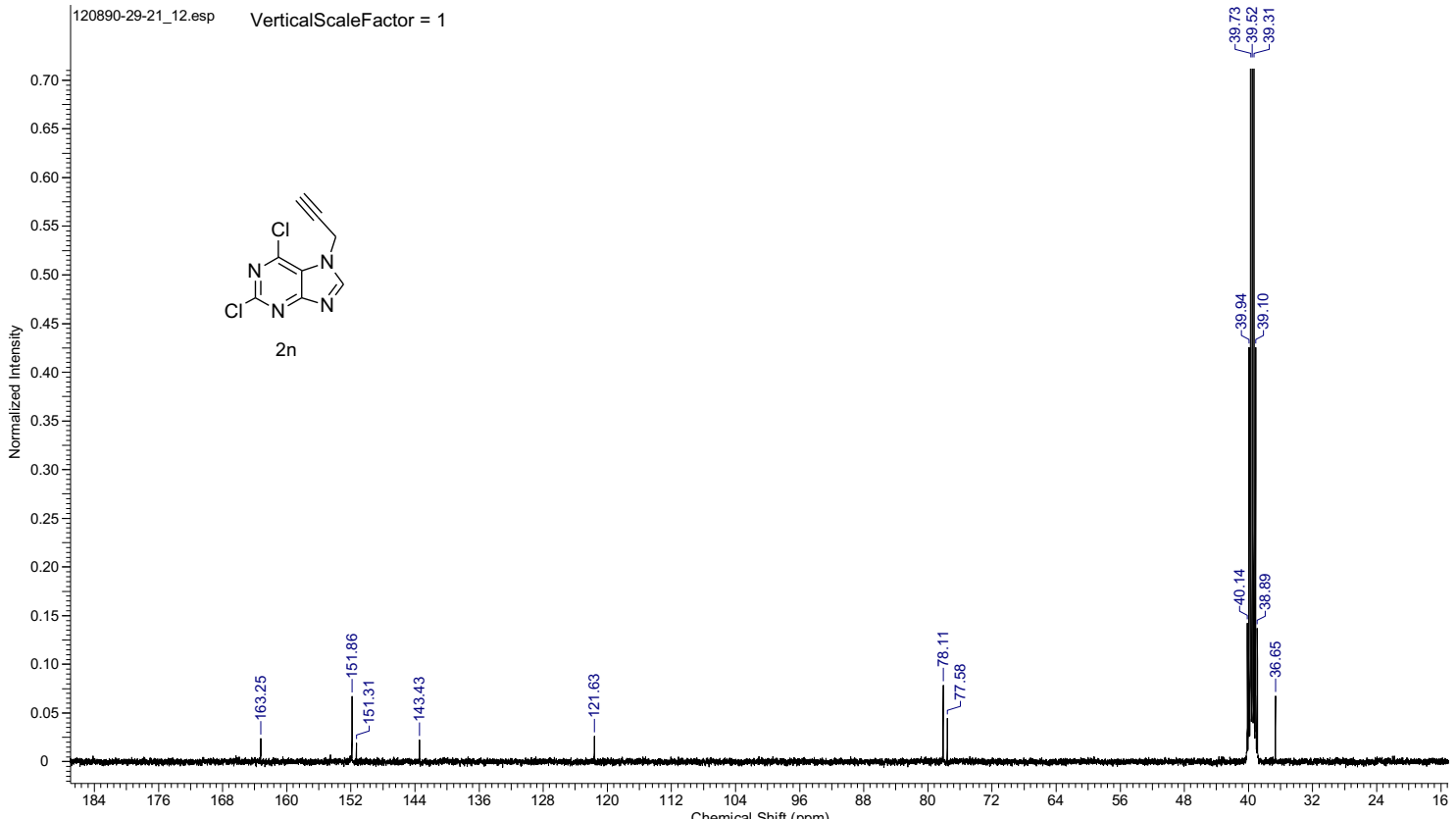

S-26 

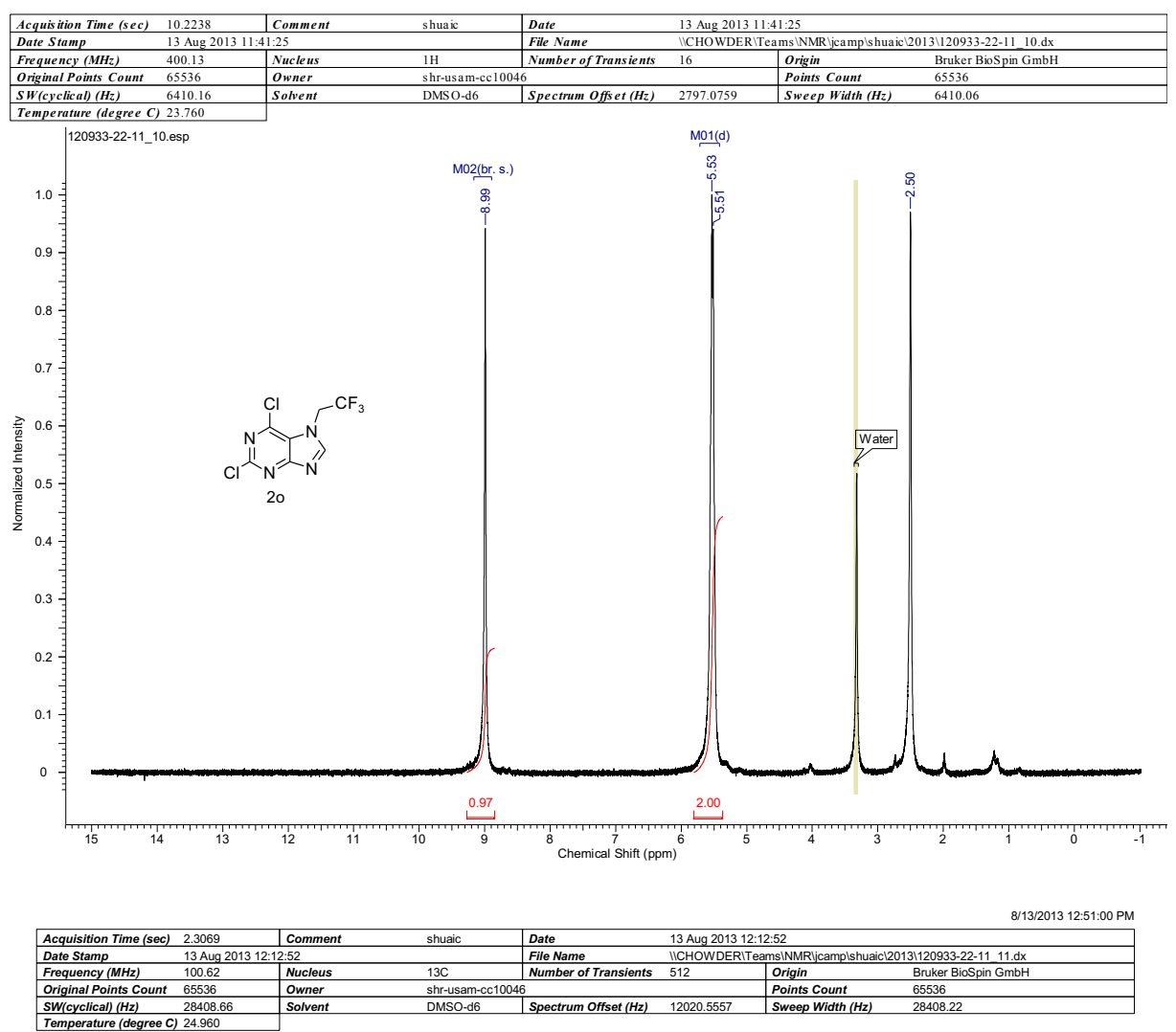

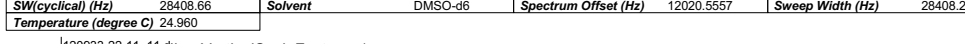

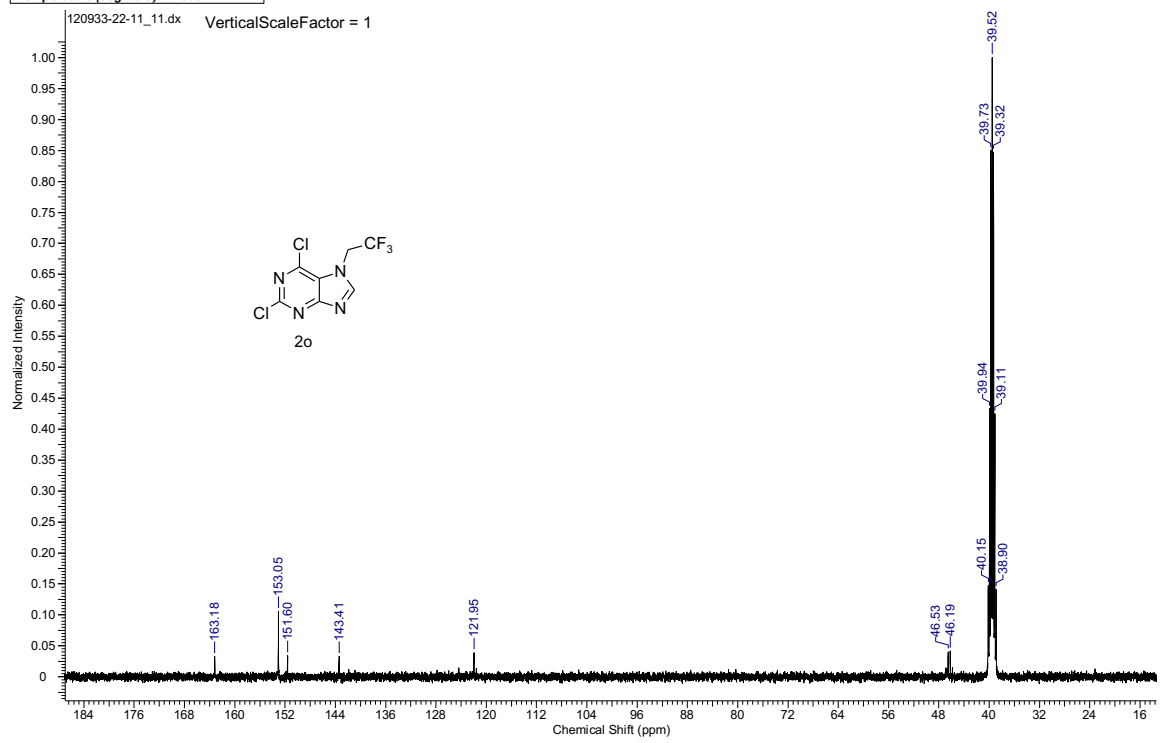




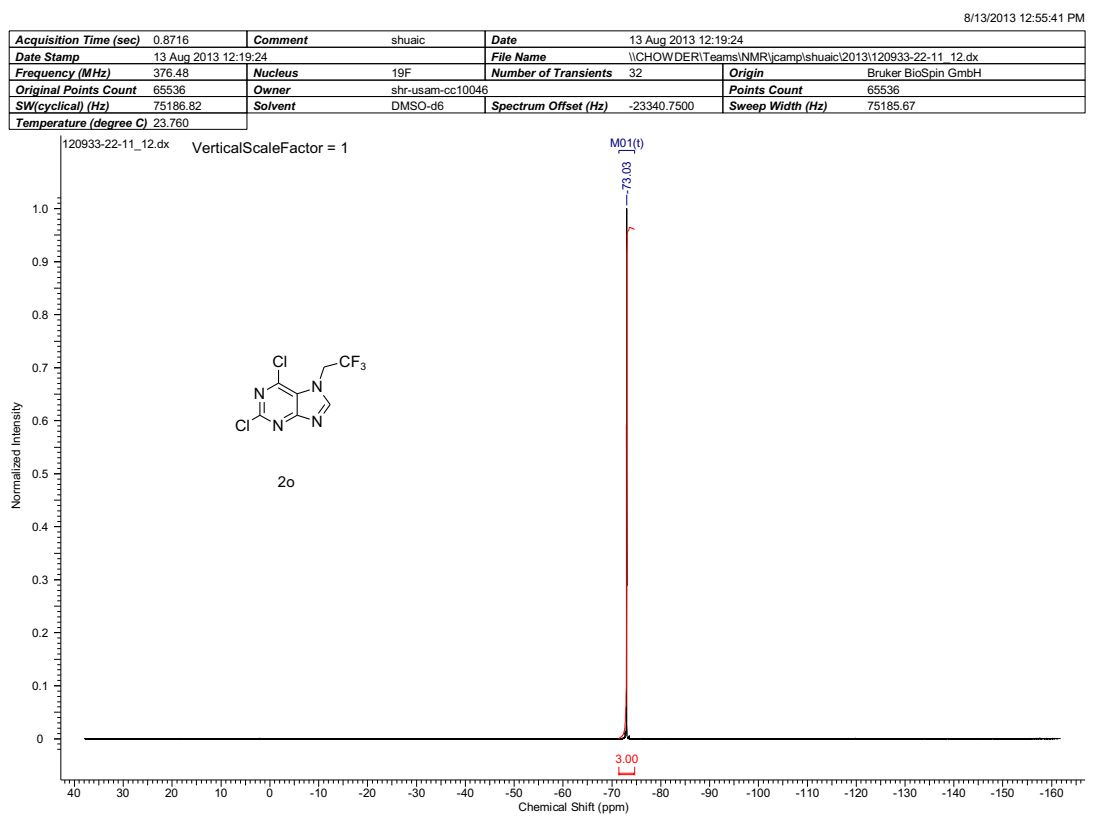

S-28 


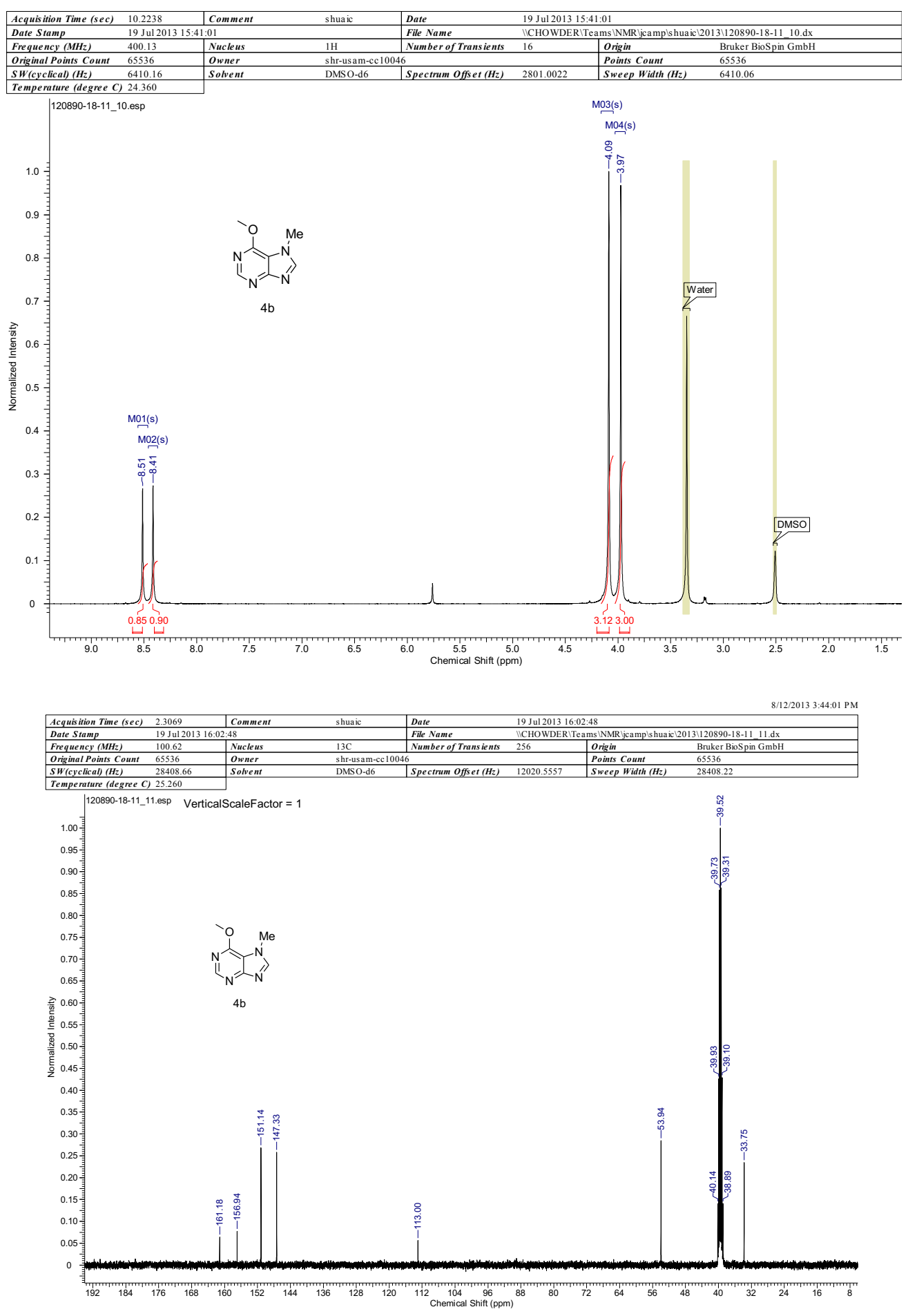

S-29 

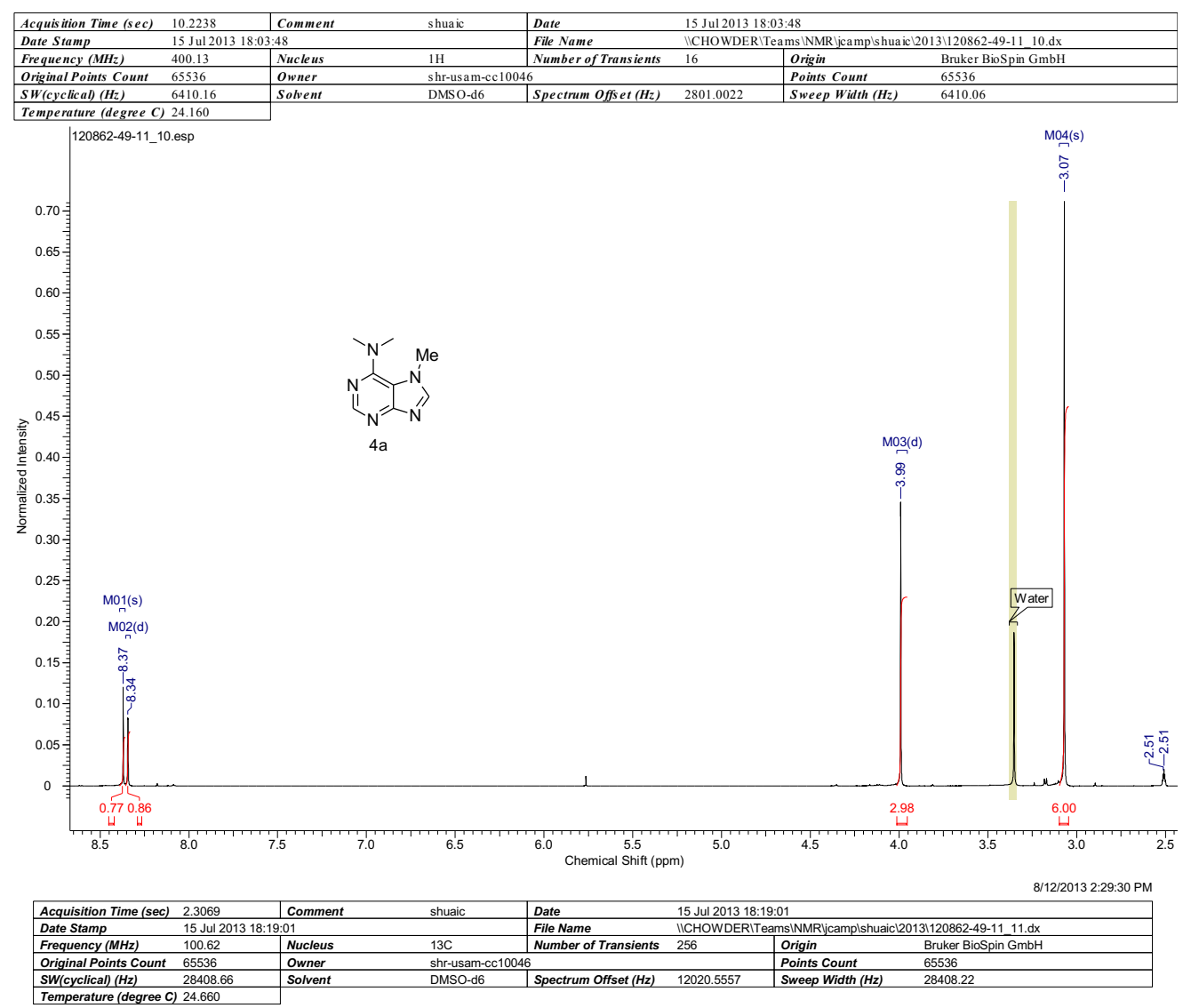

Temperature $($ degree C) 24.660
$\mid$ 120862-49-11_11.esp VerticalScaleFactor $=1$

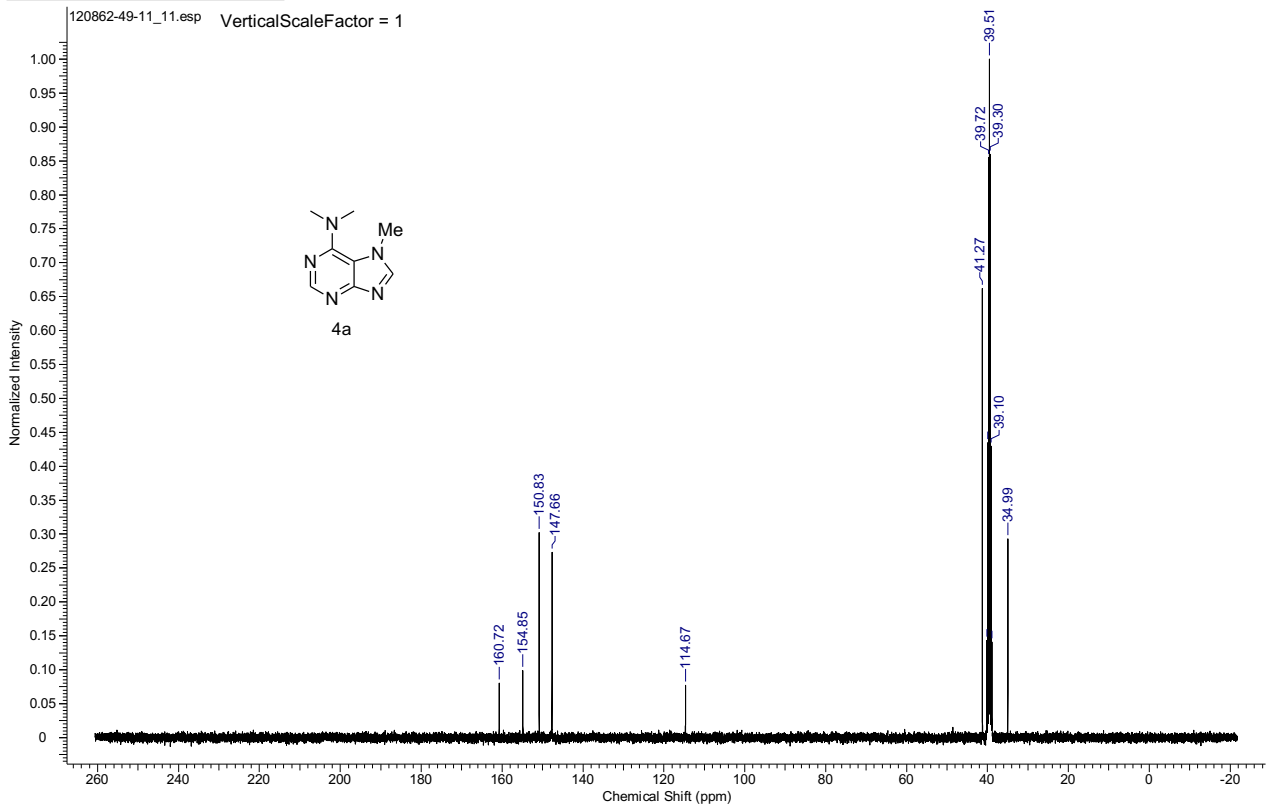

S-30 

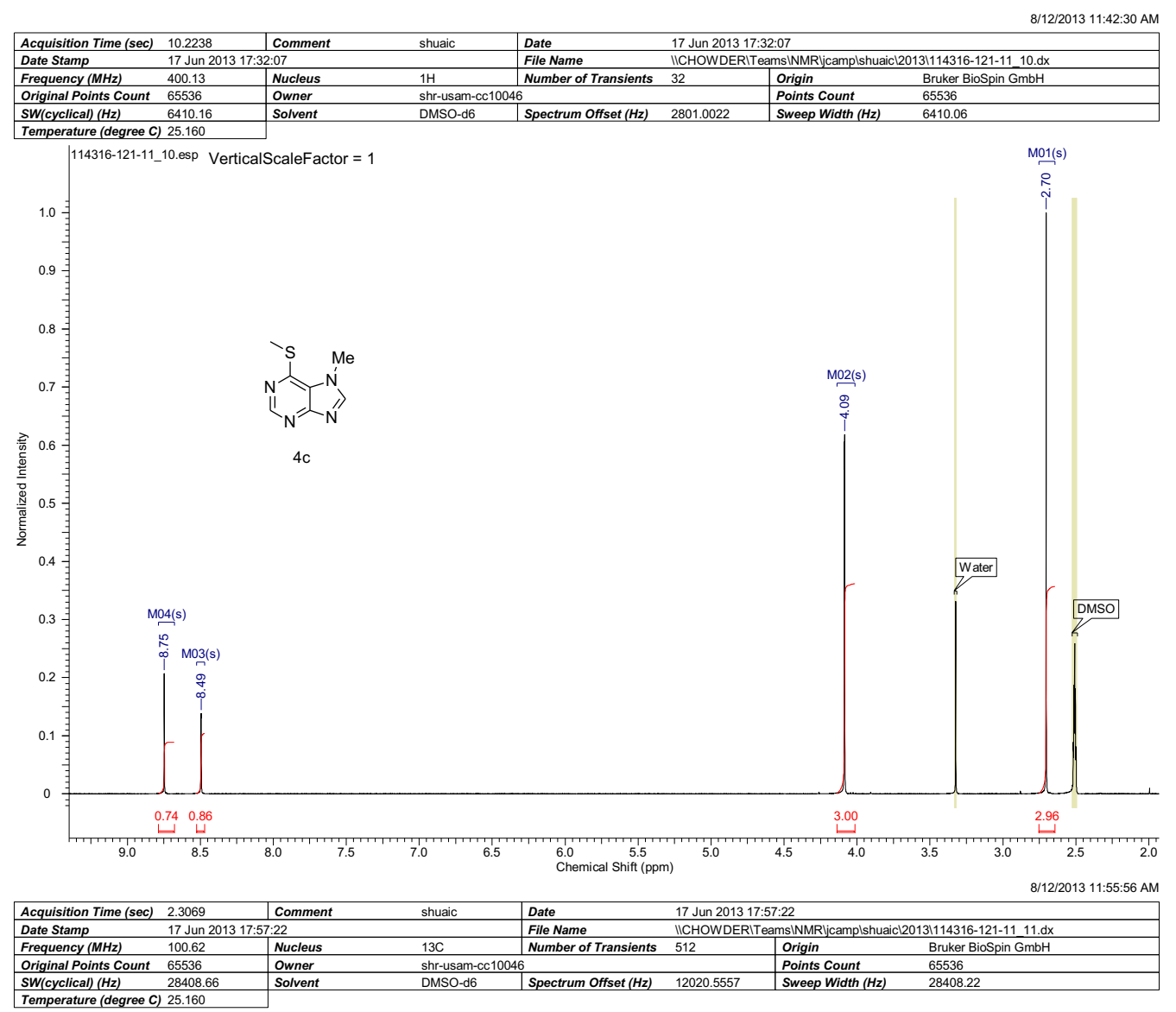

\begin{tabular}{|c|c|c|c|c|c|c|}
\hline Frequency $(\mathrm{MHz})$ & 100.62 & Nucleus & $13 \mathrm{C}$ & Number of Transients & Origin & Bruker BioSpin GmbH \\
\hline Original Points Count & 65536 & Owner & shr-usam-cc10046 & & Points Count & 65536 \\
\hline$S W($ cyclical) $(H z)$ & 28408.66 & Solvent & DMSO-d6 & Spectrum Offset $(\mathrm{Hz})$ & Sweep Width (Hz) & 28408.22 \\
\hline
\end{tabular}
Temperature (degree

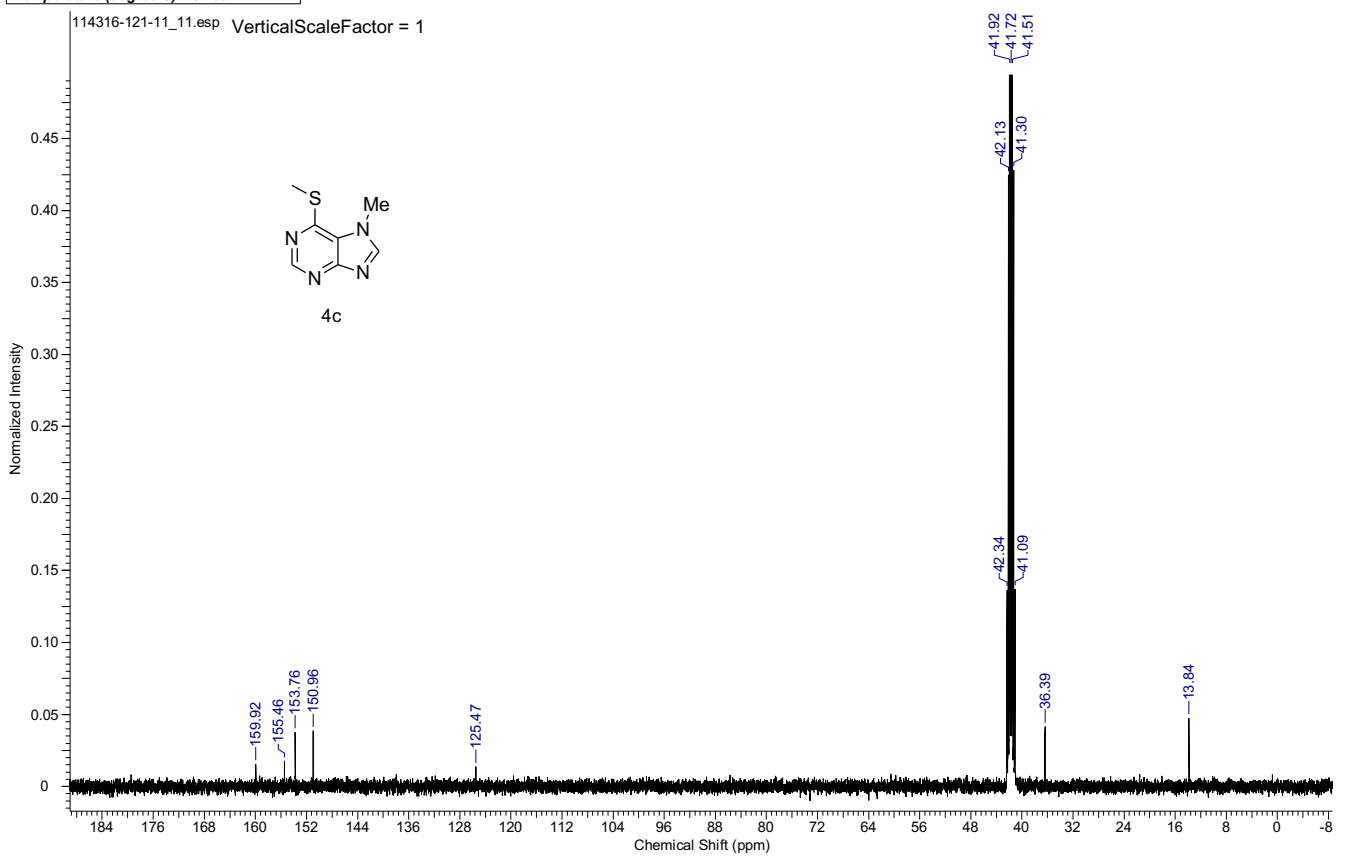

S-31 

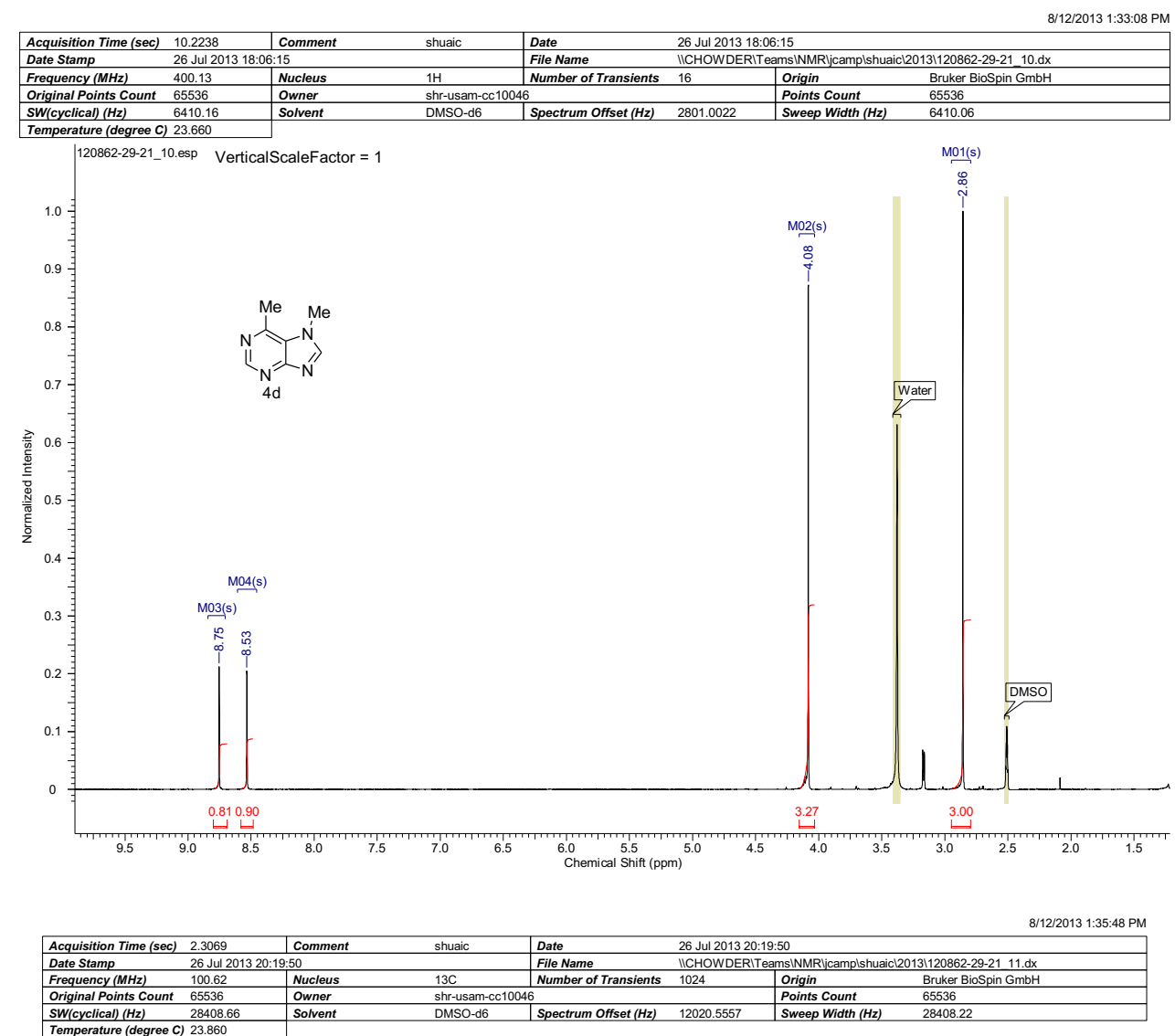

$\frac{\text { Temperature (degree C) 23.860 }}{\mid \text { 120862-29-21_11.esp VerticalscaleFactor }=}$

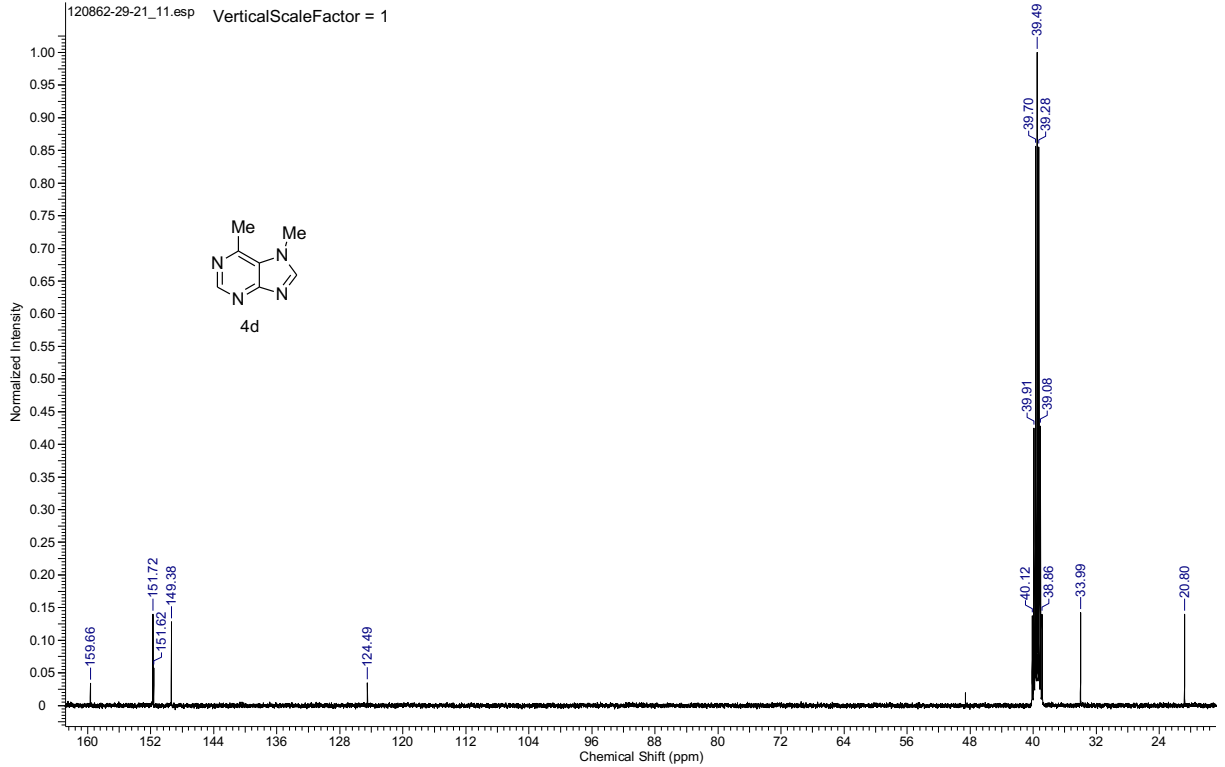

S-32 

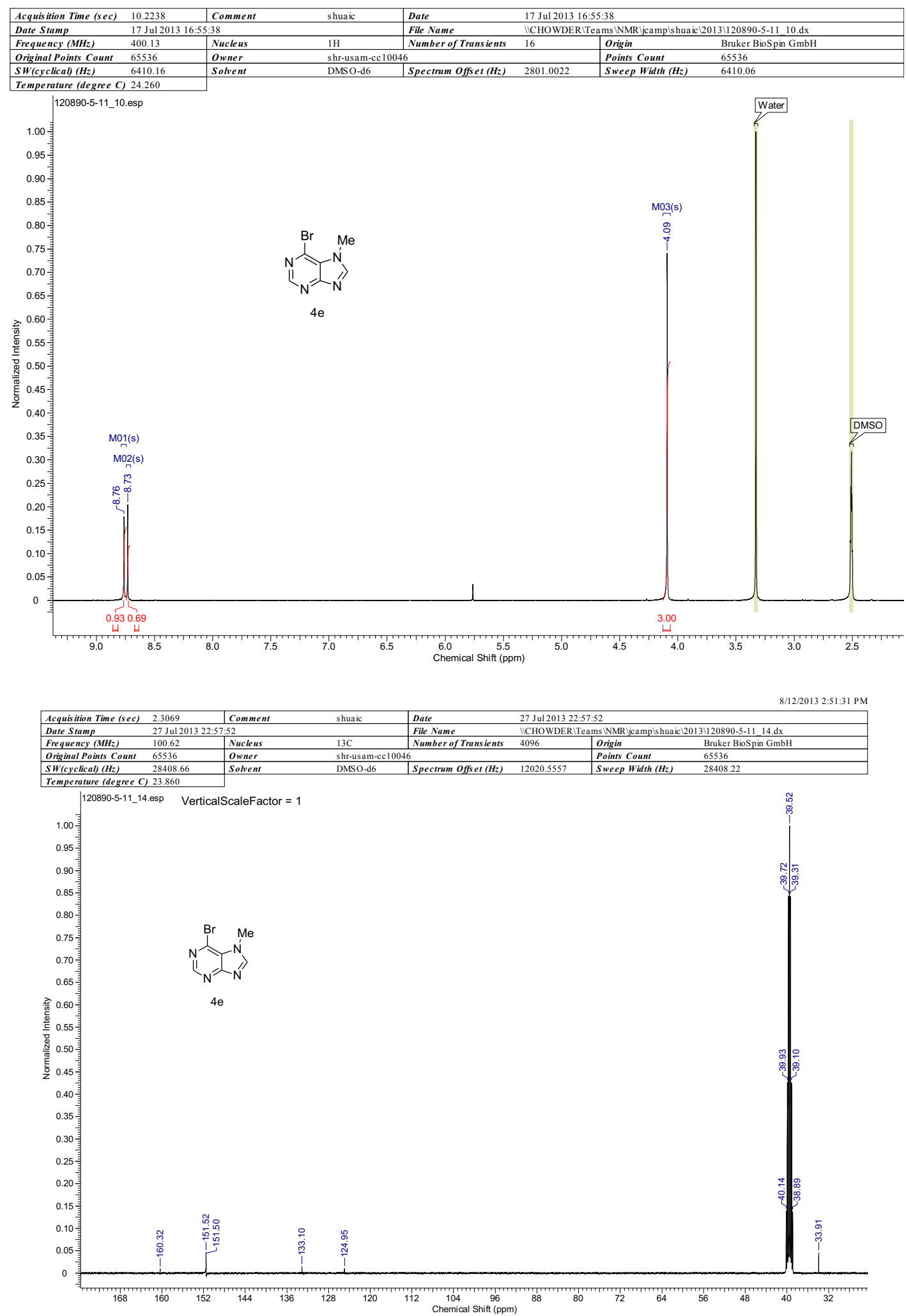

S-33 

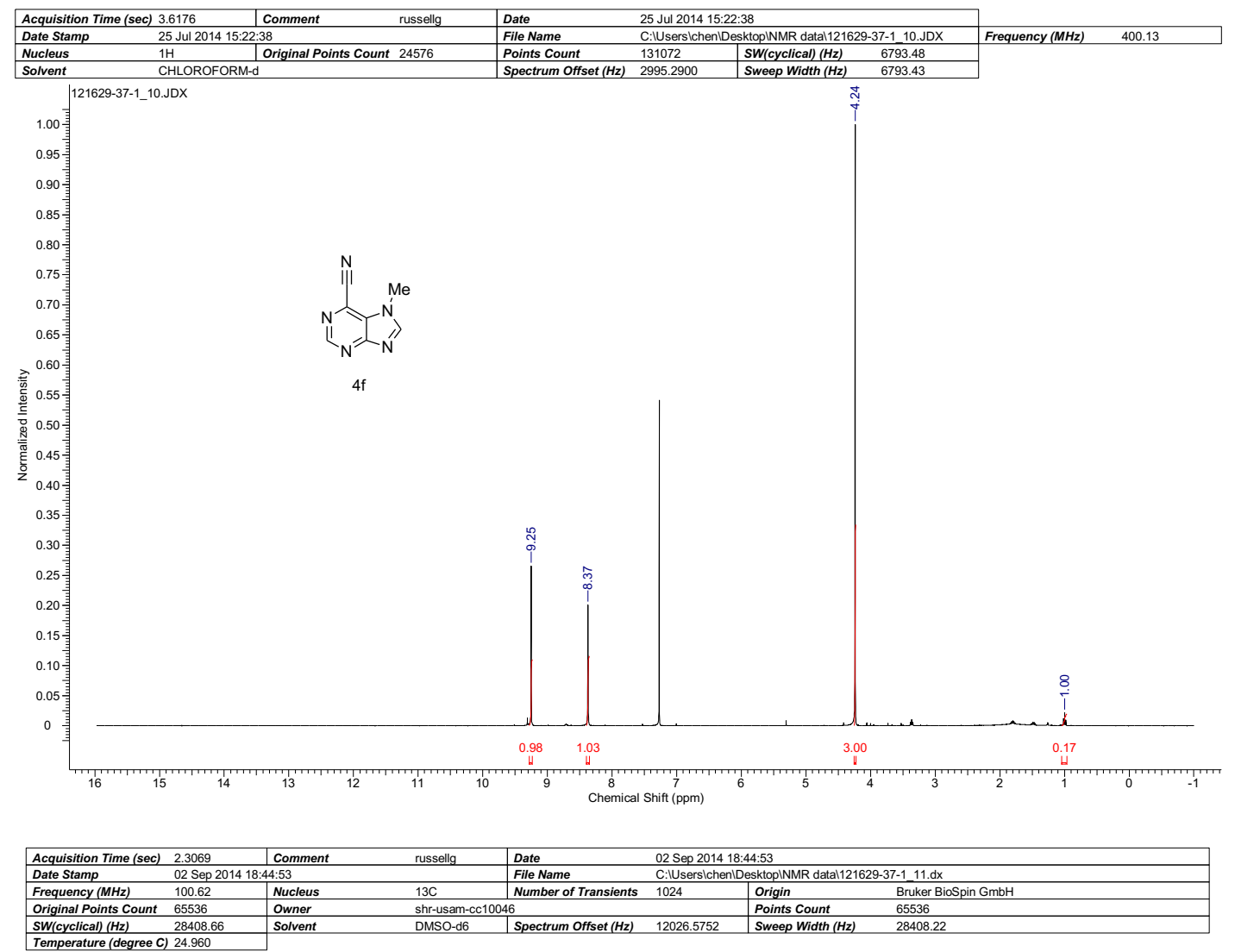

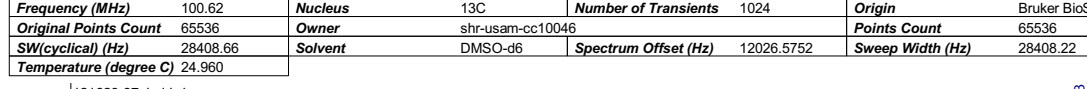

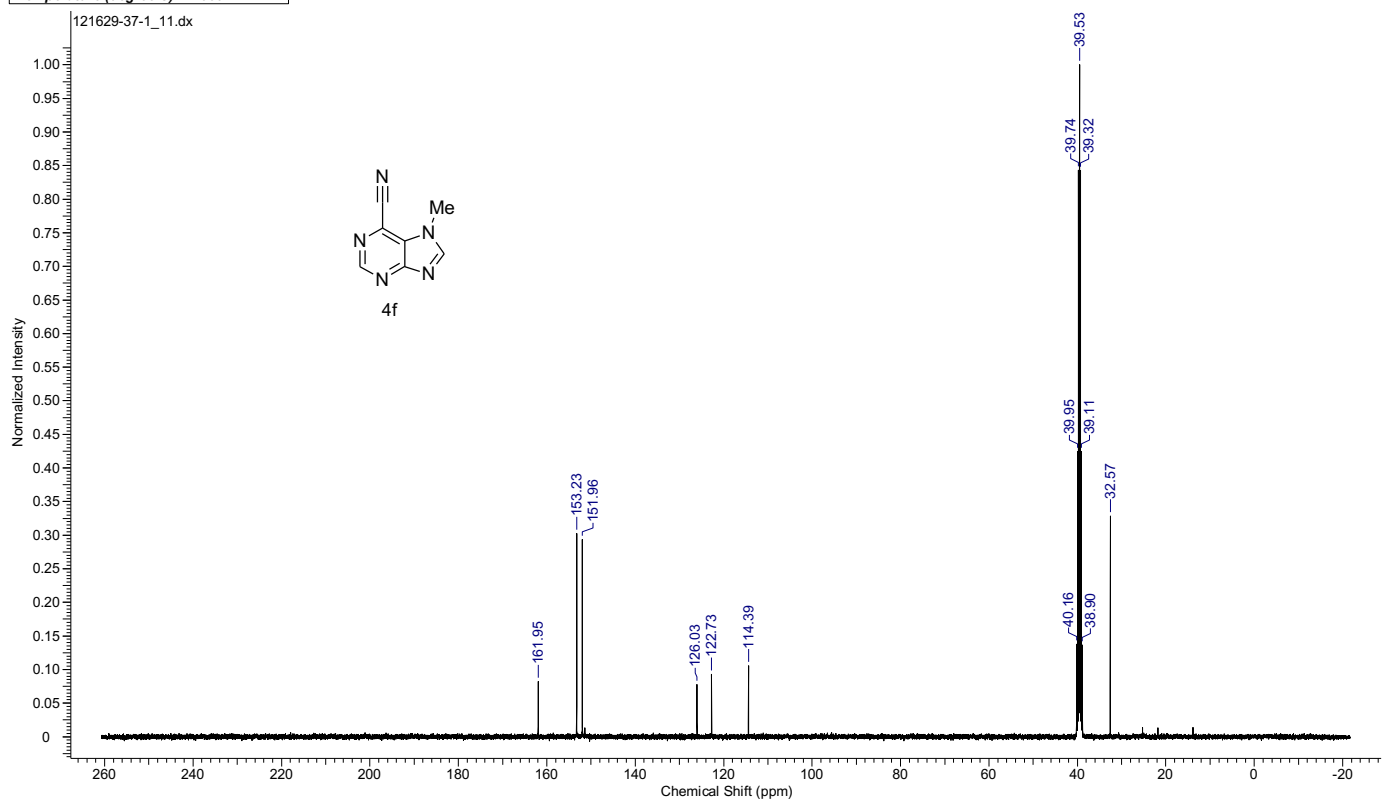

S-34 

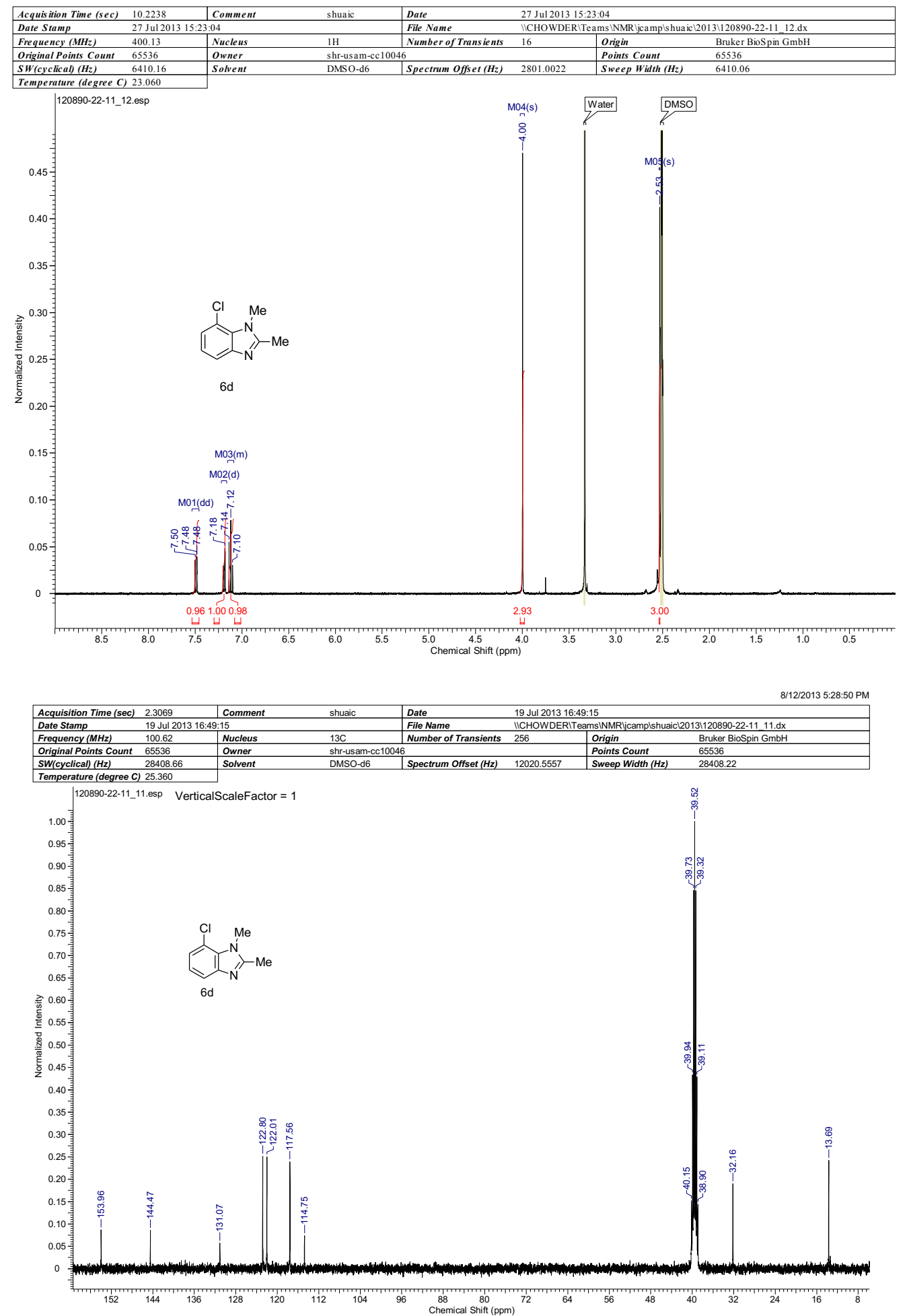

S-35 


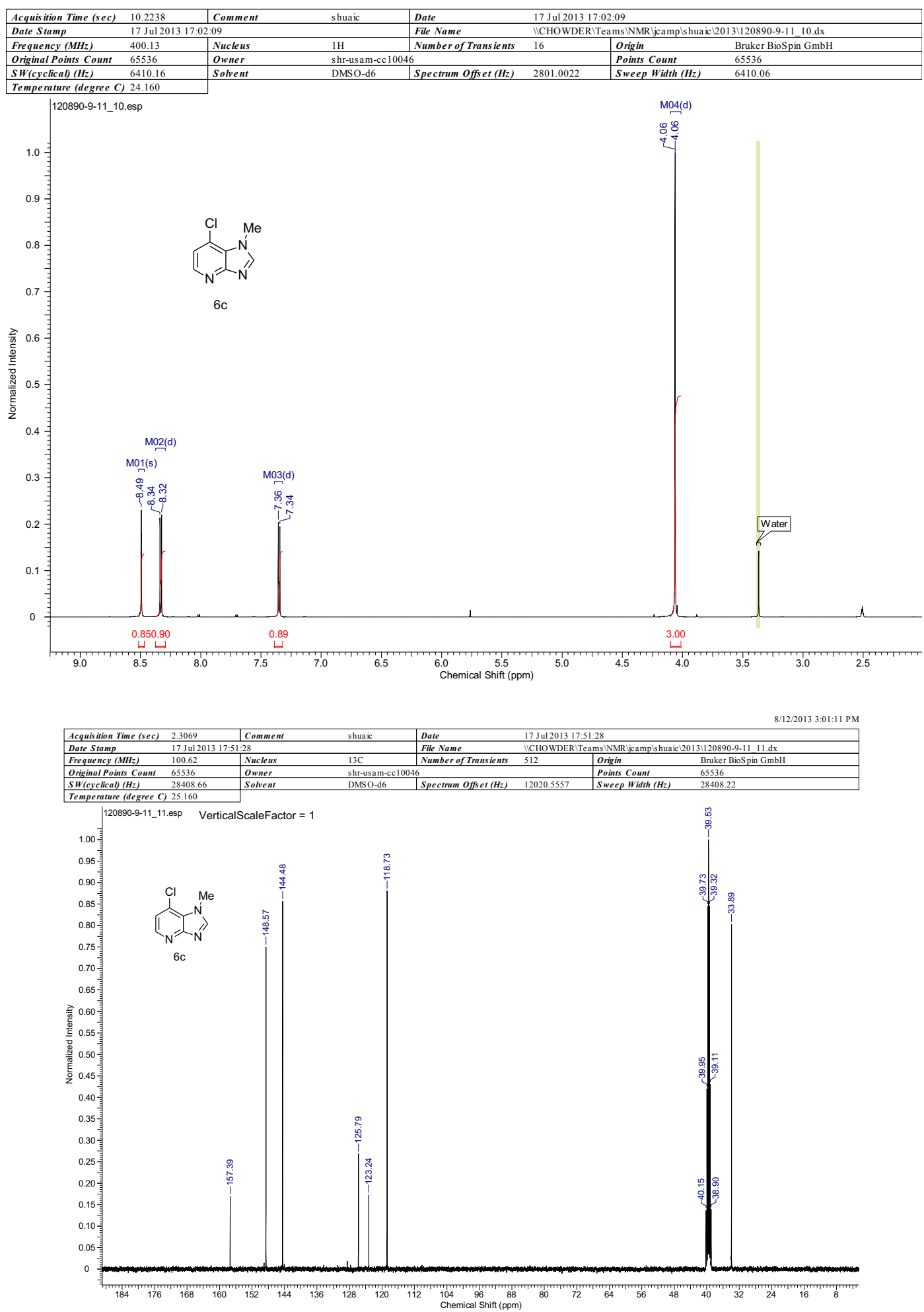

S-36 
8/15/2013 8:34:28 AM

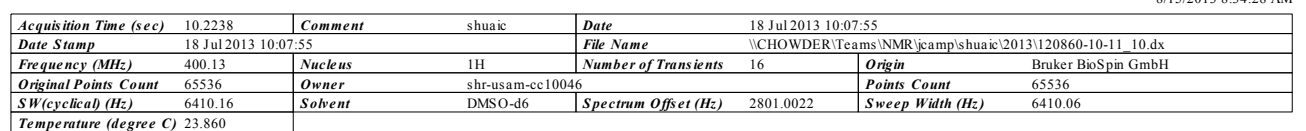

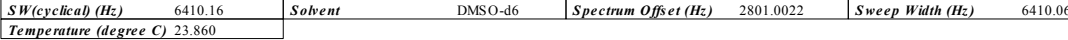
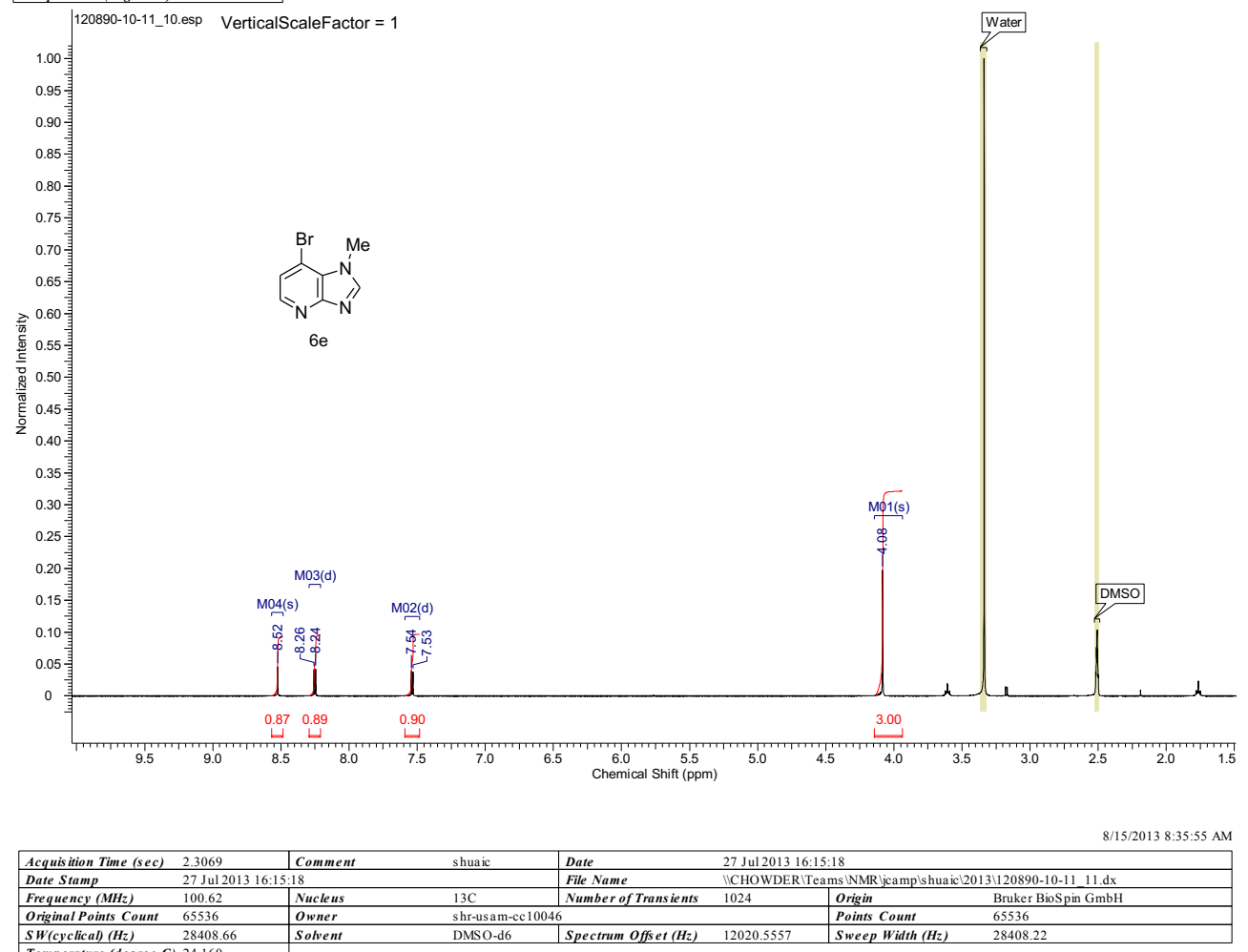
\begin{tabular}{|l|l|l|l}
\hline SW (cyclical) $(\mathrm{H} z)$ & 28408.66 & Solvent \\
\hline Temperature (degree C) 24.160 &
\end{tabular}

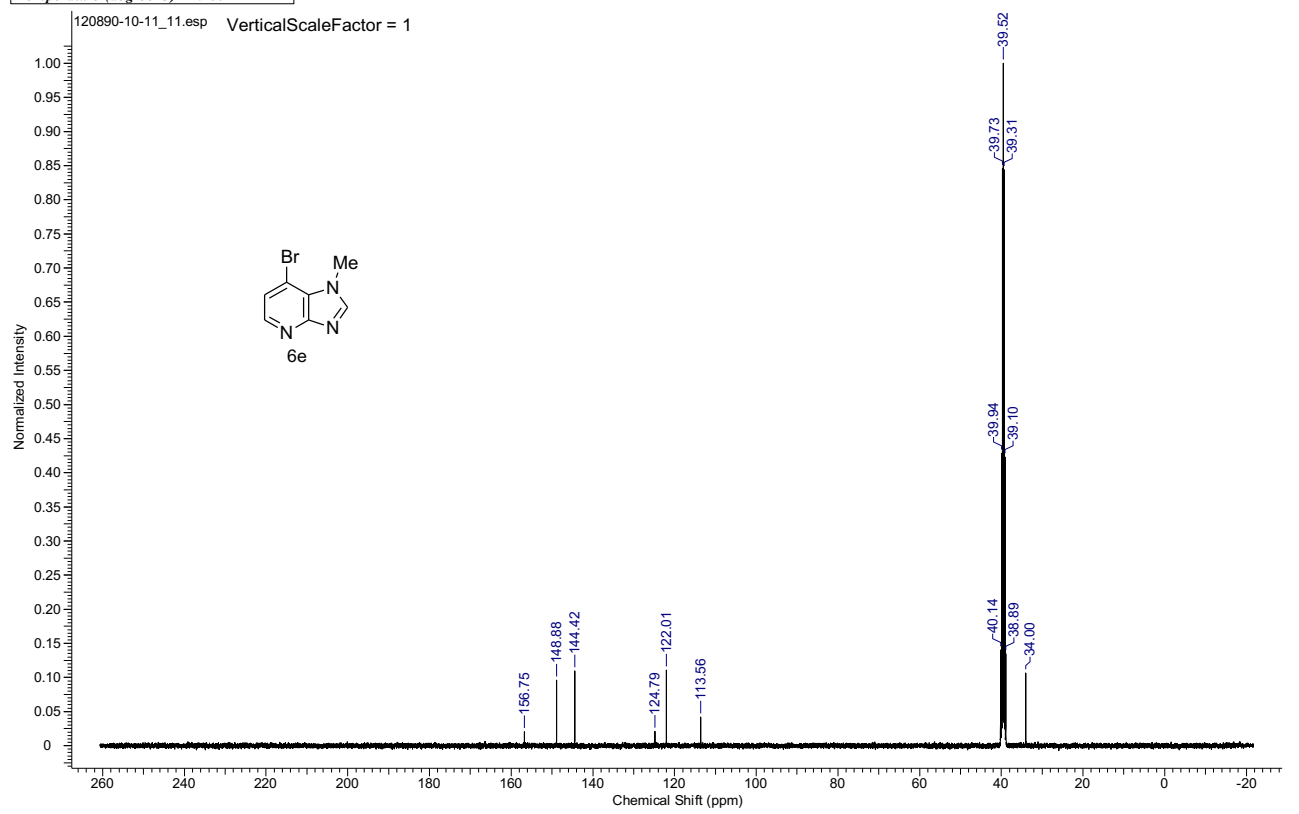


8/13/2013 11:10:55 AM
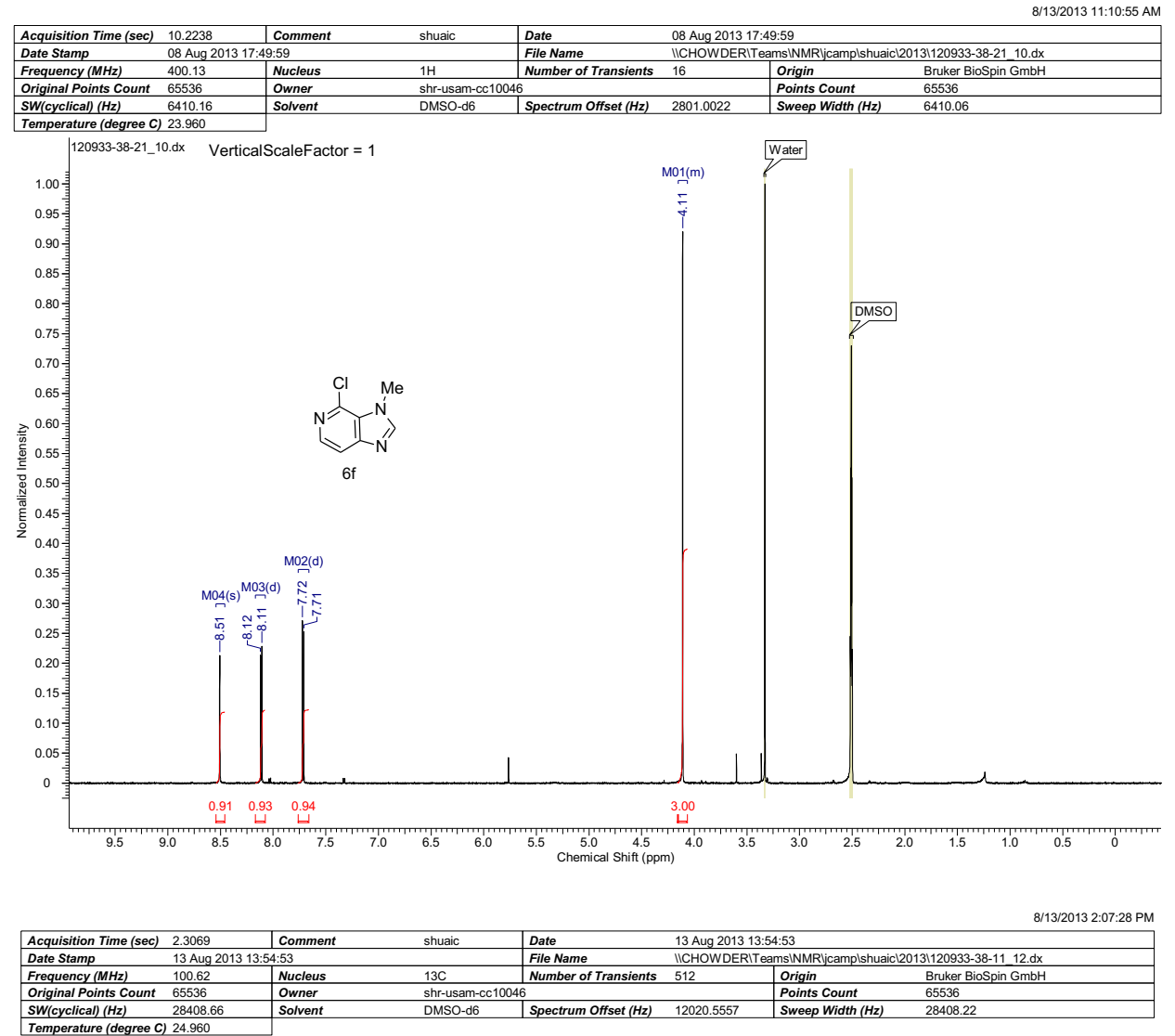

SW/cyclical

|120933-38-11_12.dx VerticalScaleFactor $=$

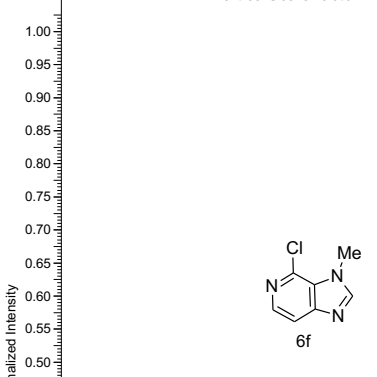

0.50

$6 f$

0.40 害

0.35 事

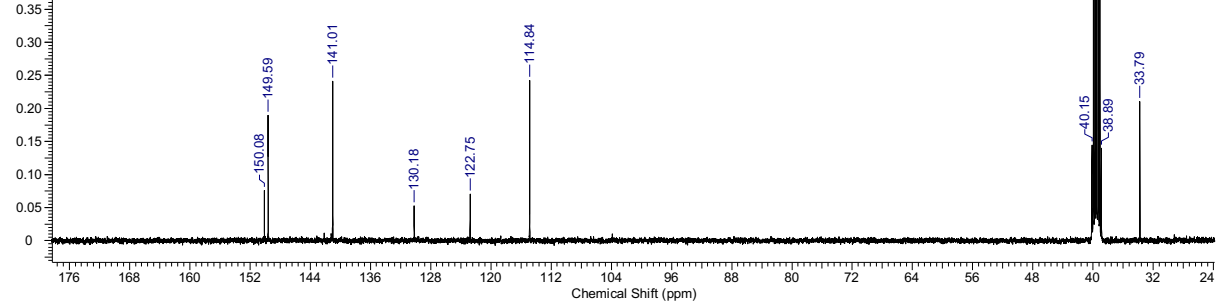


8/15/2013 8:37:58 AM

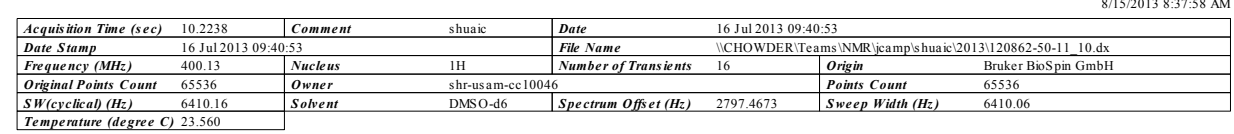

Temperature (degree C) 23.560
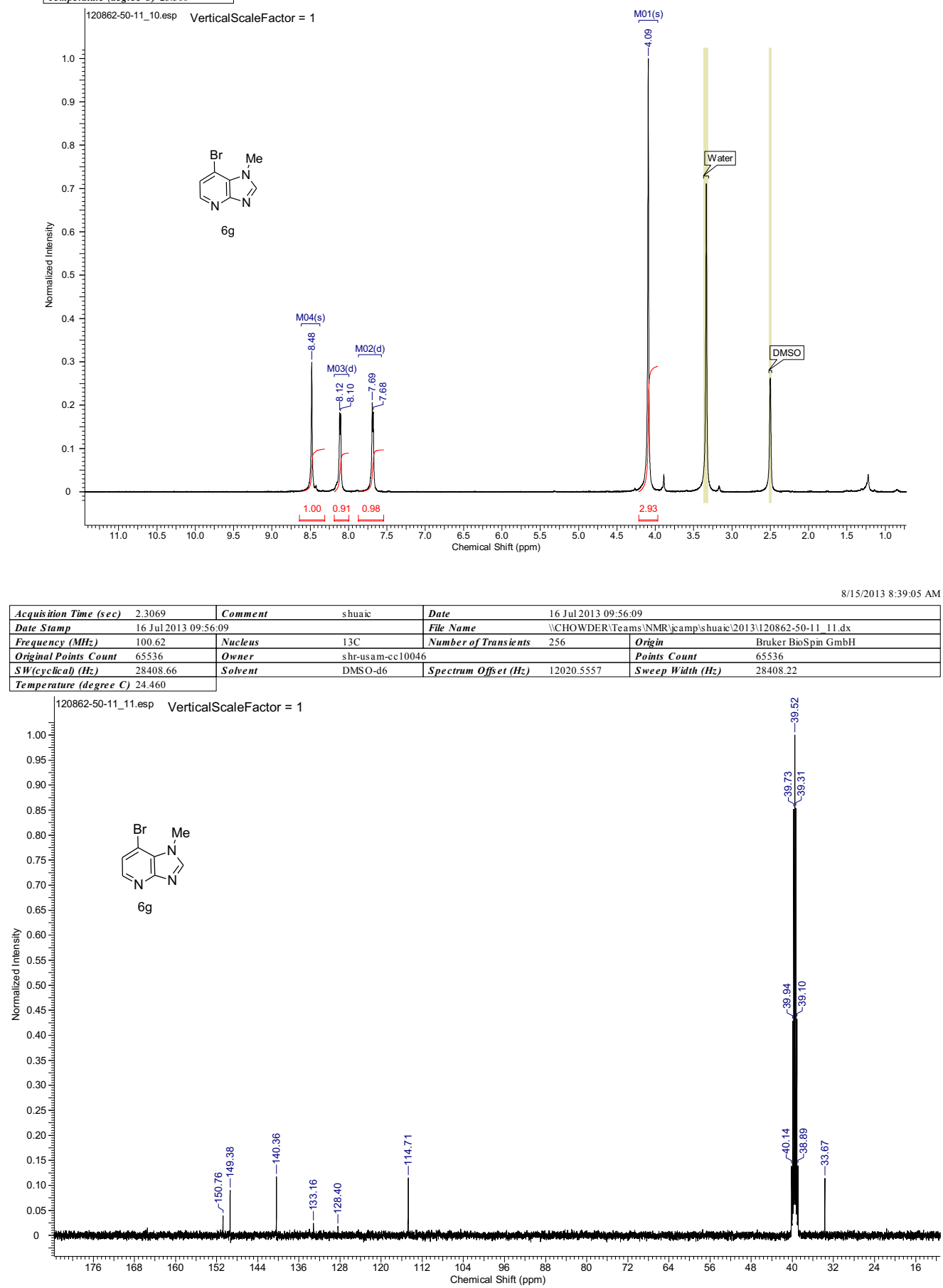

S-39 

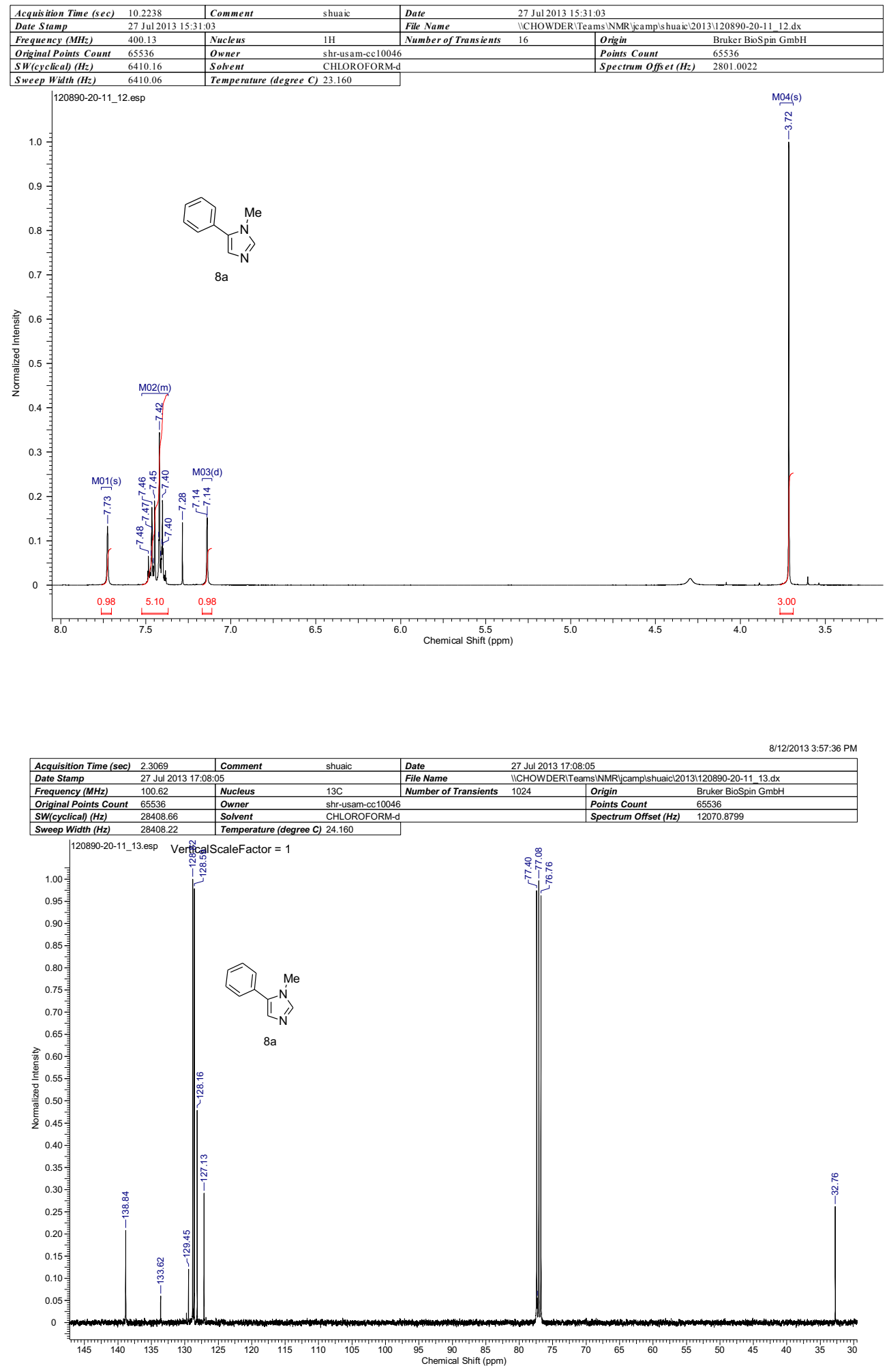

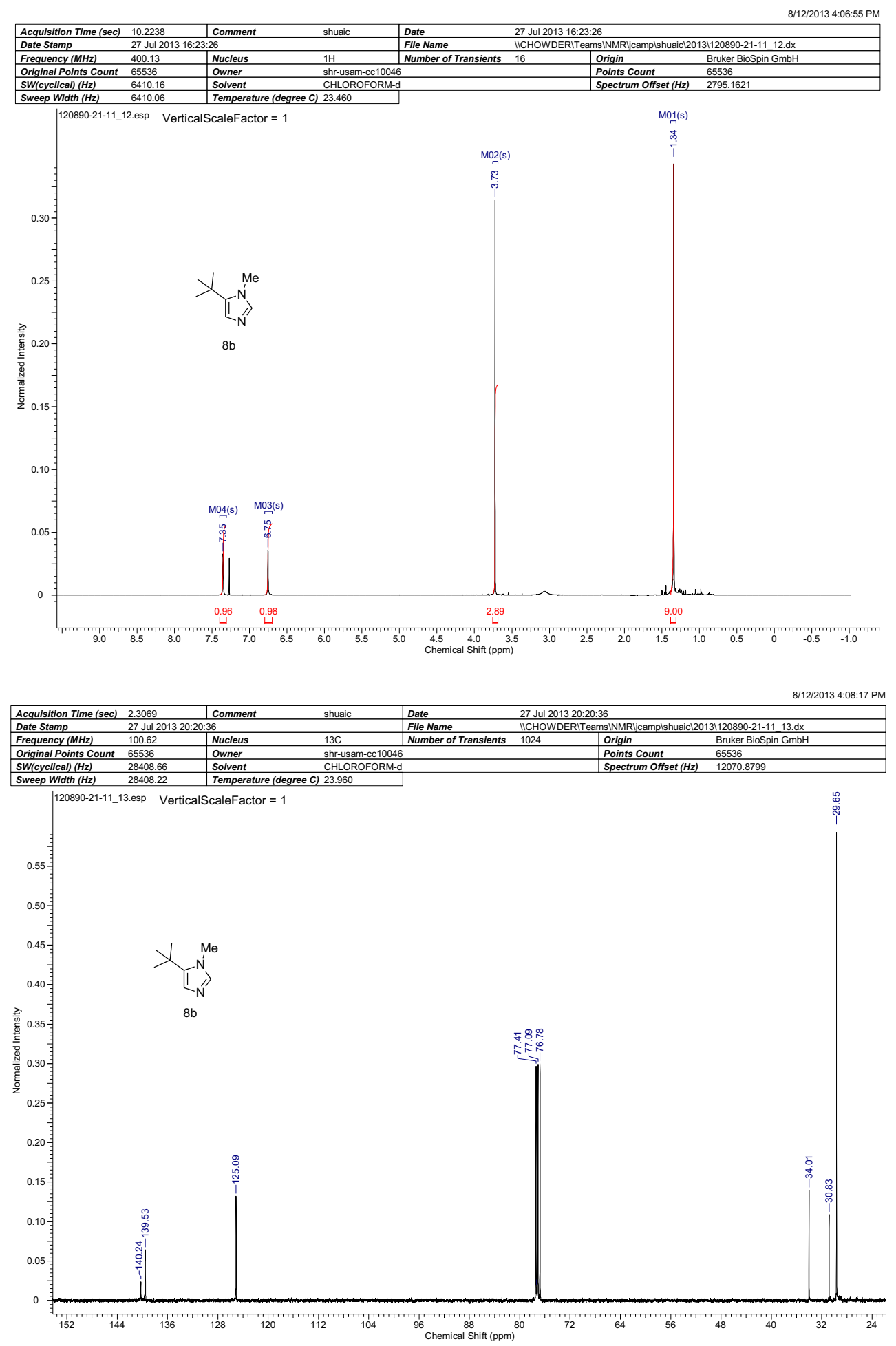

S-41 

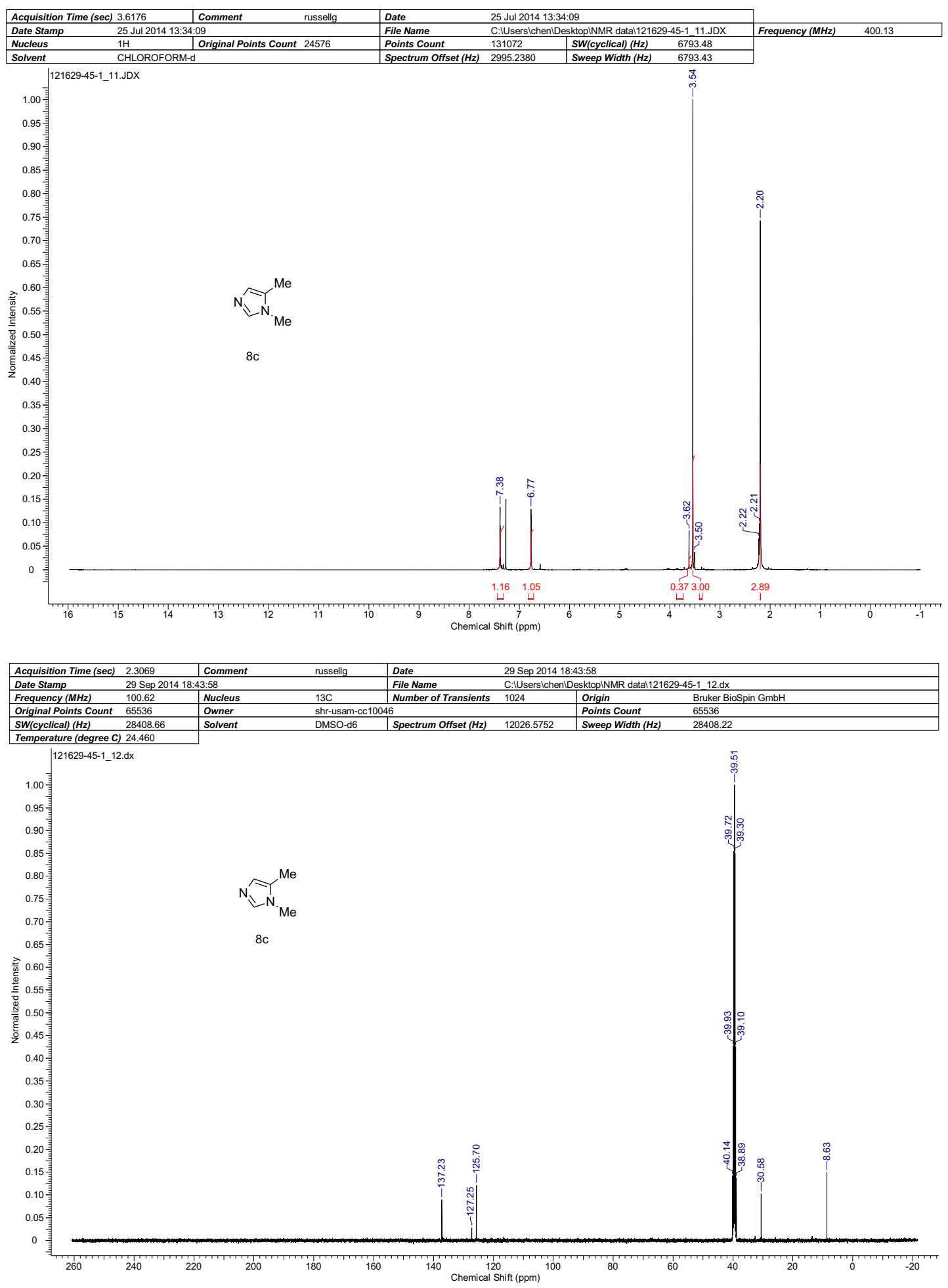

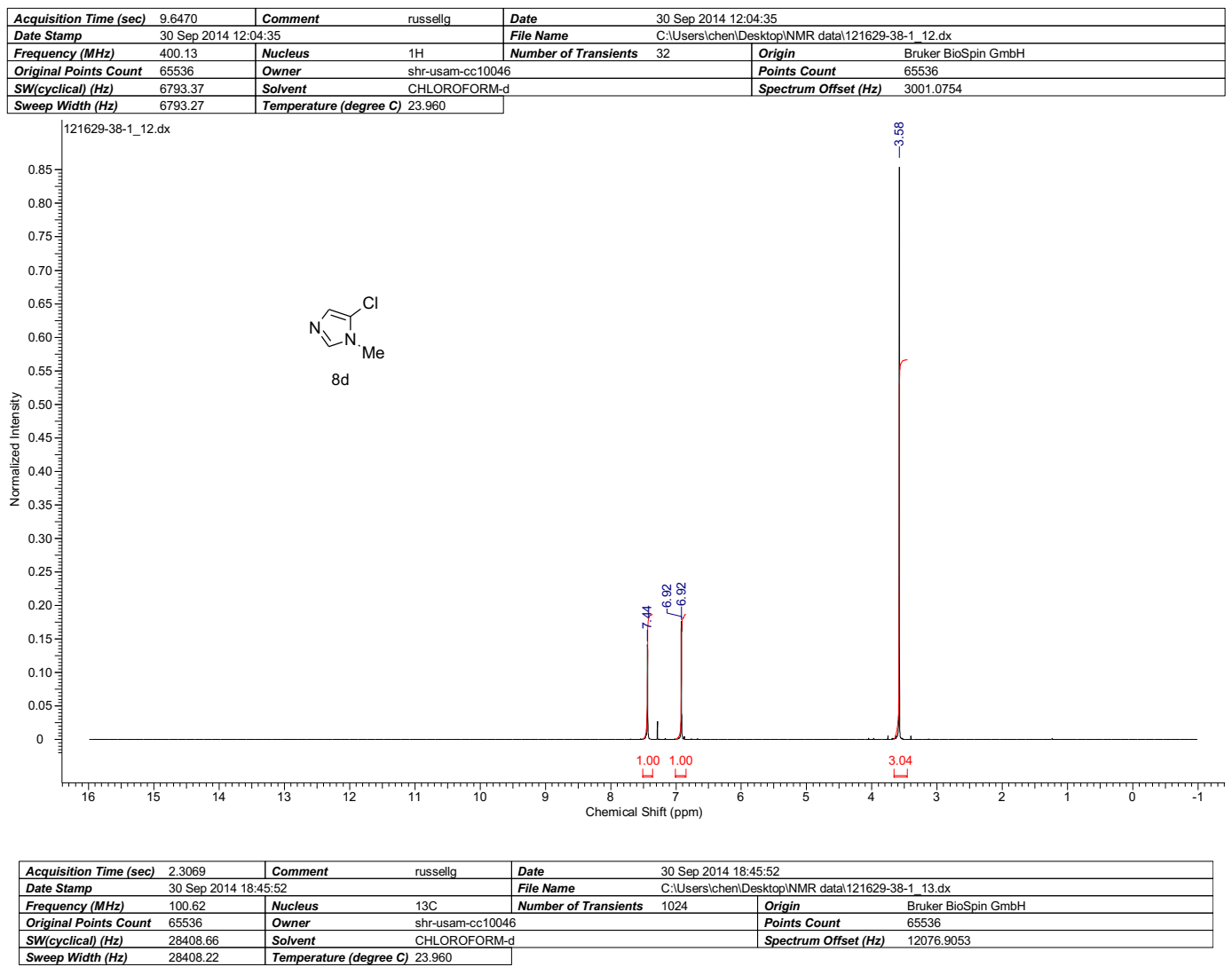

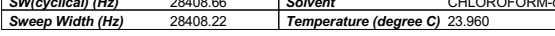

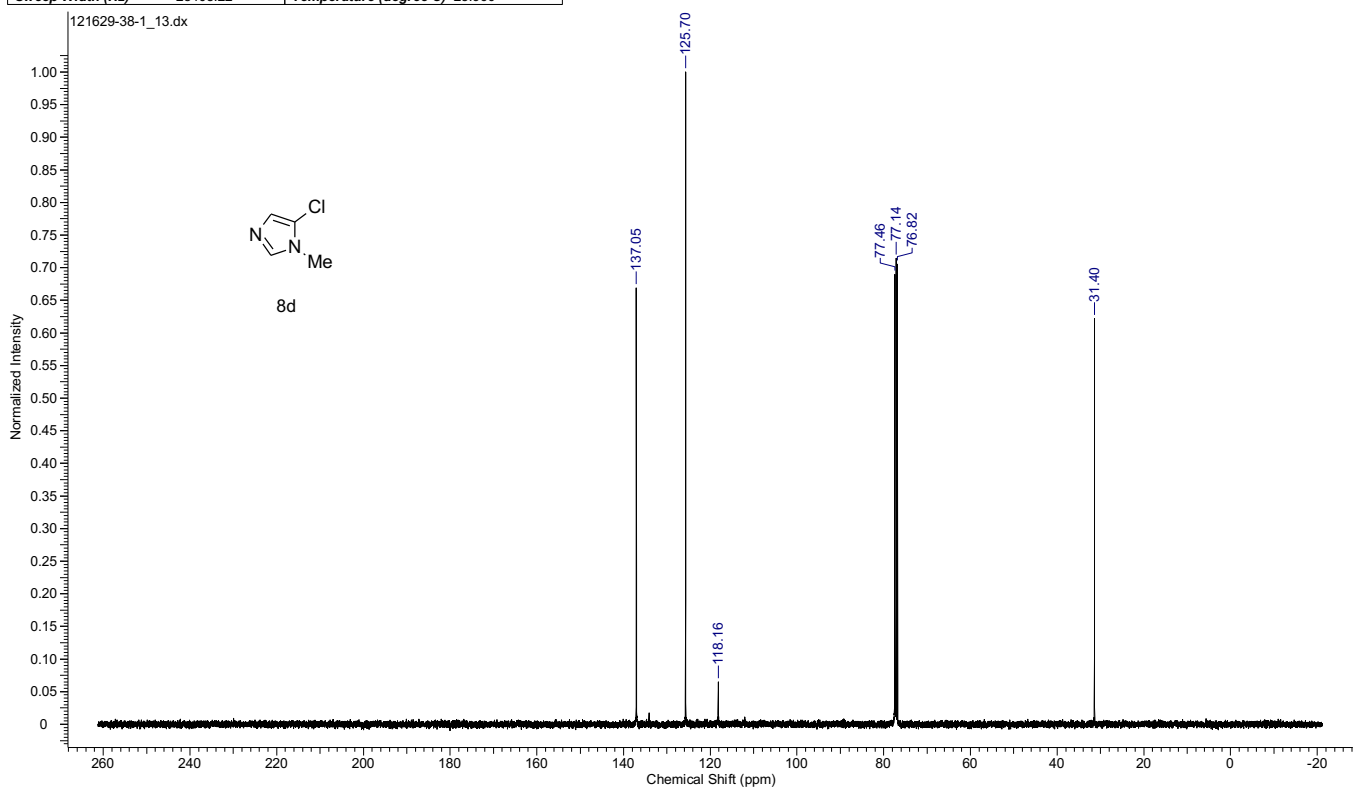



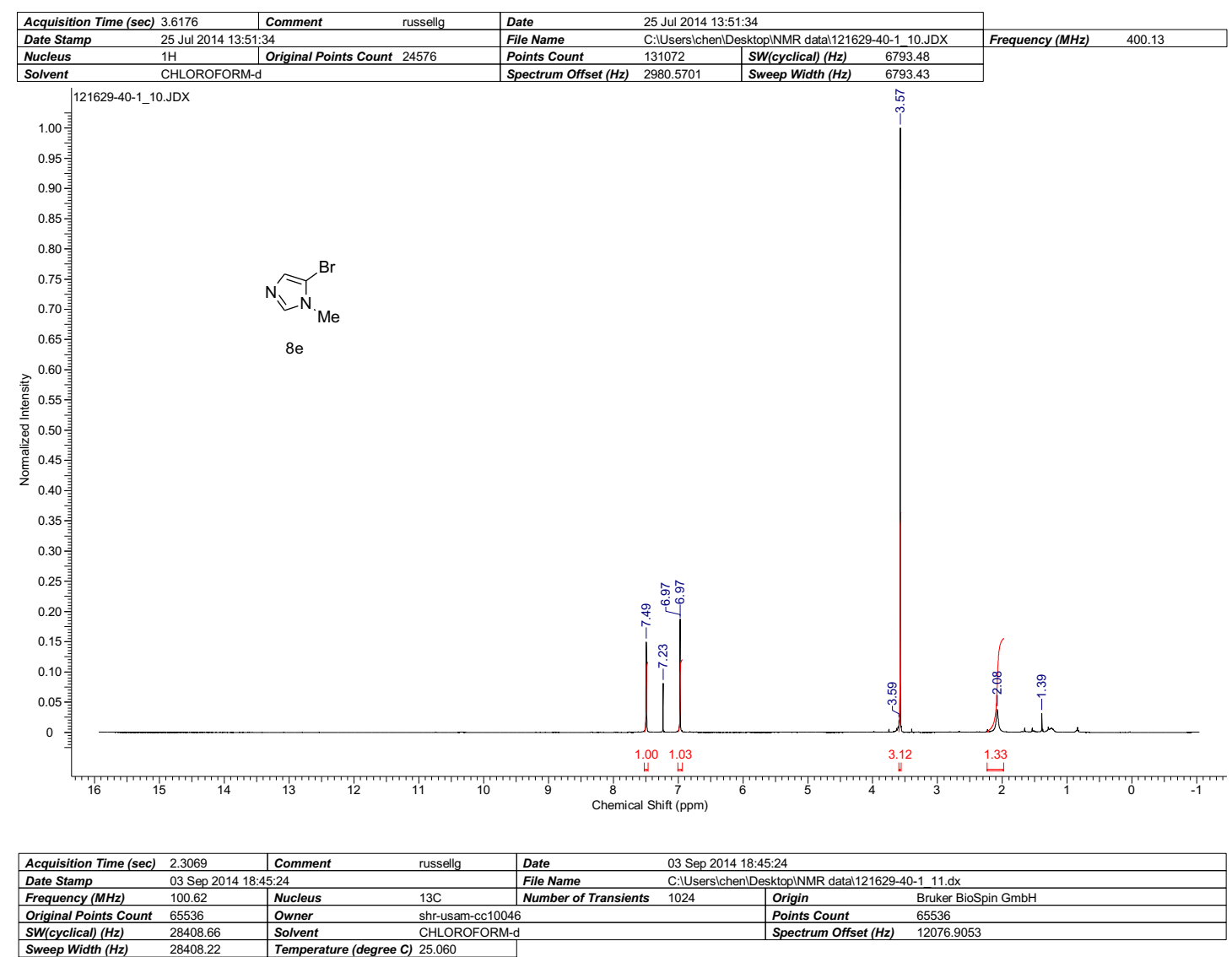

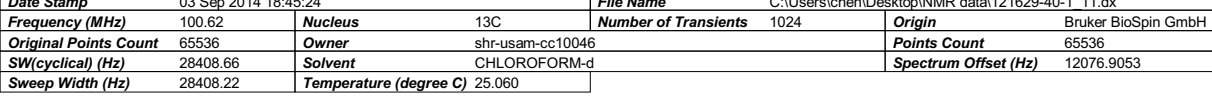

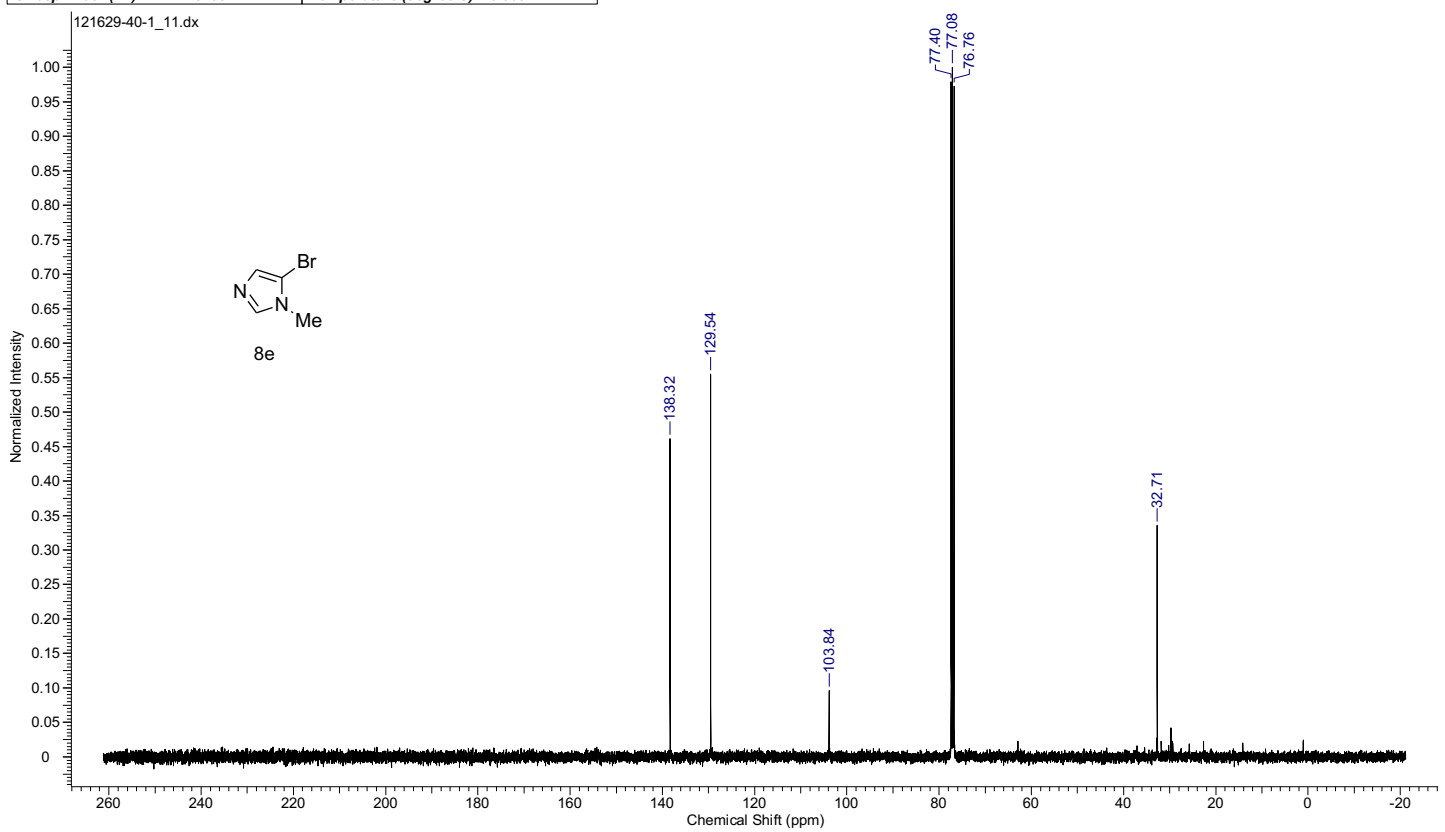




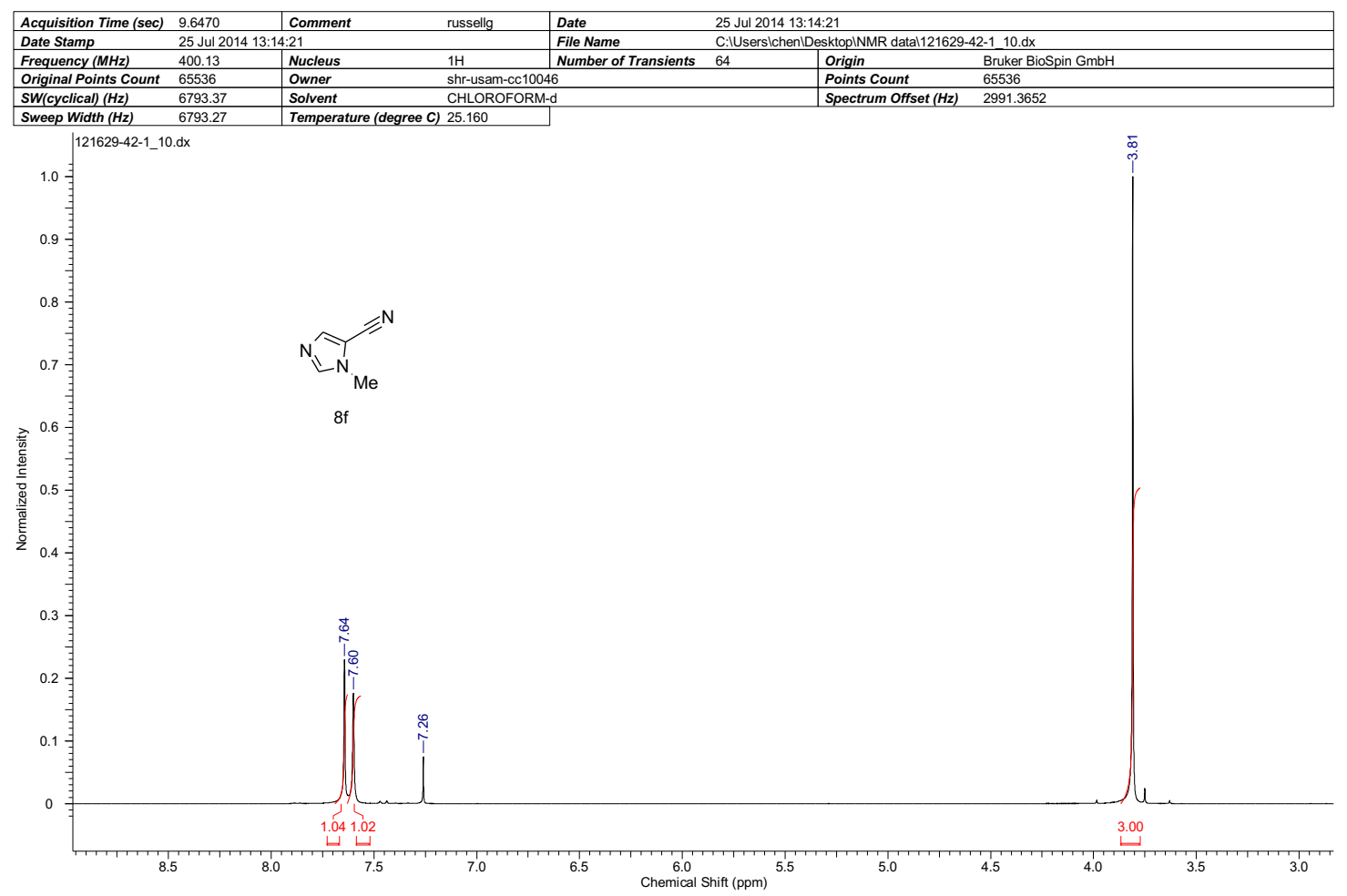

\begin{tabular}{|c|c|c|c|c|c|c|c|}
\hline \multirow{2}{*}{ Acquisition Time (sec) } & \multirow{2}{*}{\multicolumn{2}{|c|}{\begin{tabular}{l|l}
2.3069 & Comment \\
$29 \mathrm{Sep} 2014$ 19:27:45
\end{tabular}}} & russellg & \multirow{3}{*}{\begin{tabular}{|l|} 
Date \\
File Name \\
Number of Transients \\
\end{tabular}} & \multicolumn{3}{|c|}{29 Sep 2014 19:27:45 } \\
\hline & & & & & C:IUsersich & sktoplNMR datal121 & $2-1 \_12 . d x$ \\
\hline Frequency $(\mathrm{MHz})$ & 100.62 & Nucleus & $13 \mathrm{C}$ & & 1024 & Origin & Bruker BioSpin GmbH \\
\hline Original Points Count & 65536 & Owner & shr-usam & & & Points Count & 65536 \\
\hline$S W($ cyclical) $(\mathrm{Hz})$ & 28408.66 & Solvent & DMSO-d & Spectrum Offset $(\mathrm{Hz})$ & 12026.5752 & Sweep Width $(\mathrm{Hz})$ & 28408.22 \\
\hline
\end{tabular}

Temperature (degree $C$ ) 24.460

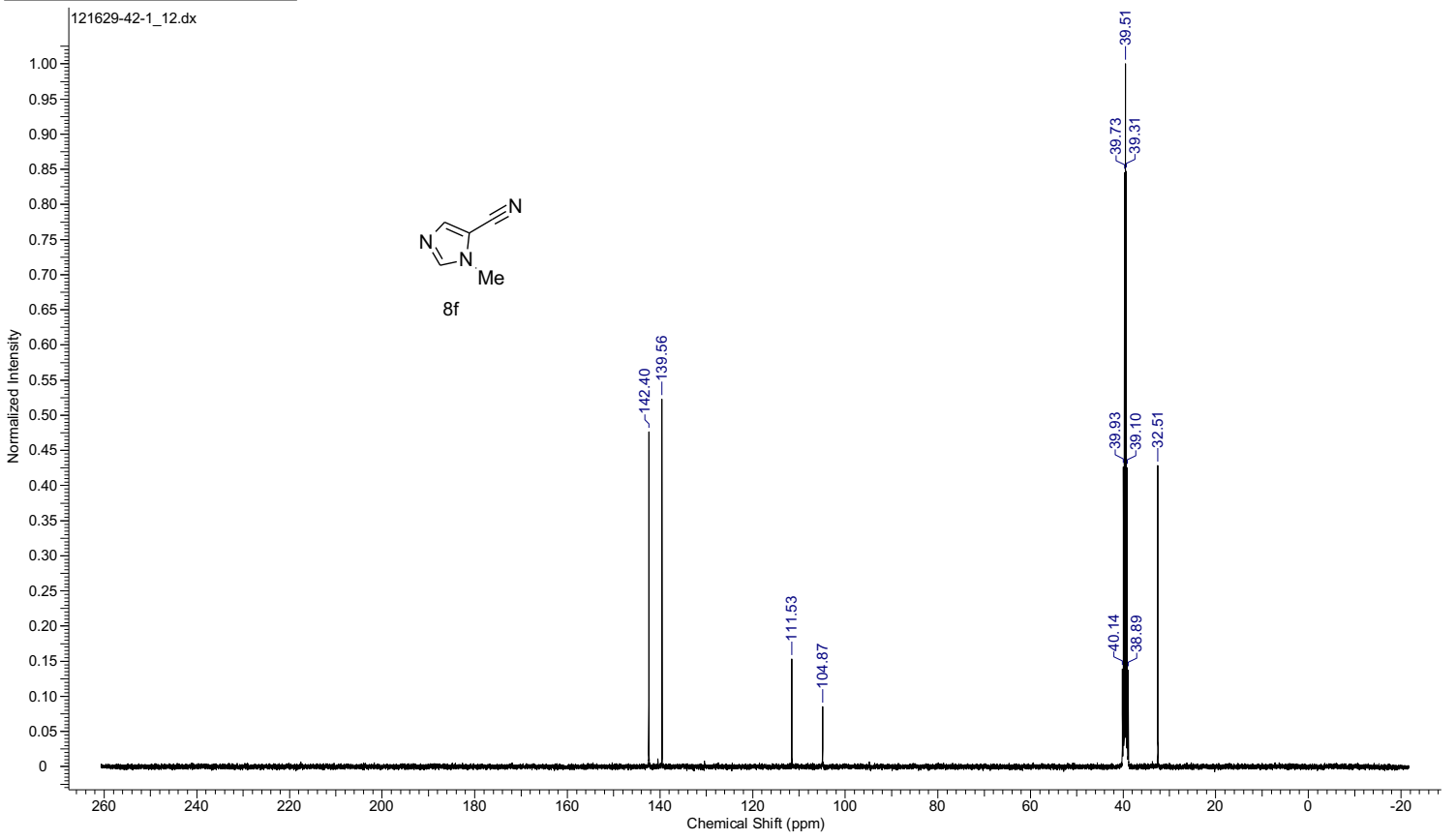



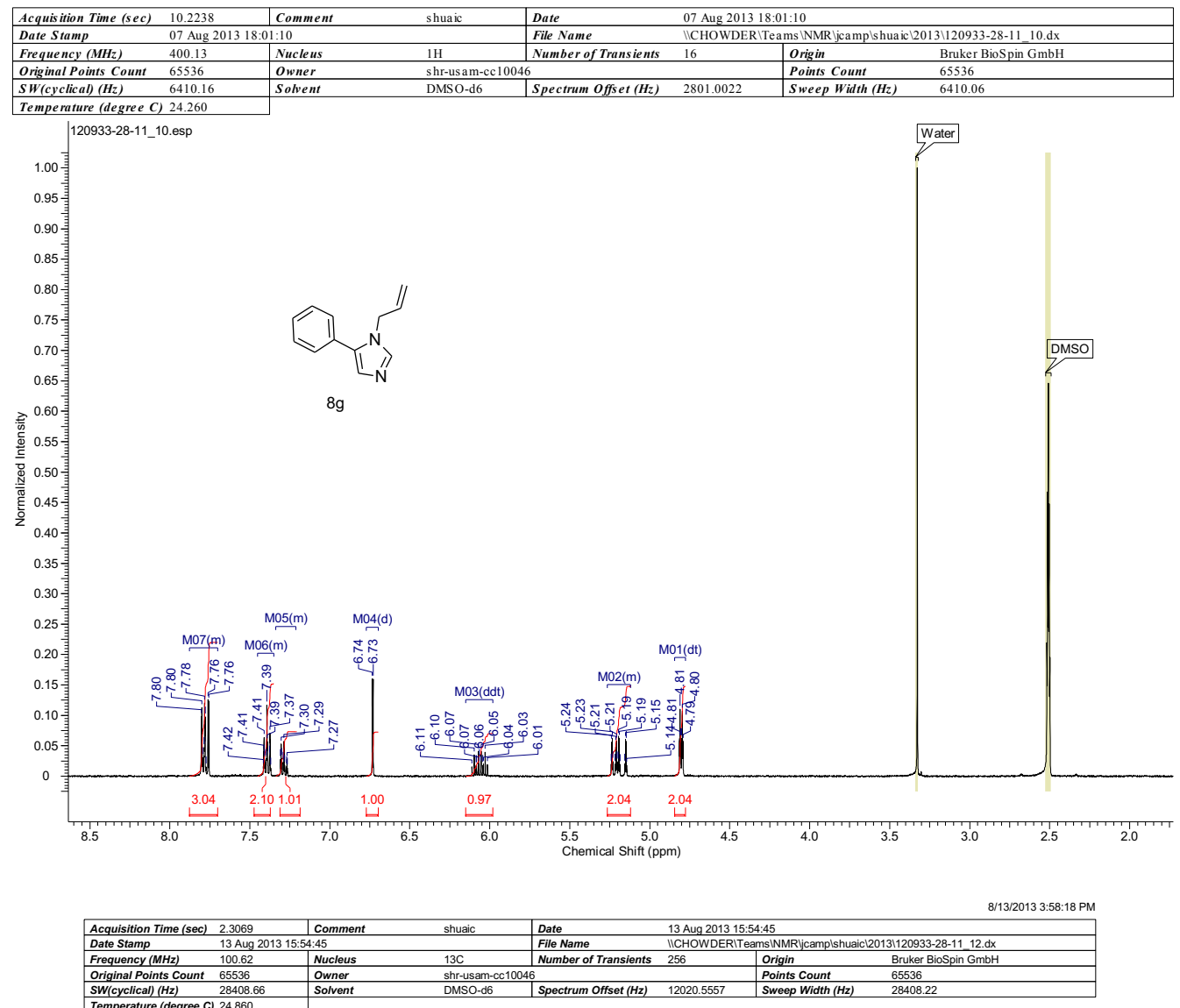

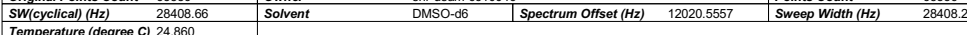

|20933-28-11 12.dx Verticis

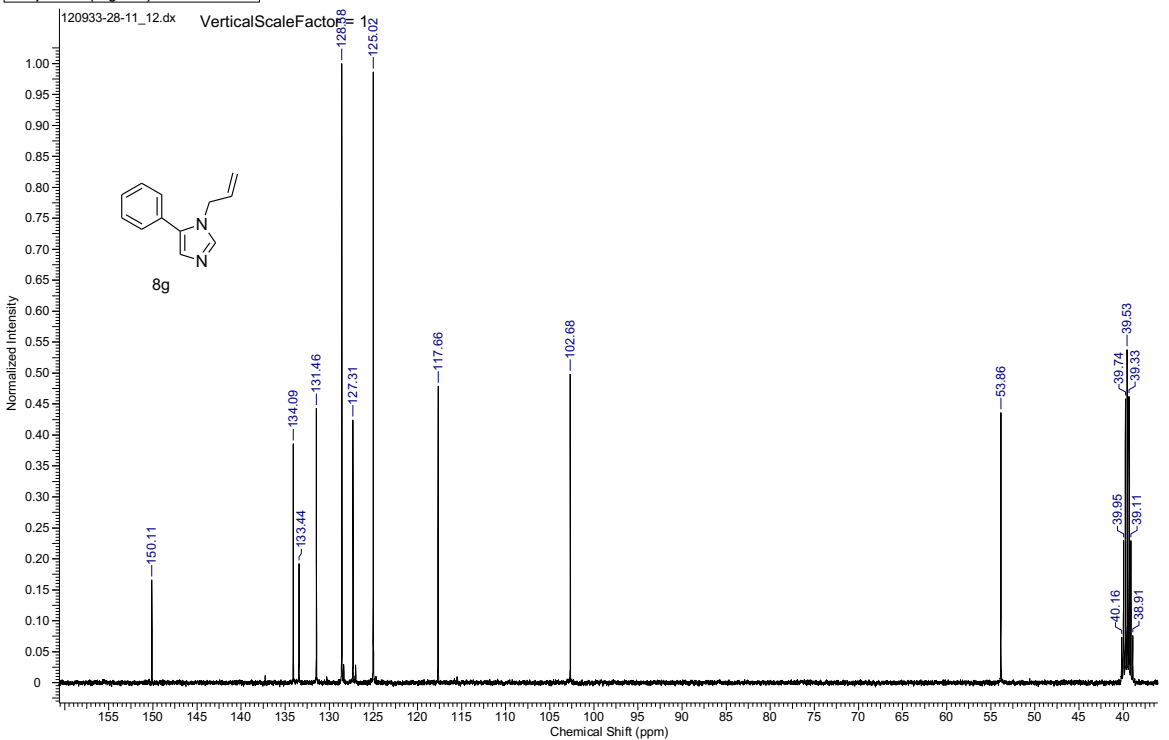



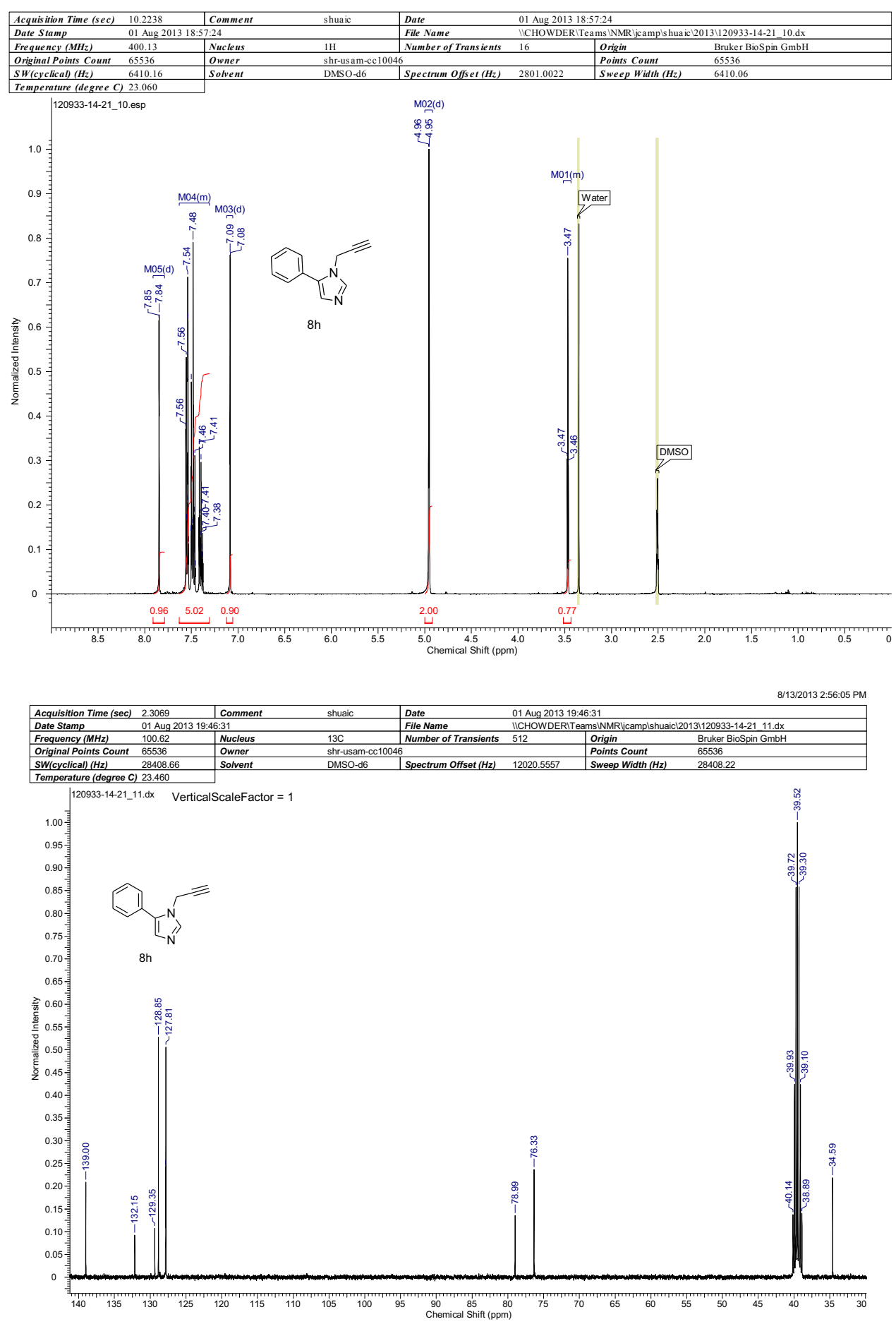
AR200212-1

$114316-118-11$

TID200235

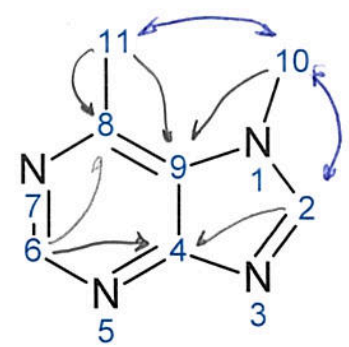

The NMR data are consistent with the proposed structure on the right.

HMBC connectivities:

ROESY cross-peaks:

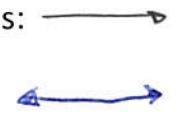




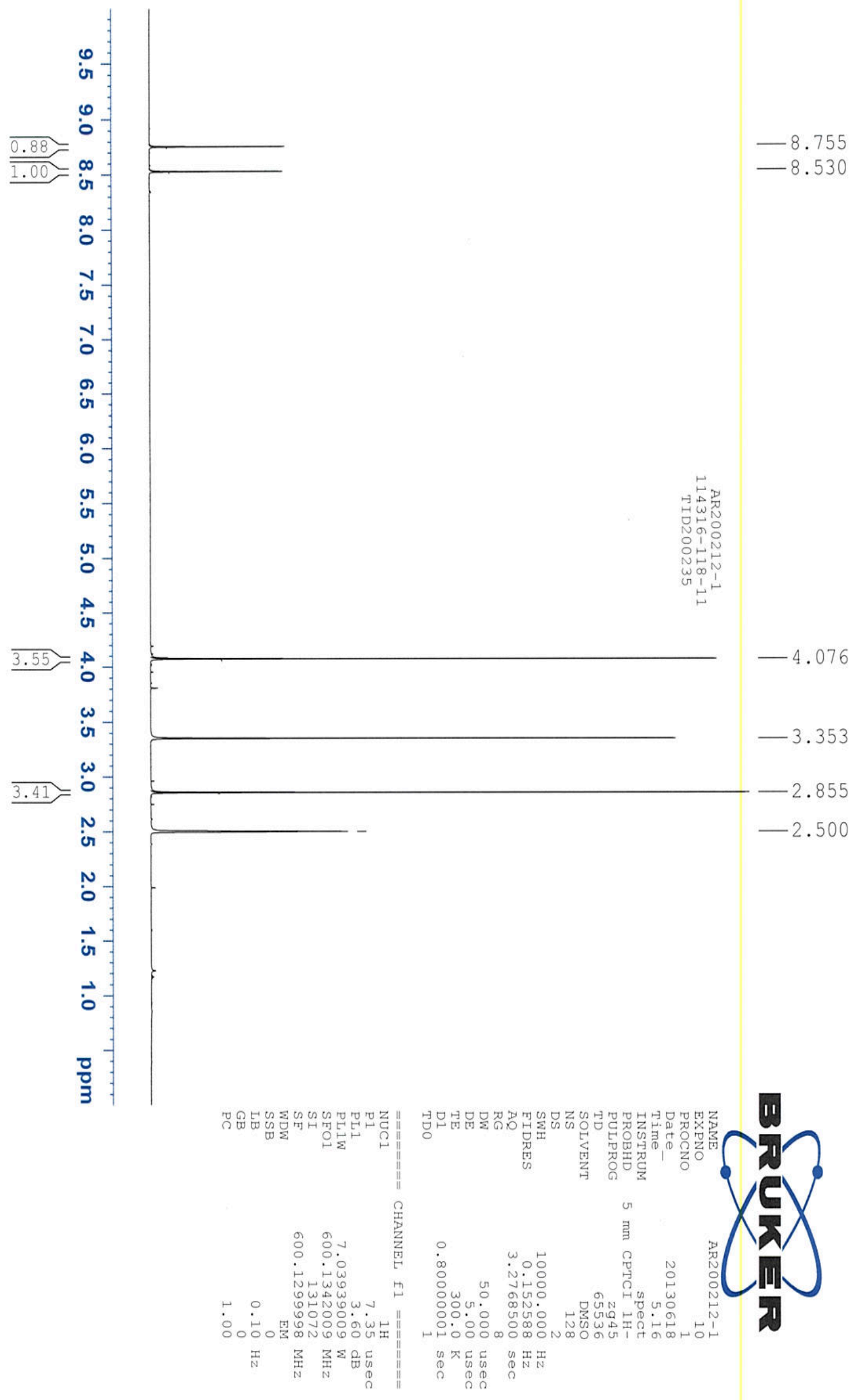




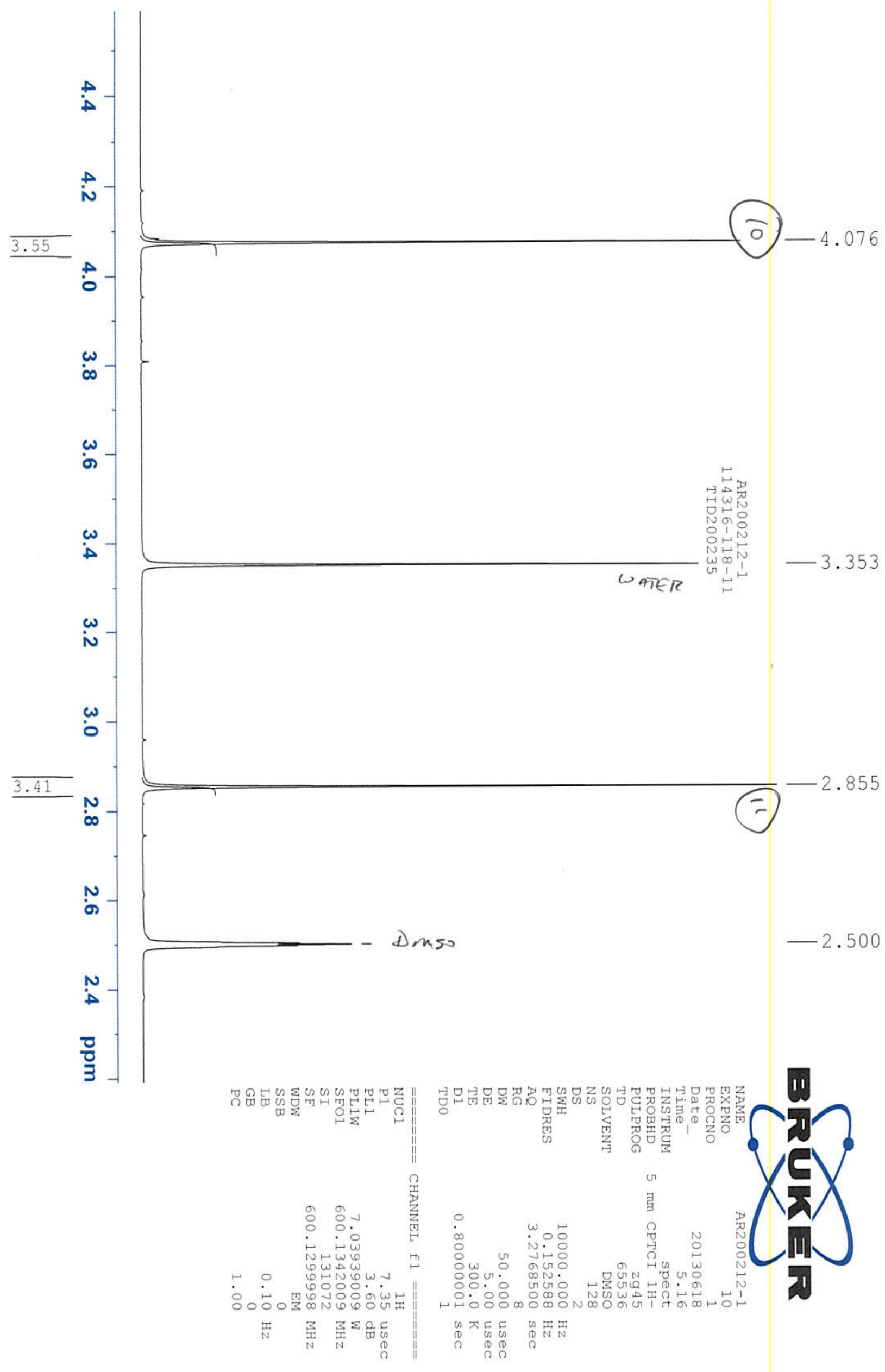




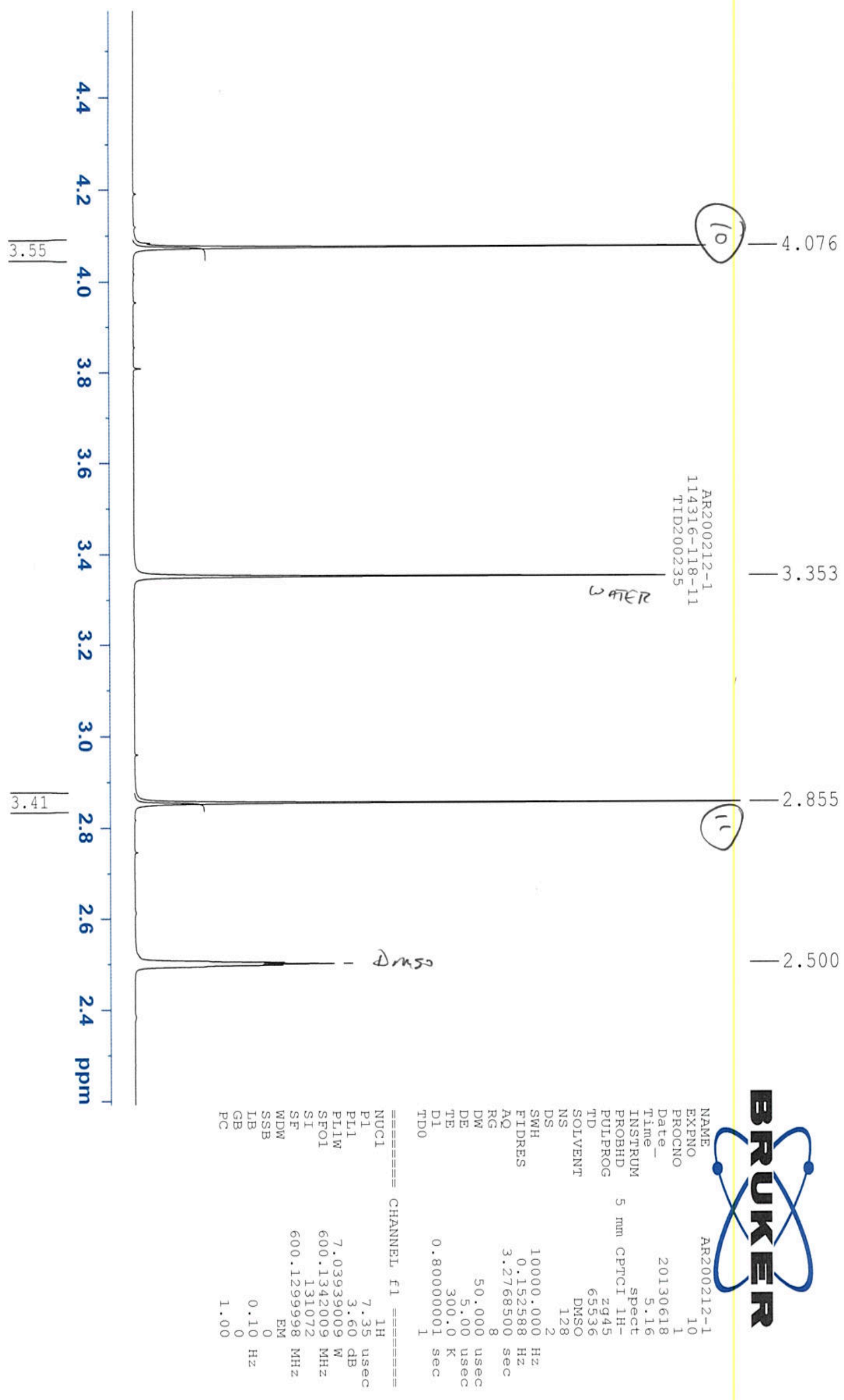




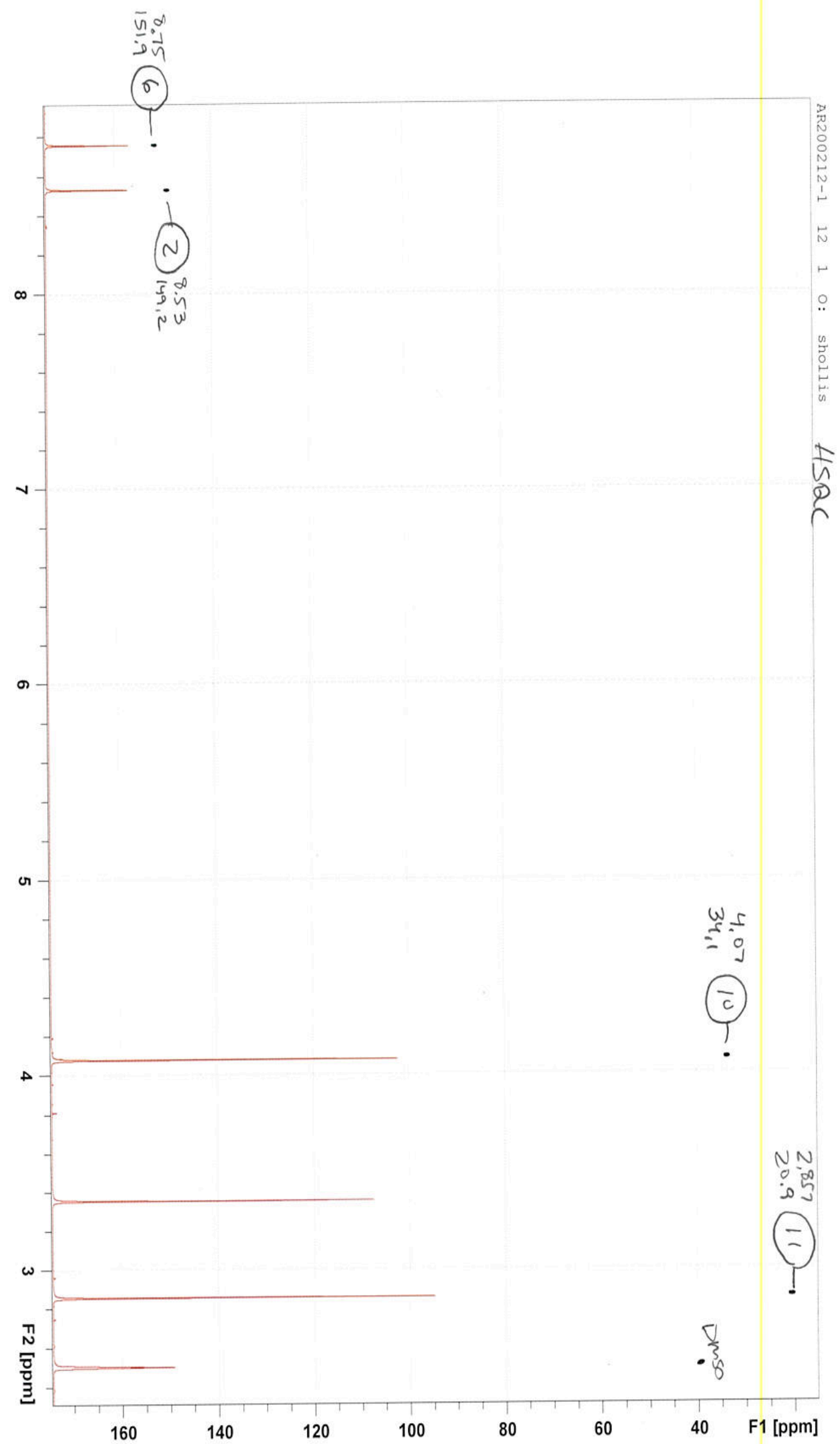




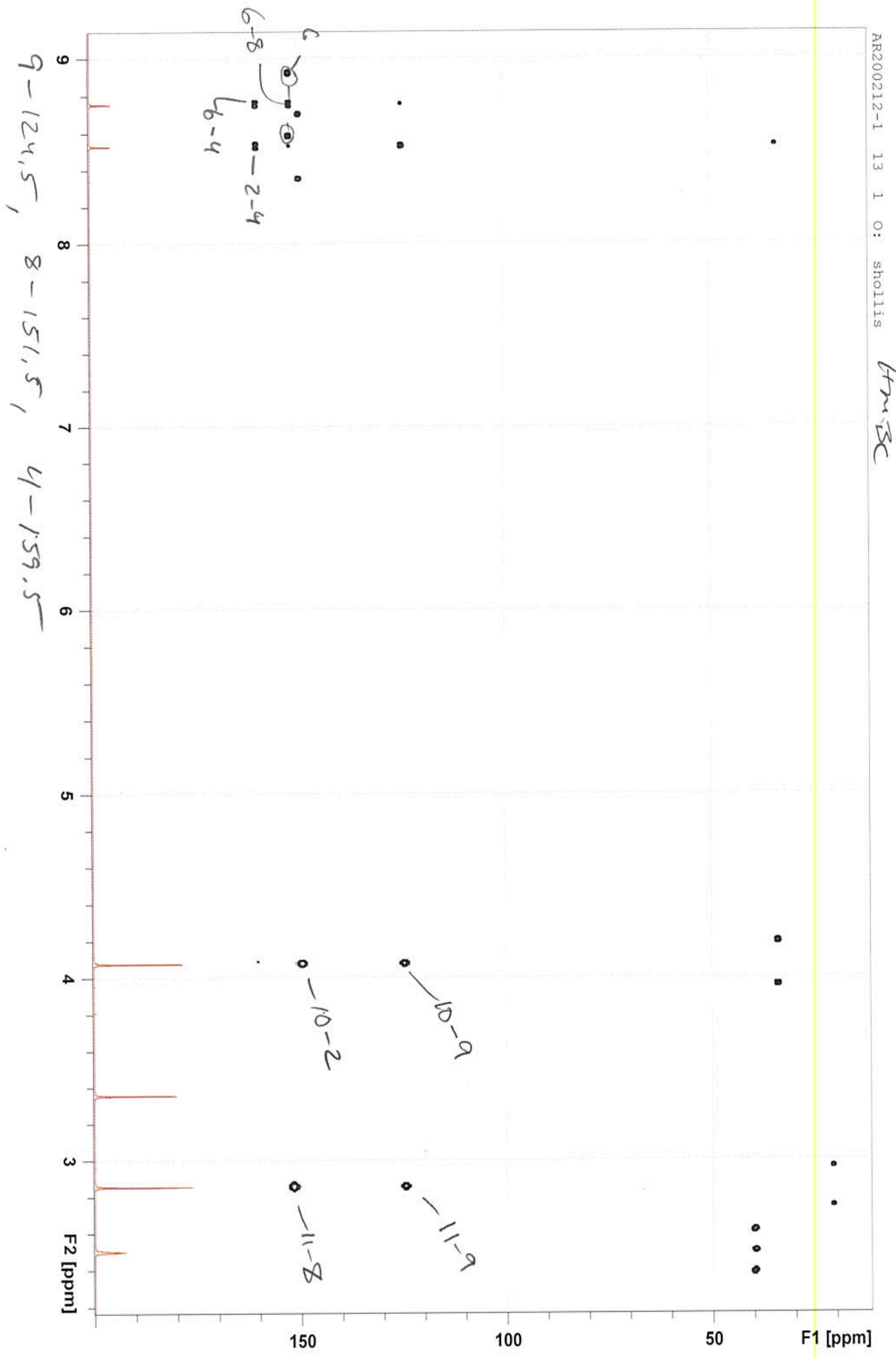




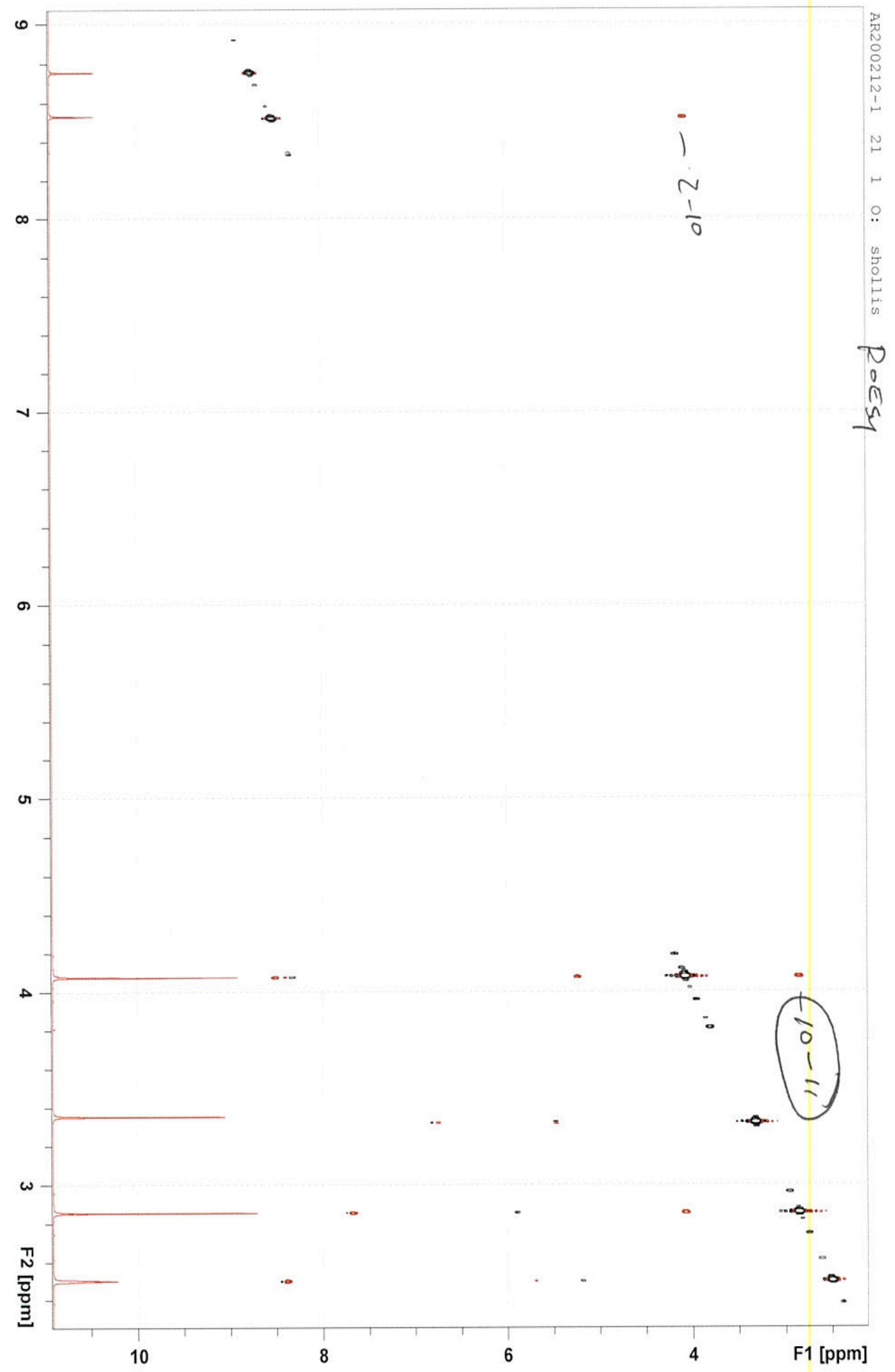




\section{References:}

1. Schlecker, W. ; Huth, A. ; Ottow, E. J. Org. Chem. 1996, 60, 8414-8416.

2. Kotek, V. ; Chudíková, N. ; Tobrman, T. ; D. Dvořák, Org. lett., 2010, 12, 5724-5727.

3. Zhang, Q.; Cheng, G.; Huang, Y.-Z.; Qu, G.-R.; Niu, H.-Y.; Guo, H.-M. Tetrahedron, 2012, 78227826.

4. Lambertucci, C.; Buccioni, M.; Dal Ben, D.; Kachler, S.; Marucci, G.; Spinaci, A.; Thomas, A.; Klotz, K.-N.; Volpini, R. MedChemComm, 2015, 6, 963-970.

5. Rivkin, A.; Ahearn, S. P.; Chichetti, S. M.; Hamblett, C. L.; Garcia, Y.; Martinez, M.; Hubbs, J. L.; Reutershan, M.H.; Daniels, M. H.; Siliphaivanh, P. Bioorg. Med. Chem. Lett. 2010, 20, 2279-2282.

6. Dalby, C. ; Bleasdale, C. ; Clegg, W. ; Elsegood, M. R. J. ; Golding, B. T. ; Griffin, R. J. Angew. Chem., 1993, 105, 1822-1823; Angew. Chem., Int. Ed. 1993, 32, 1696-1697.

7. Kowalsaka, A.; Pluta, K. Heterocycles, 2008, 75, 555-569.

8. Purandare, A. V.; Wan. H.; Somerville, J. E.; Burke, C.; Vaccaro. W.; Yang, X.; McIntyre, K. W.; Poss, M. A. Bioorg. Med. Chem. Lett. 2007, 12, 679-682.

9. Tumma, H.; Nagaraju, N.; Reddy, K. V. Synth. Commun. 2010, 40, 1856-1866.

10. Dhainaut, A.; Regnier, G.; Tizot, A.; Pierre, A.; Leonce, S.; Guilbaud, N.; Kraus-Berthier, L.; Atassi, G. J. Med. Chem. 1996, 39, 4099-4108.

11. Cesnek, M.; Holy, A.; Masojidkova, M. Tetrahedron, 2002, 58, 2985-2996.

12. Pettit, G. R.; Blazer, R. M.; Einck, J. J.; Yamauchi, K. J. Org. Chem. 1980, 45, 4073-4076.

13. Barlin, G. B.; Fenn, M. D. Aus. J. Chem. 1983, 36, 633-638.

14. Lam, F. L.; Parham, J. C. Heterocycles, 1978, 9, 289-291.

15. Okamura, T.; Kikuchi, T.; Fukushi, K.; Irie, T. J. Med. Chem. 2009, 52, 7284-7288.

16. Standar, S.; Bouzkova, K.; Straka, M.; Zacharova, Z.; Hocek, M.; Marek, J.; Marek, R. Phy. Chem. Chem. Phy. 2011, 13, 15854-15864.

17. Itoh, T.; Ono, K.; Sugawara, T.; Mizuno, Y. J. Heter. Chem. 1982, 19, 513-517.

18. Reddy, V. M.; Reddy, K. K. Ind. J. Chem., Section B: Org. Chem. Med. Chem. 1979, 17, 441-444.

19. Itoh, T.; Ishikura, T.; Mizuno, Y. Chem.Pharma. Bull. 1983, 31, 4130-4134.

20. Guo, S.; Huynh, H. V. Organometallics, 2014, 33, 2004-2011.

21. Van Leusen, A. M.; Wildeman, J.; Oldenziel, O. H. J. Org. Chem. 1977, 42, 1153-1159.

22. Van Den Berge, E.; Robiette, R. J. Org. Chem. 2013, 78, 12220-12223.

23. Wang, M.; Zhang, Z.; Xie, F.; Zhang, W. Chem. Comm. 2014, 50, 3163-3165.

24. Milner, P.J.; Yang, Y.; Buchwald, S. L. Organometallics, 2015, 34, 5361.

25. Oresmaa, L.; Taberman, H.; Haukka, M.; Vainiotalo, P.; Aulaskari, P. J. Hetero. Chem. 2007, 44, 1445-1451.

26. Alzieu, T.; Lehmann, J.; Naidu, A. B.; Martin, R. E.; Britton, R. . Chem. Comm. 2014, 50, 1867-1870. 